\author{
UNIVERSIDADE DE SÃO PAULO - USP \\ ESCOLA DE ENGENHARIA DE SÃO CARLOS - EESC \\ DEPARTAMENTO DE ENGENHARIA ELÉTRICA - SEL
}

FELIPE SANCHES ZANONI

AVALIAÇÃO DE ARQUITETURA PARALELA PARA SMARTPHONES E TABLETS UTILIZANDO GNU/LINUX E MPI PARA PROCESSAMENTO DE DADOS

SÃO CARLOS - SP 2013 

FELIPE SANCHES ZANONI

\section{AVALIAÇÃO DE ARQUITETURA PARALELA PARA SMARTPHONES E TABLETS UTILIZANDO GNU/LINUX E MPI PARA PROCESSAMENTO DE DADOS}

Orientador: Prof. Dr. Carlos Dias Maciel

Área de Concentração: Sistemas Dinâmicos

Dissertação submetida à Escola de Engenharia de São Carlos da Universidade de São Paulo como parte dos requisitos para a obtenção do grau de Mestre em Ciências, Programa de Engenharia Elétrica.

SÃO CARLOS - SP

2013

Trata-se de versão corrigida da dissertação. A versão original se encontra disponível na EESC/USP que aloja o Programa de Pós-Graduação de Engenharia Elétrica. 
AUTORIZO A REPRODUÇÃO TOTAL OU PARCIAL DESTE TRABALHO, POR QUALQUER MEIO CONVENCIONAL OU ELETRÔNICO, PARA FINS DE ESTUDO E PESQUISA, DESDE QUE CITADA A FONTE.

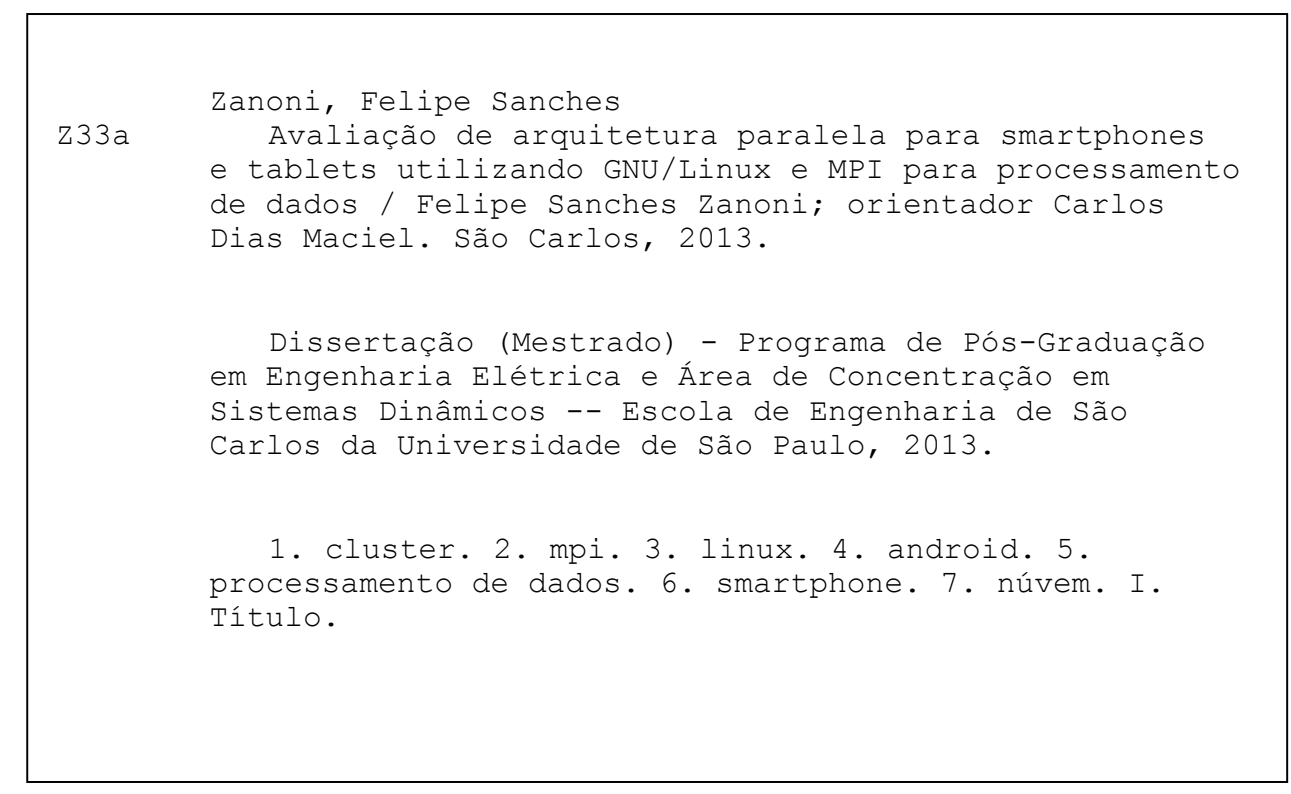


FOLHA DE IULGAMENTO

Candidato: Engenheiro FELIPE SANCHES ZANONI.

Título da dissertação: "Avaliação de arquitetura paralela para smartphones e tablets utilizando GNU/Linux e MPI para processamento de dados".

Data da defesa: 06/09/2013

\section{Comissão Julgadora:}

Prof. Associado Carlos Dias Maciel (Orientador)

(Escola de Engenharia de São Carlos/EESC)

Prof. Dr. José Roberto Boffino de Almeida Monteiro

(Escola de Engenharia de São Carlos/EESC)

Prof. Dr. Carlos Henrique Costa Ribeiro

(Instituto Tecnológico de Aeronáutica/ITA)
Resultado:
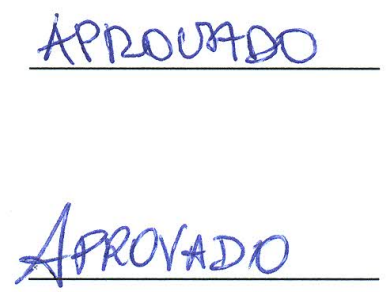

APROVADO

Coordenador do Programa de Pós-Graduação em Engenharia Elétrica e Presidente da Comissão de Pós-Graduação:

Prof. Titular Denis Vinicius Coury 



\section{Resumo}

ZANONI, F. S. Avaliação de arquitetura paralela para smartphones e tablets utilizando GNU/Linux e MPI para processamento de dados. 2013. 96 f. Dissertação (Mestrado) - Escola de Engenharia de São Carlos, Universidade de São Paulo, São Carlos, 2013.

A versatilidade e principalmente o poder de processamento dos atuais celulares, mais conhecidos como smartphones, e também dos tablets, impulsionam a computação de algorítimos complexos nesses dispositivos. Cada celular ou tablet pode fazer parte de uma grande rede de computadores com capacidade para processar uma enorme quantidade de dados com um consumo muito baixo de energia se comparado aos computadores convencionais. Um outro grande motivador é que muitos desses celulares possuem o sistema operacional Android, o qual é baseado no núcleo Linux. Isso facilita a migração de projetos já desenvolvidos em computadores para essa nova plataforma móvel, uma vez que é possível executar um sistema operacional completo GNU/Linux nesses dispositivos. O objetivo desse trabalho é avaliar e comparar o desempenho de um cluster híbrido formado por dispositivos móveis e computadores, mostrando que é possível desenvolver aplicativos utilizando MPI para processamento paralelo em celulares da mesma forma com que se desenvolve aplicativos para computadores em GNU/Linux. Os resultados mostram qual é a diferença de poder computacional entre os computadores de arquitetura x86 e os dispositivos móveis de tecnologia ARM.

Palavras-chave: computação em cluster, mpi, linux, Android, processamento de dados, smartphone, computação em núvem. 



\section{Abstract}

\section{ZANONI, F. S. Evaluation of paralle architecture for smartphones and ta-}

blets using GNU/Linux and MPI for data processing. 2013. 96 f. Dissertação (Mestrado) - Escola de Engenharia de São Carlos, Universidade de São Paulo, São Carlos, 2013.

Versatility and mainly processing power of nowadays smartphones and tablets boost complex algorithms computation on these devices. Each cellphone or tablet can be part of a big computer network capable of processing a huge amount of data with low power consumption compared to personal computers. A great motivator also is that these devices have the Android operational system that is based on Linux kernel, what facilitates developed projects to migrate easily to this new platform. The goal of this project is to evaluate and compare a hybrid cluster performance formed by mobile devices and computers, showing that is possible to develop software using MPI for parallel processing over smartphones and tablets the same way as for GNU/Linux computers. The results show what is the processing power difference between $\mathrm{x} 86$ architecture computers and mobile devices using ARM architecture.

Keywords: cluster computing, mpi, linux, Android, data processing, smartphone, cloud computing. 



\section{Sumário}

1 Introdução $\quad 19$

1.1 Objetivo . . . . . . . . . . . . . . . . . . . . . . 22

1.2 Organização da Dissertação . . . . . . . . . . . . . . . . . . . . . . 22

2 Fundamentos Teóricos $\quad 25$

2.1 Arquitetura $\mathrm{x} 86 \ldots \ldots \ldots \ldots \ldots \ldots \ldots$

2.2 Arquitetura ARM . . . . . . . . . . . . . . . . . . . 27

2.3 Processadores com múltiplos núcleos . . . . . . . . . . . . . . . . 30

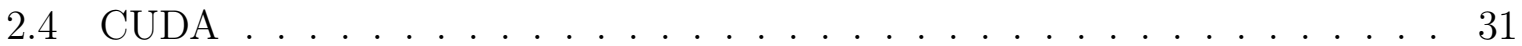

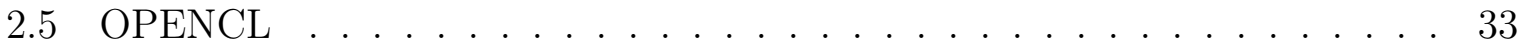

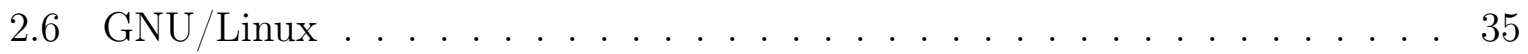

2.7 Ubuntu Linux . . . . . . . . . . . . . . . . . . . . . . 36

2.8 Android . . . . . . . . . . . . . . . . . . . . . . . 37

2.9 Linux no Android . . . . . . . . . . . . . . . . . . . . . . . 38

2.10 Programação Paralela . . . . . . . . . . . . . . . . . . . . 38

2.10 .1 Lei de Amdahl . . . . . . . . . . . . . . . . . . . . . . . 40

3 Materiais e Métodos $\quad 43$

3.1 Dispositivos utilizados . . . . . . . . . . . . . . . . . . . 43

3.2 Algoritmos para avaliação . . . . . . . . . . . . . . . . . . . 44

3.2.1 Aplicativo para cálculo de DFT em cluster . . . . . . . . . . . . 46

3.2.2 Aplicativo para cálculo do número $\pi$ em cluster . . . . . . . . . . . 51

4 Resultados e Discussão $\quad 57$

4.1 Experimentos com algoritmo de DFT . . . . . . . . . . . . . . 57

4.2 Experimentos com cálculo do número $\pi \ldots \ldots$. . . . . . . . . . 60

$\begin{array}{lll}5 & \text { Conclusão } & 67\end{array}$

$\begin{array}{ll}\text { Referências Bibliográficas } & 71\end{array}$ 
Anexos

Anexo A Códigos fonte dos aplicativos de testes

A.1 Arquivo 'fft_mpi.c' . . . . . . . . . . . . . . . . . . 77

A.2 Arquivo 'data/DataProcessor.h' . . . . . . . . . . . . . . . . 83

A.3 Arquivo 'data/DataProcessor.c' . . . . . . . . . . . . . . . . . 84

A.4 Arquivo 'filesystem/DataReader.h' . . . . . . . . . . . . . . . 85

A.5 Arquivo 'filesystem/DataReader.c' . . . . . . . . . . . . . . . . . 85

A.6 Arquivo 'filesystem/DataWriter.h' . . . . . . . . . . . . . . . 86

A.7 Arquivo 'filesystem/DataWriter.c' . . . . . . . . . . . . . . . . 87

A.8 Arquivo 'filesystem/WindowReader.h' . . . . . . . . . . . . . . . . 87

A.9 Arquivo 'filesystem/WindowReader.c' . . . . . . . . . . . . . . . 88

A.10 Arquivo 'pi_mpi.c' . . . . . . . . . . . . . . . . . . . . . . . 90

Anexo B Manual de Compilação e Uso dos Aplicativos 


\section{Lista de Figuras}

2.1 Processador 8086 fabricado pela Intel em 1978. Fonte: (DAS, 2010). . . . . 27

2.2 Um dos processadores Core 2 Quad fabricado pela Intel. O lançamento dessa família de processadores foi em 2006. Fonte: (WASSON, 2008). . . . 27

2.3 Processadores Am386 fabricado pela AMD. O processador já estava pronto para lançamento em 1991, mas por batalha judicial com a Intel alegando que não havia licenciado a arquitetura x86 para a AMD, foi lançado apenas em 1992. Fonte: (LILLY, 2009). . . . . . . . . . . . . . . . . . . 28

2.4 Um dos processadores Phenom II X4 fabricado pela AMD. O lançamento dessa família de processadores foi em 2007. Fonte: (AMD, 2013). . . . . . . 28

2.5 Imagem do silício de um processador AMD Phenom II X6, de 6 núcleos. É possível identificar cada núcleo separadamente. Fonte: (HUMPHRIES, 2010). . . . . . . . . . . . . . . . . . . . . 31

2.6 Código simples do tipo "Hello World!" exemplificando o processamento paralelo utilizando MPI . . . . . . . . . . . . . . . . . . . . . . 33

2.7 Código exemplificando o uso da interface MPI em conjunto com os comandos CUDA. . . . . . . . . . . . . . . . . . . 33

2.8 Ilustração de como o MPI é executado em um cluster com CUDA. O parâmetro - $n p$ indica quantos processos serão executados em paralelo, no caso 4 (KRAUS, 2013).

2.9 Ilustração mostrando a arquitetura de memória quando utilizado o sistema CUDA sem (esquerda) e com (direita) memória unificada. A memória unificada favorece a implementação MPI transparente para o programador.(KRAUS, 2013).

2.10 Do lado esquerdo da imagem, um código tradicional compondo um loop finito do tipo for. Do lado direito esse mesmo código é reescrito paralelizado e adaptado para o padrão OpenCL (ROSENBERG, 2011) . . . . . . . . . . 34 
2.11 Modelagem da organização da memória em sistemas OpenCL. As memórias privadas, em azul, são apenas acessadas por cada item de trabalho. A memória local, em verde, é compartilhada dentro do mesmo grupo de trabalho. A memória global, em laranja, é acessível por todos os grupos de trabalho. Por último, a memória do Host é apenas acessível pela CPU(ROSENBERG, 2011).

2.12 Gráfico da Lei de Amdahl calculando o speedup para vários números diferentes de processadores e porcentagens de código paralelizável. É possível perceber que a limitação teórica de speedup é definida pela porção paralelizável do código. . . . . . . . . . . . . . . . . . . . . 42

3.1 Dispositivos utilizados na avaliação de desempenho do cluster híbrido . . . 44

3.2 Representação de uma organização de X dispositivos com Y processadores e Z núcleos de processamento. Os dispositivos estão interligados em rede. . 45

3.3 Esboço representando um sinal com duas janelas temporais retangulares e observações para a distância entre as janelas e o tamanho de cada janela. Quando essa janela temporal é feita no espaço discreto, esse valores de distância são medidos em amostras e não mais no tempo. . . . . . . . . . .

3.4 Diagrama de sequência das trocas de mensagens entre os nós do cluster. O nó mestre é responsável por distribuir o trabalho entre os outros nós do cluster. Com essa arquitetura é possível adicionar N nós para executar a tarefa em conjunto sem alteração no algoritmo. . . . . . . . . . . . . . 48

3.5 Trecho de código em linguagem $\mathrm{C}$ mostrando o envio da mensagem de fim de processamento de um nó escravo por interface MPI. . . . . . . . . . . . 48

3.6 Sequência de uso dos processadores do experimento 1. O processo servidor é executado no dispositivo Galaxy Note II. O dispositivo Galaxy S II é o responsável por complementar o processamento do cluster. Para cada configuração (de 1 a 6 ) são repetidas 10 medições. . . . . . . . . . . . . . .

3.7 Sequência de uso dos processadores do experimento 2. O processo servidor é executado no dispositivo Galaxy S II. O dispositivo Galaxy Note II é o responsável por complementar o processamento do cluster. Para cada configuração (de 1 a 6) são repetidas 10 medições. . . . . . . . . . . . . . . 50

3.8 Sequência de uso dos processadores do experimento 3. O processo servidor é executado no dispositivo HP Pavilion e apenas ele faz parte do cluster. Para cada configuração (de 1 a 4) são repetidas 10 medições. . . . . . . . . 50

3.9 Espectrograma do sinal de som utilizado na avaliação. . . . . . . . . . . 51

3.10 Sequência de uso dos processadores do experimento 4. O processo servidor é executado no dispositivo HP Pavilion e os dispositivos Galaxy Note II e Galaxy S II complementam o cluster. Para cada configuração (de 1 a 10) são repetidas 10 medições. 
3.11 Exemplo de integração numérica pelo método dos retângulos. As áreas dos infinitos retângulos são somadas para resultar no total da área do gráfico. Quanto maior o número de retângulos, mais próximo do valor exato é o resultado. . . . . . . . . . . . . . . . . . . 53 



\section{Lista de Tabelas}

2.1 Histórico de ano de lançamento dos processadores Intel desde o primeiro processador 8086 até a família Core-2 Quad (DAS, 2010). . . . . . . . . . . 26

2.2 Histórico de ano de lançamento dos processadores AMD desde o primeiro processador Am386 até a família Phenom II de 6 núcleos. . . . . . . . . . . 28

2.3 Lançamentos e tecnologias dos processadores ARM desde a primeira versão de 1985 até a versão 7 de 2005 . . . . . . . . . . . . . . . . . . . 30

3.1 Especificação dos dispositivos utilizados nos experimentos . . . . . . . . . . 44

4.1 Dez medições de tempo de execução do experimento 1 com suas respectivas médias e intervalos de confiança de $95 \%$ para processamento com 1 a 6 processos concorrentes. . . . . . . . . . . . . . . . . . 59

4.2 Dez medições de tempo de execução do experimento 2 com suas respectivas médias e intervalos de confiança de $95 \%$ para processamento com 1 a 6 processos concorrentes. . . . . . . . . . . . . . . . . . . . . . . 59

4.3 Dez medições de tempo de execução do experimento 3 com suas respectivas médias e intervalos de confiança de $95 \%$ para processamento com 1 a 4 processos concorrentes. . . . . . . . . . . . . . . . . . . . 61

4.4 Dez medições de tempo de execução do experimento 4 com suas respectivas médias e intervalos de confiança de $95 \%$ para processamento com 1 a 5 processos concorrentes. . . . . . . . . . . . . . . . . . . 61

4.5 Dez medições de tempo de execução do experimento 4 com suas respectivas médias e intervalos de confiança de $95 \%$ para processamento com 6 a 10 processos concorrentes. . . . . . . . . . . . . . . . . . 62

4.6 Dez medições de tempo de execução do experimento 5 com suas respectivas médias e intervalos de confiança de $95 \%$ para processamento com 1 a 6 processos concorrentes. . . . . . . . . . . . . . . . . . 62

4.7 Dez medições de tempo de execução do experimento 6 com suas respectivas médias e intervalos de confiança de $95 \%$ para processamento com 1 a 6 processos concorrentes. . . . . . . . . . . . . . . . . 63 
4.8 Dez medições de tempo de execução do experimento 7 com suas respectivas médias e intervalos de confiança de $95 \%$ para processamento com 1 a 4 processos concorrentes. . . . . . . . . . . . . . . . . 63

4.9 Dez medições de tempo de execução do experimento 8 com suas respectivas médias e intervalos de confiança de $95 \%$ para processamento com 1 a 5 processos concorrentes. . . . . . . . . . . . . . . . . 65

4.10 Dez medições de tempo de execução do experimento 8 com suas respectivas médias e intervalos de confiança de $95 \%$ para processamento com 6 a 10 processos concorrentes. . . . . . . . . . . . . . . . . . 65 


\section{Lista de Siglas}

$\begin{array}{ll}\text { AMD } & \text { Advanced Micro Devices } \\ \text { ARM } & \text { Acron RISC Machine } \\ \text { CGA } & \text { Color Graphics Adapter } \\ \text { CMP } & \text { Chip Multiprocessor } \\ \text { CUDA } & \text { Compute Unified Device Architecture } \\ \text { GPU } & \text { Graphics Processing Unit } \\ \text { JVM } & \text { Java Virtual Machine } \\ \text { MPI } & \text { Message Passing Interface } \\ \text { PC } & \text { Personal Computer }\end{array}$





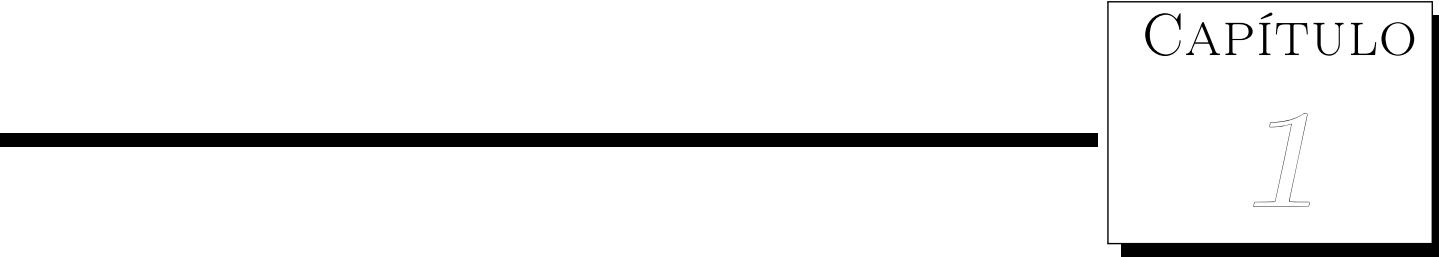

Introdução

Alta capacidade de processamento sempre foi necessária em computação científica, engenharia, simulações e outras áreas. Normlamente apenas um computador somente, mesmo sendo este um super computador, não supre essa demanda. O poder de processamento pode ser um fator limitante para alguns algoritmos mais complexos ou por uma grande quantidade de dados, levando até mesmo anos para serem executados (FOSTER et al., 2008).

Uma das soluções é a computação concorrente. Há computadores com mais de um processador, usando memória compartilhada, que possibilitam a computação multi tarefa real, executando dois processos diferentes ao mesmo tempo, e não a multi tarefa simulada, em que é feito o escalonamento de tarefas no mesmo processador para aparentar que os processos são executados simultaneamente. Há também aglomerados de computadores, chamados de clusters, que são computadores interligados em rede capazes de trocar informações entre si por interfaces de programação como o MPI, do inglês Message Passing Interface, para, organizadamente, executar tarefas de forma paralela em sistemas que não compartilham memória entre os processos (LIN et al., 2006).

Com o avanço da tecnologia, as fabricantes de processadores como Intel e AMD chegaram em um limite da frequência de clock que permite a tecnologia eletrônica atual. 
Com esse limite o caminho encontrado foi desenvolver processadores de múltiplos núcleos, possibilitando a execução de tarefas concorrentes nos computadores pessoais a um custo relativamente baixo. É possível criar cluster de computadores que possuem vários processadores e que, por sua vez, podem possuir vários núcleos, garantindo um grande poder de processamento para aplicações especialmente desenvolvidas (CHAI; GAO; PANDA, 2007).

Mesmo assim, essa configuração pode não ter o melhor custo benefício. O mercado de jogos digitais trouxe a demanda por processadores gráficos (GPU) cada vez mais poderosos. Esses processadores podem processar uma grande quantidade de dados em paralelo. Inicialmente desenvolvidos apenas para processamento gráfico, atualmente estão sendo usados para processamento de dados gerais. Isso foi possível com o desenvolvimento das interfaces CUDA e OpenCL. A primeira foi criada pela NVIDIA, fabricante de processadores gráficos, e apenas suas GPUs são suportadas. A segunda é um padrão aberto que pode ser usado para programar CPUs, GPUs ou outros dispositivos compatíveis, de diversos fabricantes diferentes. Há diversos laboratórios que possuem cluster de GPUs com interface CUDA para processamento de grandes quantidades de dados ou algoritmos mais complexos (SU et al., 2012).

Outro mercado que se expandiu foi o de dispositivos móveis, que abrange smartphones e tablets. Esses dispositivos demandam baixo consumo energético, uma vez que operam com baterias, e alto poder de processamento, principalmente para fluidez na experiência de uso e também para executar jogos cada vez mais elaborados visualmente. A arquitetura mais difundida para esses dispositivos é a ARM com os núcleos da série Cortex-A. Assim como no segmento de computadores, os primeiro processadores dessa arquitetura possuíam apenas um núcleo. Atualmente há processadores com até 8 núcleos, fabricado pela Samsung com o nome de Exynos 5 Octa (SAMSUNG, 2013).

O avanço dessa arquitetura foi bastante rápido, devido ao grande sucesso desses dispositivos e à disputa de mercado dos grandes fabricantes. Já é possível comparar o desempenho desses processadores aos de computadores pessoais.

Há vários sistemas operacionais disponíveis para smartphones. Entre eles estão iOS, desenvolvido pela Apple, Windows Phone, desenvolvido pela Microsoft, Android, forne- 
cido pela Google, entre outros. A vantagem do Android é que, por ser de código aberto, permite que modificações sejam feitas para melhorias ou mesmo para adicionar funções extras. Por ser um sistema que utiliza o kernel Linux como base e pelo alto poder de processamento dos atuais smartphones, é possível executar um sistema completo GNU/Linux nesses dispositivos.

Um aplicativo para Android chamado Complete Linux Installer, disponível na loja de aplicativos Play, da Google, no endereço https://play.google.com/store/apps/ details?id=com.zpwebsites.linuxonandroid\&hl=pt_BR, oferece algumas distribuições Linux para instalação. O Ubuntu 12.04 LTS, distribuição muito comum em computadores pessoais, com mais de 20 milhões de pessoas utilizando, segundo seus fornecedores, é uma das distribuições disponíveis (UBUNTU, 2013). O alto poder de processamento desses dispositivos e a possibilidade de se instalar um sistema GNU/Linux completo permite compará-los aos computadores.

O ambiente GNU/Linux possibilita criar um cluster de celulares e executar aplicativos com computação concorrente. Esse cluster pode ser formado não apenas por dispositivos móveis, mas também por computadores, formando um cluster de arquitetura híbrida. A biblioteca OpenMPI disponível para GNU/Linux implementa a interface para programação concorrente MPI. Esta é uma interface para troca de mensagens entre processos para organizar o tratamento dos dados em computação concorrente.

A venda de smartphones já supera a venda de celulares convencionais e cresce a cada ano (EXAME.COM, 2013). Utilizar o seu processamento em períodos de ociosidade do usuário e quando estiver conectado à rede elétrica para efetuar o recarregamento da bateria possibilitaria agrupar esses dispositivos em um gigantesco cluster para processar grandes quantidades de dados em um período de tempo bastante baixo.

Uma das vantagens dos smartphones é a alta eficiência energética e a não necessidade de refrigeração ativa, como ventiladores utilizados em computadores para dissipar o calor produzido pelos processadores, diminuindo ruído e espaço.

Com essa enorme capacidade de processamento nos dispositivos móveis atuais e com a grande necessidade de processamento de dados cada vez mais numerosos e mais complexos, esses dispositivos poderiam contribuir nesse processamento, se cada dispositivo fosse capaz 
de executar uma relativamente pequena quantidade de dados.

\subsection{Objetivo}

O objetivo desse trabalho é propor e avaliar uma arquitetura para processamento de dados, usando dispositivos móveis que utilizam sistema operacional Android como base e com a distribuição Ubuntu Linux 12.04 LTS instalada. A vantagem de se utilizar o sistema operacional GNU/Linux é que a portabilidade de aplicativos já desenvolvidos para computadores é facilitada. O mesmo código criado para computadores x86 pode ser compilado para dispositivos móveis ARM sem qualquer alteração necessária na maioria dos casos. O conhecimento dos programadores também é aproveitado, diminuindo tempo e custo para a migração de plataforma. Também possibilita a fácil implantação de clusters híbridos, mesclando diferentes arquiteturas, como celulares, tablets e computadores, já que o mesmo código fonte pode ser utilizado nas diferentes arquiteturas.

Outro fator importante da arquitetura proposta é poder fazer uso de recursos avançados que os celulares oferecem, como serviços de GPS, conectividade 3G, Bluetooth, entre outros, contribuindo para algoritmos mais inteligentes e mais complexos.

Também será comparado o desempenho dos processadores ARM de dispositivos móveis com processadores x86 de computadores para avaliar qual a diferença de processamento entre os diferentes sistemas e se há vantagens ao inserir nós de smartphones em um cluster formado inicialmente por computadores.

\subsection{Organização da Dissertação}

Na seção 2 será apresentada toda a teoria estudada para alcançar os objetivos desse trabalho. A história da arquitetura x86 e da arquitetura ARM mostrarão a evolução dos computadores nas últimas décadas e quais as vantagens e desvantagens de cada arquitetura. Na seção 3 serão propostos os experimentos para avaliar o desempenho dos dispositivos móveis em um cluster. Também serão apresentadas todas as ferramentas computacionais usadas para desenvolver os algoritmos de avaliação e quais equipamentos foram utilizados nos experimentos. A seção 4 trará todos os resultados obtidos com a 
execução dos experimentos propostos. A seção 5 discutirá todos os resultados obtidos, mostrando as vantagens e desvantagens da arquitetura proposta. A conclusão do trabalho e os próximos passos também serão apresentados nesta seção. Por último, na seção 6, todas as referências desse estudo são listadas. 



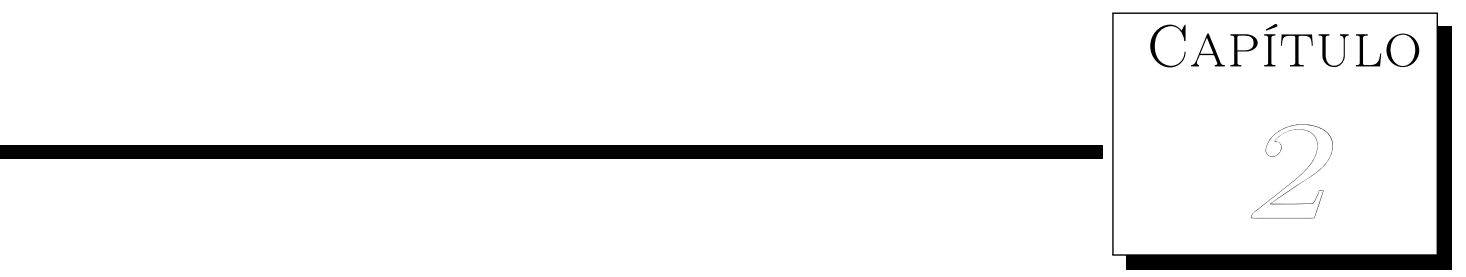

\section{Fundamentos Teóricos}

\subsection{Arquitetura $\times 86$}

A arquitetura x86 teve início com a fabricante de semicondutores Intel, em 1978, quando foi anunciado o microprocessador 8086. Ele tinha barramento interno e externo de 16 bits. Em 1979 foi lançado o 8088, também com barramento interno de 16 bits, mas com barramento externo de 8 bits apenas. Essa versão era mais barata e possuía maior compatibilidade com os dispositivos na época (DAS, 2010).

Em 1981 a IBM escolheu o 8088 para ser o processador da sua linha de computadores pessoais. Esse fato ajudou a Intel a crescer no mercado e a investir cada vez mais nessa arquitetura. O nome desse computador era IBM 5150 e foi criado por uma equipe de 12 pessoas (DAS, 2010). Possuía um processador 8088, 64KBytes de memória RAM que poderia ser expandida para até 256KBytes, uma unidade de disco flexível usada para inicializar o sistema com uma versão do MS-DOS e um adaptador de vídeo monocromático ou até mesmo CGA, do inglês Color Graphics Adapter, que foi o primeiro adaptador de vídeo colorido para computadores, capaz de exibir até 16 cores e uma resolução máxima de 640x200 pontos (DAS, 2010).

O próximo processador da família x86 foi o 80186, mas que não foi utilizado em 
computadores pessoais, apesar de ser encontrado em algumas aplicações embarcadas.

Um outro avanço nos computadores foi o lançamento do 80286 que trouxe o conceito de memória virtual e operações de modo protegido. Essas características foram herdadas pelos sucessores da família x86.

Em 1985 foi lançado o 80386 com unidade de processamento de 32 bits. Também era capaz de acessar periféricos em 32 bits. Desde então todos os processadores possuíam unidade de processamento de 32 bits, mas com o lançamento da linha Pentium, o acesso externo era feito com barramento de 64 bits (DAS, 2010).

Um breve histórico dos processadores Intel e suas respectivas datas de lançamento podem ser vistas na tabela 2.1. Como curiosidade pode-se observar a figura 2.1, do processador 8086 de 1978, e compará-la com a figura 2.2, do processador Core 2 Quad de 2006.

Tabela 2.1: Histórico de ano de lançamento dos processadores Intel desde o primeiro processador 8086 até a família Core-2 Quad (DAS, 2010).

\begin{tabular}{lc}
\hline \hline Processador Intel x86 & Ano de lançamento \\
\hline \hline 8086 & 1978 \\
8088 & 1979 \\
80186 & 1982 \\
80286 & 1982 \\
80386 & 1985 \\
80486 & 1989 \\
Pentium & 1993 \\
Pentium Pro & 1995 \\
Pentium-2 & 1997 \\
Pentium-3 & 1999 \\
Pentium-M & 2002 \\
Pentium-4 & 2004 \\
Pentium-D & 2005 \\
Core-2 & 2006 \\
Core-2 Quad & 2007 \\
\hline \hline
\end{tabular}

Outra grande fabricante de processadores, Advanced Micro Devices (AMD), fundada em 1969 com sede em Sunnyvale, California, introduziu seu primeiro semicondutor em 1970, um contador lógico chamado AM2501. Em 1982 a IBM entrou em acordo com a AMD para que ela fosse uma fornecedora alternativa à Intel de processadores para os PCs IBM. Em 1995 a AMD lançou o processador AMD-K5, primeiro projeto independente, 


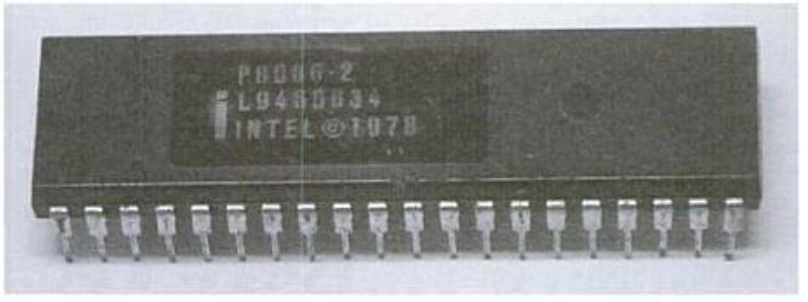

Figura 2.1: Processador 8086 fabricado pela Intel em 1978. Fonte: (DAS, 2010).

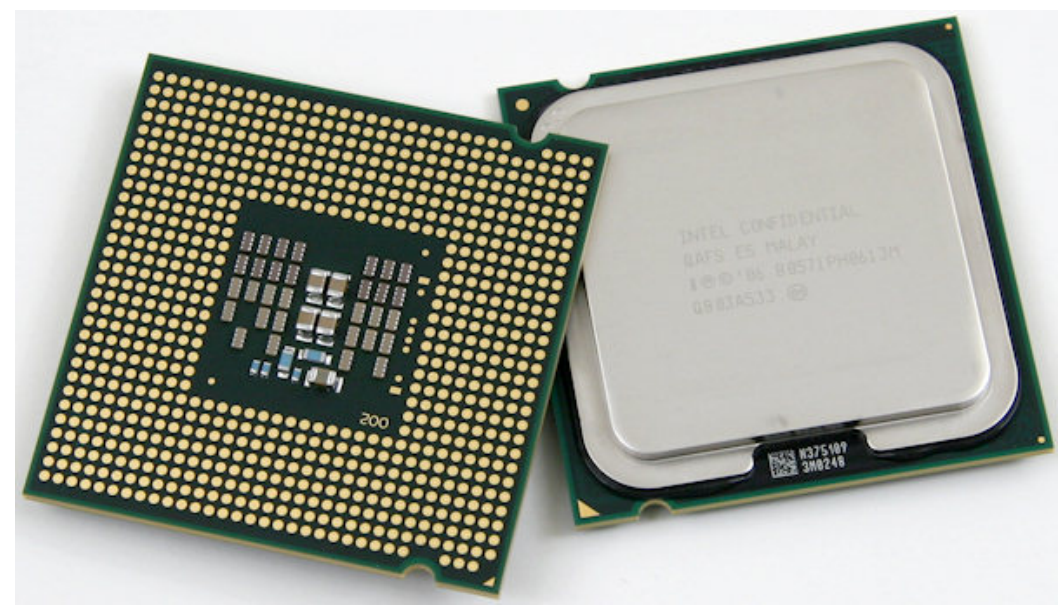

Figura 2.2: Um dos processadores Core 2 Quad fabricado pela Intel. O lançamento dessa família de processadores foi em 2006. Fonte: (WASSON, 2008).

compatível com o socket padrão x86 e foi um forte concorrente frente ao Pentium e Pentium Pro da Intel. Em 1997 foi lançado seu sucessor, o AMD-K6. Esse processador ajudou a diminuir os preços dos PCs para abaixo dos mil dólares pela primeira vez, tornando os computadores mais acessíveis ao consumidores. Em 2004 a AMD demonstrou o primeiro processador de arquitetura x86 de dois núcleos e em 2005 lançaria o Athlon 64 X2, processador de 64-bit com dois núcleos para computadores pessoais (AMD, 2013).

Os principais lançamentos de processadores para computadores de mesa fabricados pela AMD está detalhado na Tabela 2.2. A Figura 2.3 mostra o processador AM386 fabricado pela AMD em 1992 e a Figura 2.4 mostra o Phenom II X4, também da AMD, lançado em 2007.

\subsection{Arquitetura ARM}

O primeiro processador ARM foi desenvolvido pela Acron Computers Limited de Cambridge, Inglaterra entre os anos de 1983 e 1985. Estavam à procura de um processador para computador de mesa da próxima geração e descobriram que não existia nenhum 
Tabela 2.2: Histórico de ano de lançamento dos processadores AMD desde o primeiro processador Am386 até a família Phenom II de 6 núcleos.

\begin{tabular}{lc}
\hline \hline Processador AMD x86 & Ano de lançamento \\
\hline \hline Am386 & 1991 \\
Am486 & 1993 \\
AMD-K5 & 1995 \\
AMD-K6 & 1997 \\
AMD Athlon & 1999 \\
AMD Athlon MP & 2001 \\
AMD Athlon 64 & 2003 \\
AMD Athlon 64 X2 & 2005 \\
AMD Phenom X4 & 2007 \\
AMD Phenom II X4 & 2009 \\
AMD Phenom II X6 & 2010 \\
\hline \hline
\end{tabular}

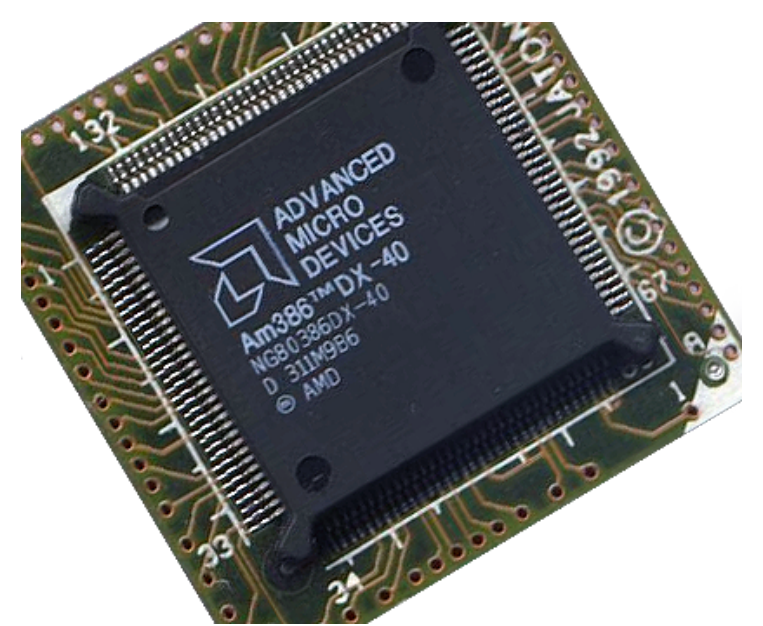

Figura 2.3: Processadores Am386 fabricado pela AMD. O processador já estava pronto para lançamento em 1991, mas por batalha judicial com a Intel alegando que não havia licenciado a arquitetura x86 para a AMD, foi lançado apenas em 1992. Fonte: (LILLY, 2009).

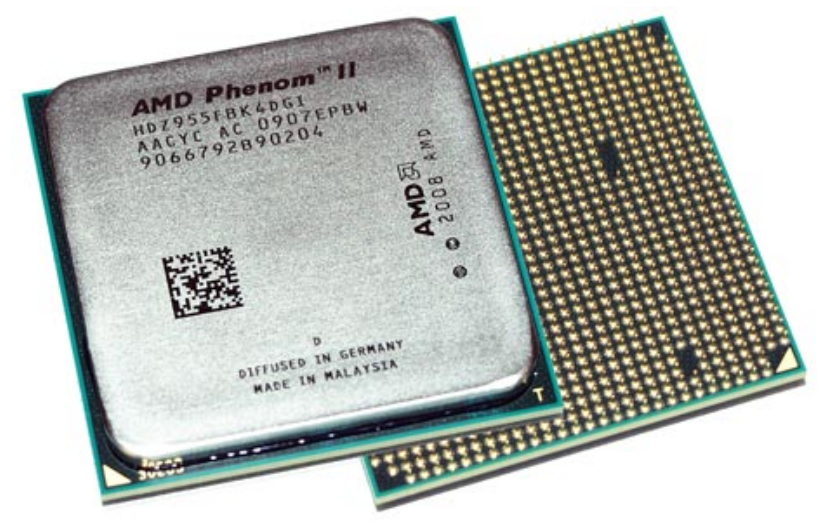

Figura 2.4: Um dos processadores Phenom II X4 fabricado pela AMD. O lançamento dessa família de processadores foi em 2007. Fonte: (AMD, 2013). 
no mercado que atendesse suas especificações. Primeiro porque esses processadores eram mais lentos que as memórias da época, e segundo, porque as instruções de máquina eram complexas, com algumas levando vários ciclos para serem terminadas, aumentando a latência no atendimento às interrupções (CHATTOPADHYAY, 2013).

Apesar disso, sabiam que desenvolver um processador novo não era uma tarefa trivial. Mesmo empresas com conhecimento em desenvolvimento de processadores levariam anos para desenvolver um novo processador bastante complexo. A solução foi usar o projeto Berkley RISC 1 que provou que o era possível construir um processador simples, mas capaz de ter desempenho comparável ou melhor que de um excelente processador CISC da época (CHATTOPADHYAY, 2013).

A Acron desenvolveu seu primeiro processador de 26-bit chamado Acron RISC Machine (ARM) em 1985, baseado no projeto Berkley. Ele usava 25000 transistores a menos que o processador 80286 da Intel, porém com desempenho igual ou melhor. Essa arquitetura foi então chamada de ARM versão 1. A versão 2 foi lançada em 1987 com suporte a co-processador. Na versão 3, em 1992, foi introduzido memória cache no próprio chip e também possuía endereçamento de 32-bit e Unidade de Gerenciamento de Memória (MMU), além de instruções de multiplicação-adição de 64-bit (CHATTOPADHYAY, 2013).

A Apple, em 1990, se interessou pelos processadores e desenvolveu seu PDA Newton utilizando essa arquitetura. Desde então a ARM entrou no mercado de dispositivos móveis. A quarta geração dos processadores ARM, lançada em 1996, teve a introdução de um conjunto de instruções de 16-bit, chamada THUMB. Essa nova tecnologia é um pouco menos eficiente, mas ocupa cerca de $40 \%$ menos espaço no chip. Esse processador foi bastante utilizado em dispositivos móveis, como nos iPods da Apple, inclusive no iPod com tocador de vídeo (CHATTOPADHYAY, 2013).

Os últimos processadores ARM possuem várias instruções para processamento de dados multimídia. A Tabela 2.3 resume a história dos processadores ARM desde a versão 1 até a versão 7 de 2005. 
Tabela 2.3: Lançamentos e tecnologias dos processadores ARM desde a primeira versão de 1985 até a versão 7 de 2005.

\begin{tabular}{cclll}
\hline \hline Versão & Ano & Características & Implementação \\
\hline \hline v1 & 1985 & $\begin{array}{l}\text { Primeiro processador RISC } \\
\text { mercial (26-bit) }\end{array}$ & ARM1 & \\
& & ARM2, ARM3 & \\
\hline v2 & 1987 & Suporte a co-processador & ARM6, ARM7 & ARM8, \\
\hline v3 & 1992 & 32-bit, MMU e 64-bit MAC & ARM7TDMI, \\
\hline v4 & 1996 & THUMB & ARM9TDMI, StrongARM \\
\hline v5 & 1999 & Extensões DSP e Jazelle & ARM10, XScale \\
\hline v6 & 2001 & $\begin{array}{l}\text { SIMD, THUMB-2, TrustZone, } \\
\text { Multiprocessing }\end{array}$ & ARM11, ARM11 MPCore \\
\hline v7 & 2005 & NEON, VFP & Cortex-R, Cortex-A \\
\hline
\end{tabular}

\subsection{Processadores com múltiplos núcleos}

A indústria de microprocessadores chegou a um limite tecnológico no desenvolvimento de processadores de apenas um núcleo cada vez mais velozes. Tornou-se impossível aumentar a frequência do clock sem aumentar consideravelmente o consumo energético e a dissipação de calor. Para resolver esse problema as grandes fabricantes de microprocessadores mudaram o paradigma de desenvolvimento. Passaram então a fabricar os chip multiprocessados, do inglês chip multiprocessor, CMP(OLUKOTUN et al., 2007). A Figura 2.5 mostra o silício de um processador de 6 núcleos.

Processadores do tipo CMP tem um menor esforço de engenharia para cada geração de novos processadores. Em alguns momentos é apenas necessário melhorar um núcleo, replicá-lo um determinado número de vezes e então fazer algumas alterações nas interconexões dos núcleos para diminuir a latência e melhorar a eficiência. Não necessariamente será preciso remodelar todo a lógica de pipeline do processador, que é bastante complexa (COMPUTER..., ).

Além disso a interface do processador com a placa mãe tem poucas alterações entre uma geração e outra de processadores, já que a externamente os CMP são muito semelhantes. As conexões externas normalmente precisam de melhorias de velocidade de barramento para memória e periféricos. Alteradas maiores são necessárias apenas quando há novos padrões de entrada e saída (KECKLER; OLUKOTUN; HOFSTEE, 2009). 
O esforço de engenharia pode ser amortizado já que pode-se criar uma família de processadores com a mesma interface externa, mas com diferentes números de núcleos disponíveis e várias frequências de clock, variando o preço e desempenho conforme necessidades do mercado (OLUKOTUN et al., 2007).

Obviamente essa nova arquitetura de processadores fez com que os programadores usassem um novo paradigma de programação. Antes os programas eram escritos para funcionar de forma sequencial, mas para aproveitar todo o poder de processamento dessa nova arquitetura, é necessário fazer uso de threads, dividindo as tarefas em vários processos que podem ser executados paralelamente em núcleos diferentes. (KECKLER; OLUKOTUN; HOFSTEE, 2009). Outra possibilidade é utilizar técnicas disponíveis para cluster de computadores, como MPI.

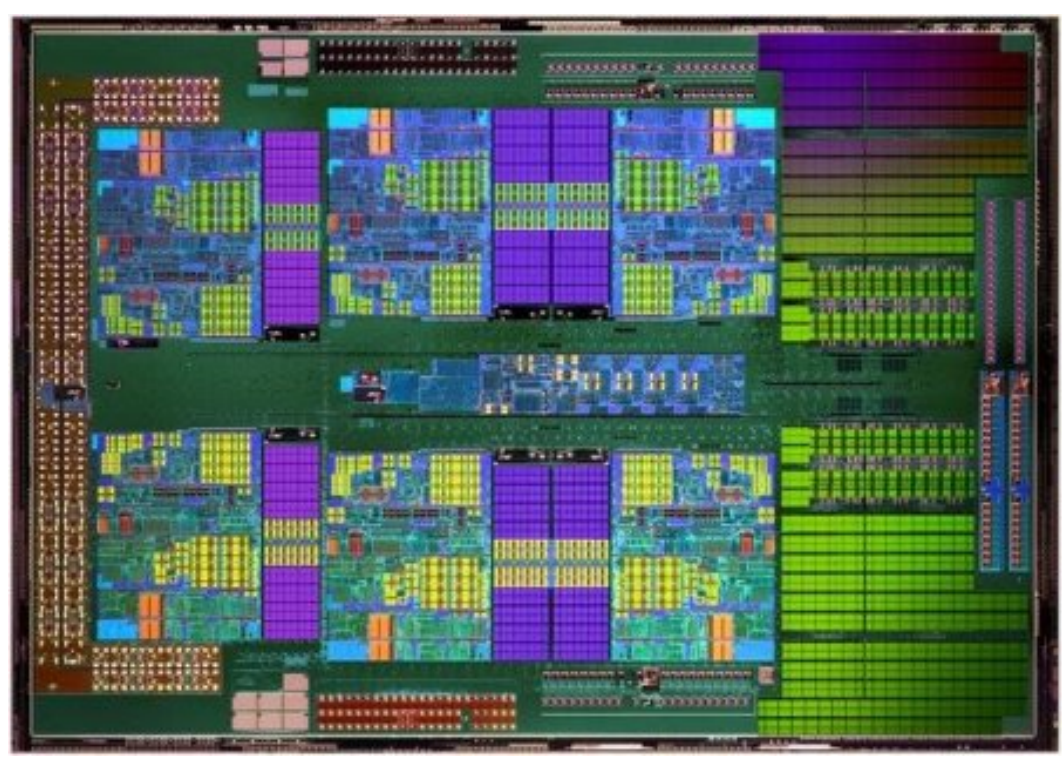

Figura 2.5: Imagem do silício de um processador AMD Phenom II X6, de 6 núcleos. É possível identificar cada núcleo separadamente. Fonte: (HUMPHRIES, 2010).

\subsection{CUDA}

Introduzido em 2006, criado e exclusivo da NVIDIA, CUDA é uma plataforma de computação paralela e modelo de programação que aumenta o desempenho computacional utilizando todo o potencial de unidades gráficas de processamento (GPU). Desde então tem sido usado em milhares de aplicações e é alvo de vários artigos de pesquisas. Há uma base instalada de mais de 300 milhões de GPUs habilitadas para o sistema CUDA 
entre notebooks, estações de trabalho, cluster de computadores e supercomputadores. É utilizado em diversas aplicações, como astronomia, biologia, química, física, finanças, manufatura, entre outras (NVIDIA, 2013).

O sistema CUDA é suportado em diversos sistemas operacionais, incluindo Windows 7, Windows XP, Linux e Mac OS, todos em versão de 32-bit ou 64-bit. O CUDA oferece compatibilidade com OpenACC, um padrão aberto da indústria com diretivas de compilação para códigos escritos em C ou Fortran para gerar códigos para sistemas de multi-CPU e acelerados por GPU. Esse padrão possibilita que o código seja compatível também com sistemas que possuem apenas uma simples CPU, sem ter de reescrevê-lo (NVIDIA, 2013).

Com o CUDA também é possível utilizar o paralelismo oferecido pelo MPI. Pode-se utilizar implementações MPI que não são integradas ao CUDA, mas há outras implementações que já são compatíveis com esse padrão de computação, como as implementações MVAPICH2 1.8 e 1.9b, OpenMPI 1.7, CRAY MPI 5.6.2 e IBM Platform MPI 8.3 (NVIDIA, 2013).

Um exemplo de código para processamento paralelo utilizando MPI pode ser observado no código da Figura 2.6:

Considerando que a implementação MPI não seja integrada ao sistema CUDA de processamento, seria necessário executar um segundo comando, cudaMemcpy quando fosse enviar dados entre um nó e outro da rede que possuíssem códigos sendo executados nos processadores gráficos (NVIDIA, 2013).

Utilizar uma implementação MPI integrada ao CUDA traz melhor desempenho e maior compatibilidade do código com clusters híbridos que integram computadores que não possuem GPU habilitada para o sistema CUDA. Para isso é necessário que o sistema de endereçamento virtual unificado esteja disponível. Esse sistema foi introduzido na versão CUDA 4.0 e faz com que o computador possa endereçar a memória do sistema e a memória de todas as GPUs conectadas nos barramentos PCI-e como se fosse uma única faixa de endereços, como pode ser observado na figura 2.9 . 


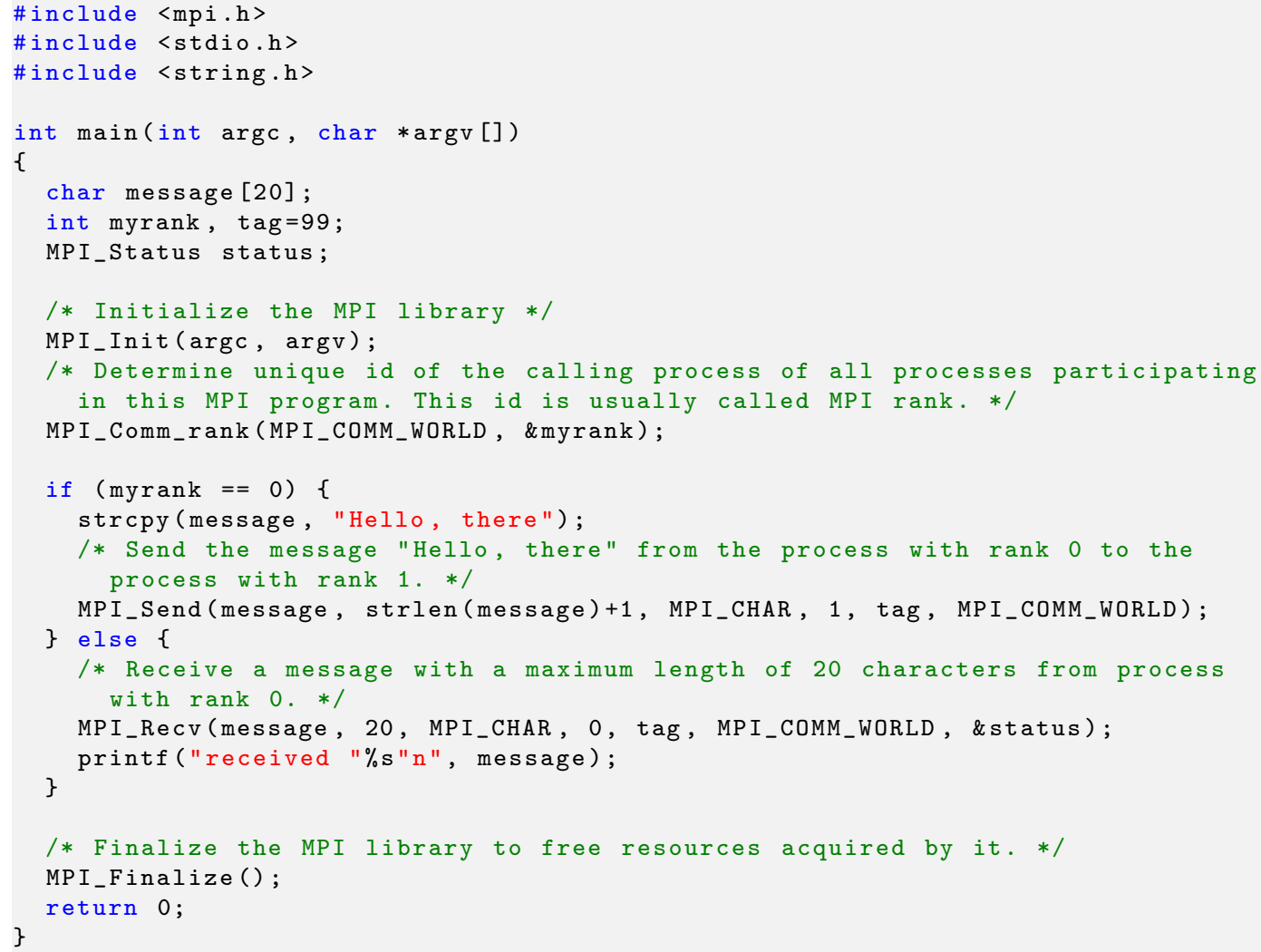

Figura 2.6: Código simples do tipo "Hello World!" exemplificando o processamento paralelo utilizando MPI

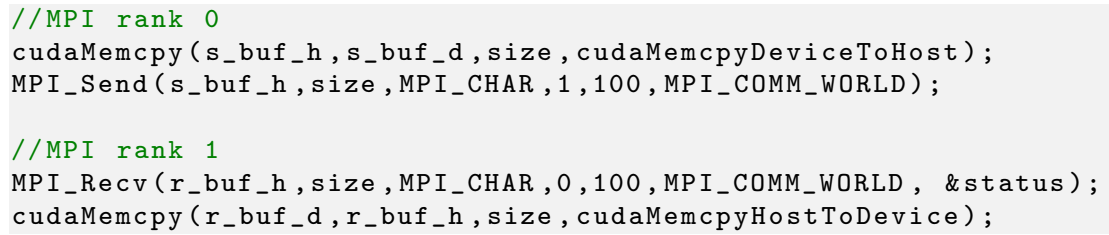

Figura 2.7: Código exemplificando o uso da interface MPI em conjunto com os comandos CUDA.

\subsection{OPENCL}

OpenCL é um padrão aberto, multi plataforma, para programação paralela de processadores modernos encontrados em computadores pessoais, servidores e dispositivos móveis e embarcados. Do inglês Open Computing Language, o OpenCL melhora o desempenho de uma grande variedade de aplicativos em diversas áreas do mercado, indo desde os jogos e entretenimento ao software científico e médico (KHRONOS, 2013).

Esse padrão é especificado por um grupo de várias grandes empresas, sendo que a NVIDIA lidera e a Apple é quem edita as especificações (ROSENBERG, 2011). 


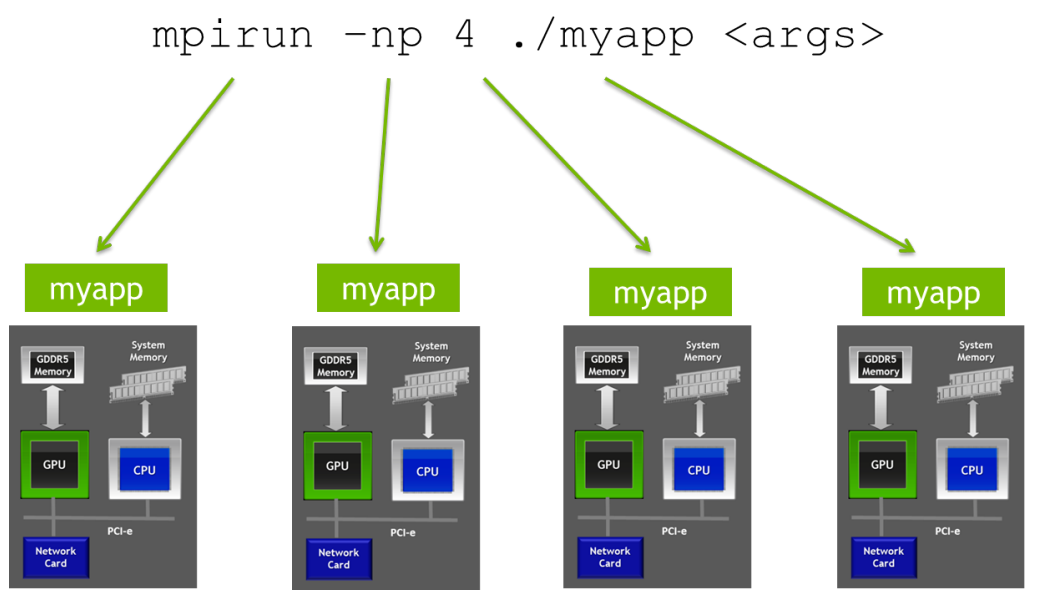

Figura 2.8: Ilustração de como o MPI é executado em um cluster com CUDA. O parâmetro - np indica quantos processos serão executados em paralelo, no caso 4 (KRAUS, 2013).

Sem UVA: Vários Espaços de Memória

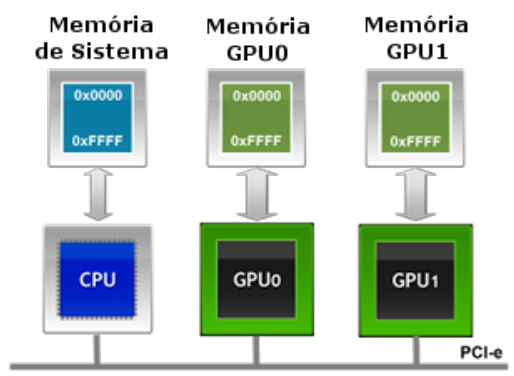

UVA: Único Espaço de Endereços

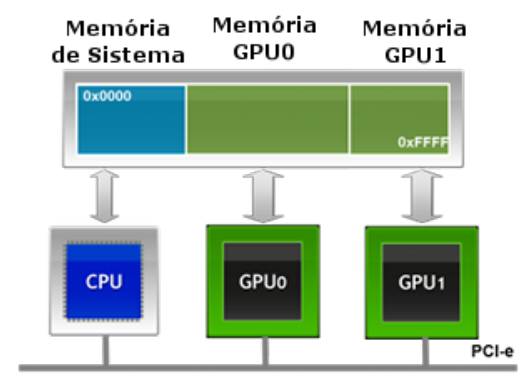

Figura 2.9: Ilustração mostrando a arquitetura de memória quando utilizado o sistema CUDA sem (esquerda) e com (direita) memória unificada. A memória unificada favorece a implementação MPI transparente para o programador.(KRAUS, 2013).

O grande diferencial dessa tecnologia é o seu modelo de execução. Define-se um domínio computacional de $\mathrm{N}$ dimensões e um código é executado em cada ponto do domínio computacional. A diferença de como o código é escrito para fazer essa transformação de um código tradicional em processadores convencionais para um código em OpenCL pode ser observado na figura 2.10.
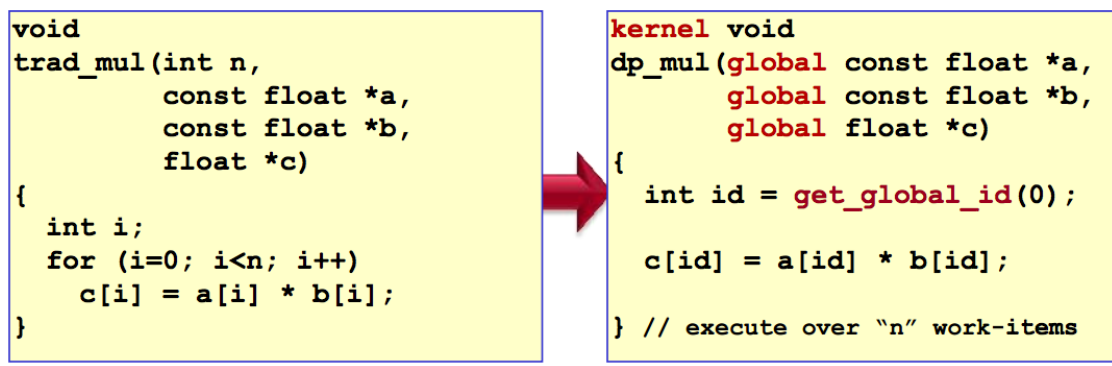

Figura 2.10: Do lado esquerdo da imagem, um código tradicional compondo um loop finito do tipo for. Do lado direito esse mesmo código é reescrito paralelizado e adaptado para o padrão OpenCL (ROSENBERG, 2011). 
O modelo de arquitetura desse padrão de computação é composto por uma CPU, o Host, e um ou mais dispositivos de computação. Cada dispositivo de computação é composto por uma ou mais unidades de computação. Cada unidade de computação é dividida em um ou mais elemento de processamento. O Host fica encarregado de enviar os trabalhos para os dispositivos de computação (ROSENBERG, 2011).

O gerenciamento de memória deve ser totalmente explícito. Os dados devem ser movidos do host para o global, do global para a memória local e então voltar.(ROSENBERG, 2011).

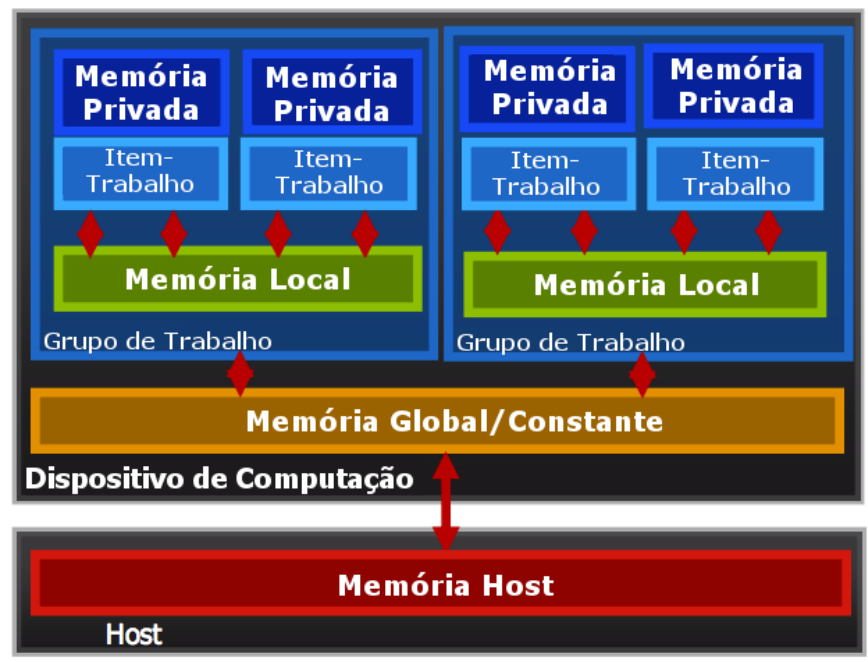

Figura 2.11: Modelagem da organização da memória em sistemas OpenCL. As memórias privadas, em azul, são apenas acessadas por cada item de trabalho. A memória local, em verde, é compartilhada dentro do mesmo grupo de trabalho. A memória global, em laranja, é acessível por todos os grupos de trabalho. Por último, a memória do Host é apenas acessível pela CPU(ROSENBERG, 2011).

O OpenCL fornece uma arquitetura com grande poder de processamento, com algumas alterações nós códigos já escritos para poder utilizar o máximo de desempenho do hardware disponível. Sua vantagem é que é um padrão aberto e está disponível tanto em GPU NVIDIA quanto AMD, as duas maiores fabricantes de dispositivos gráficos do mercado. (KHRONOS, 2013).

\subsection{GNU/Linux}

O GNU/Linux é um sistema operacional compatível com Unix e totalmente livre. O Projeto GNU teve início em 1984 e seu objetivo era desenvolver um sistema operacional 
livre similar ao Unix. O projeto visava desenvolver todas as ferramentas básicas e até avançadas para compor um sistema operacional completo e funcional totalmente livre (SYSTEM, 2013).

Em 1989 um estudante Finlandês chamado Linux Torvalds iniciou o desenvolvimento de um núcleo operacional de computador o qual hoje é conhecido como Linux. Em 1991 foi lançada a primeira versão final desse núcleo que juntamente com o Projeto GNU formava um sistema operacional totalmente livre. Depois de duas décadas o sistema está bem mais maduro e o núcleo está na versão 3.

As vantagens do GNU/Linux é que é um sistema totalmente aberto e livre para modificações e uso e também é portado para vários arquiteturas computacionais, como x86, x86_64, PowerPC, Arm, MIPS, entre outros.

O GNU/Linux está disponível em distribuições que facilitam sua instalação e manutenção. Dentre as mais famosas estão Debian, Gentoo, Fedora, openSUSE, Ubuntu, entre outros.

\subsection{Ubuntu Linux}

A distribuição Ununtu Linux é bastante conhecida atualmente. A palavra Ubuntu é de origem africana e é uma filosofia dos povos da África que define o relacionamento das pessoas umas com as outras. Uma tentativa de tradução para o português pode significar "sou o que sou pelo que nós somos"(UBUNTU, 2013).

O Linux se consolidou como arquitetura para servidores em 2004. Mas para computadores pessoais ainda estava distante de se tornar popular, principalmente pela dificuldade de instalação e uma interface não muito intuitiva, direcionado para uso de programadores ou usuários mais experientes.

Mark Shuttleworth quis modificar essa imagem que o Linux possuía e reunindo alguns poucos desenvolvedores de uma outra famosa distribuição Linux chamada Debian criou o Ubuntu (UBUNTU, 2013). A idea principal era criar um sistema bastante amigável com o usuário.

As distribuições Linux anteriores ao Ubuntu normalmente eram divididas em uma versão comercial, paga, principalmente adotadas por empresas, e uma versão grátis, para 
os usuários domésticos. A versão grátis não era bem acabada como a versão paga. O Ubuntu também tem as duas versões, mas diferente das demais, o sistema é o mesmo para as duas versões e de alta qualidade. A diferença é que a versão paga possui suporte diferenciado da Canonical, fornecedora de serviços para o sistema Ubuntu Linux.

A primeira versão lançada oficialmente do Ubuntu foi a 4.10, com codinome Warty Warhog, em Outubro de 2004 (UBUNTU, 2013). Atualmente está em sua versão 13.04, lançada em 2013 e terá suporte por 9 meses. A versão anterior, 12.04 LTS, será suportada até Abril de 2017 (UBUNTU, 2013).

\subsection{Android}

O sistema Android é a plataforma móvel mais popular no mundo (GOOGLE, 2013). Desenvolvido pela gigante de software Google, é uma plataforma móvel para smartphones e tablets. É baseado no núcleo Linux, mas com algumas modificações para o sistema móvel (ANDERSON, 2012).

As aplicações são baseadas na linguagem de programação Java, mas a máquina virtual que fará a execução do binário é uma modificação da Máquina Virtual Java (JVM), chamada de Dalvik. A Dalvik é uma máquina virtual mais integrada ao hardware de nova geração com melhor desempenho e possibilita a execução de várias máquinas virtuais paralelas, já que cada aplicação em Android é executada em uma máquina virtual separada, por motivos de segurança e estabilidade do sistema (PEREIRA; SILVA, 2009). É otimizada para trabalhar em processadores de menor frequência de clock, pouca memória RAM e sistema operacional sem espaço de Swap. A Dalvik executa arquivos de extensão .DEX (Dalvik Executable). Esses arquivos são classes Java compiladas com um bytecode diferente do JVM, pela ferramenta DX, distribuída com o SDK do Android. Essa máquina virtual especial baseia-se no kernel do Linux para funcionalidades subjacentes como o gerenciamento em baixo nível de memória RAM (PEREIRA; SILVA, 2009).

Foi escolhido utilizar máquina virtual para aumentar a portabilidade e a compatibilidade dos aplicativos com a grande variedade de dispositivos Android disponíveis no mercado, inclusive de diferentes fabricantes e arquiteturas de processamento.

O kernel Linux é utilizado para os serviços centrais do sistema, como gerenciamento de 
processos, gerenciamento de memória, pilha de protocolos de rede e drivers de dispositivos e periféricos. Por controlar os dispositivos, ele é responsável pelo gerenciamento de energia em baixo nível, principalmente escolhendo a melhor frequência de funcionamento do clock da CPU para um melhor rendimento da bateria dos smartphones. (PEREIRA; SILVA, 2009)

Há milhares de aplicativos desenvolvidos para Android para as mais diversas áreas de interesse. A distribuição dos aplicativos é feita por uma loja online de aplicativos chamada de Google Play. Essa loja reúne aplicativos, filmes, livros e música para qualquer dispositivo Android. (GOOGLE, 2013)

\subsection{Linux no Android}

Na Google Play há um aplicativo que facilita a instalação do GNU/Linux em um dispositivo Android. Essa aplicação chama-se Complete Linux Installer. Desenvolvido pelo projeto Linux On Android (ANDROID, 2012), ele tem por objetivo utilizar o próprio núcleo de processamento (kernel) do Android para a execução do sistema GNU/Linux em um smartphone ou tablet, possibilitando que o GNU/Linux seja executado através do Android, sem a necessidade de reiniciar o dispositivo ou apagar todos os dados do usuário. Todo o sistema operacional GNU é armazenado na memória do dispositivo em um arquivo de imagem, como acontece similarmente às instalações de sistemas operacionais em máquinas virtuais, como o VirtualBox da Oracle (https://www.virtualbox.org/). Isso permite independência dos dados e arquivos Android e GNU/Linux, evitando que qualquer problema no ambiente Linux cause danos ao sistema Android.

As distribuições Linux disponíveis para instalação são: Ubuntu, Debian, Backtrack. ArchLinux, openSUSE e Fedora estão em fase de testes e o projeto prevê que mais distribuições estarão disponíveis em breve (ANDROID, 2012).

\subsection{Programação Paralela}

A programação paralela é uma técnica que permite que vários cálculos sejam executados simultaneamente em vários processadores, partindo do pressuposto que os problemas 
mais complexos podem ser divididos em problemas mais simples e que podem ser resolvidos de forma concorrente para obter uma solução (ALMASI; GOTTLIEB, 1989).

Os programas de programação paralela são mais difíceis de serem escritos em relação aos serializados. A concorrência entre os processos introduz uma série de potenciais problemas no código, como por exemplo a condição de corrida. Dois processos podem tentar acessar o mesmo recurso simultaneamente e corromper os dados. Comunicação e sincronização entre os diferentes processos são normalmente os maiores obstáculos para um bom desempenho de um programa paralelo (HENNESSY, 1998).

Para avaliar qual o ganho de desempenho entre uma aplicação serializada e outra paralelizada, pode-se calcular o chamado speedup. Considerando o tempo total de execução de um programa serial com a melhor solução possível para resolver um dado problema como sendo Ts e o tempo total de um programa paralelo para resolver o mesmo problema sendo $T p$, tem-se o speedup dado por $S p$ na equação 2.1.

$$
S p=\frac{T s}{T p}
$$

O valor de $S p$ determina qual o ganho ou perda entre o processamento serial e o praralelo. Um programa com speedup linear deve ter $S p=p$, sendo $p$ o número de processos, ou seja, dobrando o número de processos, dobra a velocidade. Normalmente $S p \leq p$, uma vez que se um problema é resolvido em tempo $T s$, dividindo essa tarefa entre $p$ processos, ela será realizada em um tempo $T s / p$. Mas há alguns casos em que $S p>p$. Isso pode acontecer quando um trabalho realizado por um algoritmo serial é maior que sua formulação paralela, como é o caso de algoritmos de busca. Pode acontecer também quando algumas características do hardware coloca o algoritmo serial em desvantagem, como, por exemplo, o tamanho dos dados ser muito grande para ser colocado totalmente na memória cache. Esses casos são chamados de speedup superlineares (KADAM, 2007).

Outro índice para comparar algoritmos serializados e paralelizados é o cálculo da eficiência. Em programas paralelos não se atinge o comportamento ideal, pois cada elemento de processamento não consegue estar sempre 100\% do tempo computando o algoritmo. Esse índice mede quanto tempo cada processador está sendo aplicado de forma útil. Ele é dado pela equação 2.2 (KADAM, 2007). 


$$
E p=\frac{S p}{p}=\frac{T s}{p * T p}
$$

Em um programa paralelo ideal, a eficiência é dada por $E p=1$ e o speedup é dado por $S p=p$. Na prática a eficiência é dada por $0 \leq E p \leq 1$ e o speedup é dado por $S p<1$.

Considerando um algoritmo paralelo não ideal, a diferença de tempo entre o tempo de execução do algoritmo serial (Ts) e o tempo de execução do algoritmo paralelo $(T p)$ é o tempo de overhead do algoritmo (To). Esse cálculo é dado pela equação 2.3.

$$
T o=p * T p-T s
$$

Dessa forma, a eficiência do algoritimo também pode ser escrita conforme equação 2.4.

$$
E p=\frac{1}{1+\frac{T o}{T s}}
$$

A função de overhead é proporcional a $p$, que é o número de processos paralelos. Dado um certo problema, o valor de Ts é sempre constante em repetidas execuções. Aumentando o número de elementos de processamento, o To aumenta. Dessa forma a eficiência do algoritmo paralelo cai. Isso acontece em todos os algoritmos paralelos.

Pela equação 2.3, To é dependente do tamanho do problema Ts, e também do número de elementos de processamento $p$. Em vários casos To pode aumentar sublinearmente em relação ao Ts. Nesses casos, aumentando o problema e mantendo $p$ constante, aumentase a eficiência. Para manter a eficiência constante, pode-se simultaneamente aumentar o problema e o número de elementos de processamento. Esses sistemas são chamados de sistemas paralelos escalonáveis.

\subsubsection{Lei de Amdahl}

Em 1967, na AFIPS Spring Joint Computer Conference, o arquiteto de computação Gene Amdahl apresentou sua formulação da lei que leva seu nome; lei de Amdhal. Essa lei descreve como encontrar a máxima melhoria esperada de um sistema quando apenas parte desse sistema é otimizado. Geralmente essa lei é utlizada em computação paralela para calcular o máximo speedup teórico usando múltiplos processos (KADAM, 2007). 
Dado $p \in \mathbb{N}$ o número de processos paralelos, $B \in[1 . .0]$ sendo a fração do algoritmo que é estritamente serial, então o tempo $T(p)$ que um algoritmo leva para ser executado completamente em $p$ threads de exeução é dado pela equação 2.5:

$$
T(p)=T(1)\left(B+\frac{(1-B)}{p}\right)
$$

Sendo assim, a equação de speedup 2.1 pode ser rescrita na forma dada pela equação 2.6 .

$$
S(p)=\frac{T(1)}{T(p)}=\frac{T(1)}{T(1)\left(B+\frac{(1-B)}{p}\right)}=\frac{1}{B+\frac{(1-B)}{p}}
$$

Pelo uso da lei de Amdahl é possível determinar se um dado algoritmo é um forte candidato à paralelização.

Tome como exemplo um determinado algoritmo em que $73 \%$ pode ser paralelizado, ou seja, $B=0,27$. Considerando dividir o processamento em 4 processadores $(p=4) \mathrm{e}$ substituindo os valores na equação 2.6, obtem-se a equação 2.7 .

$$
S(4)=\frac{1}{0,27+\frac{(1-0,27)}{4}}
$$

Calculando a equação 2.7 , chega-se ao valor de $S(4) \approx 2,2099$, o que equivale a dizer que o algoritmo exemplificado, usando 4 processadores, teria uma melhoria de desempenho teórica de $220,99 \%$. Se $p \rightarrow \infty$, então $S(4) \approx 3,7037$, ou $370,37 \%$ em relação ao algoritmo serial. Essa lei mostra que o ganho de desempenho em paralelizar o algoritmo vai ser limitado pela porção de código que pode ser paralelizada. O gráfico 2.12 mostra qual o speedup para diferentes números de processadores e diferentes porcentagens de paralelização do algoritimo. Percebe-se que a 95\% de paralelização de código, a limitação de 20x de speedup é alcançada com aproximadamente 4 mil processadores. E quando apenas $50 \%$ do código for paralelizável, a limitação será de 2x já com 30 processadores aproximadamente. 


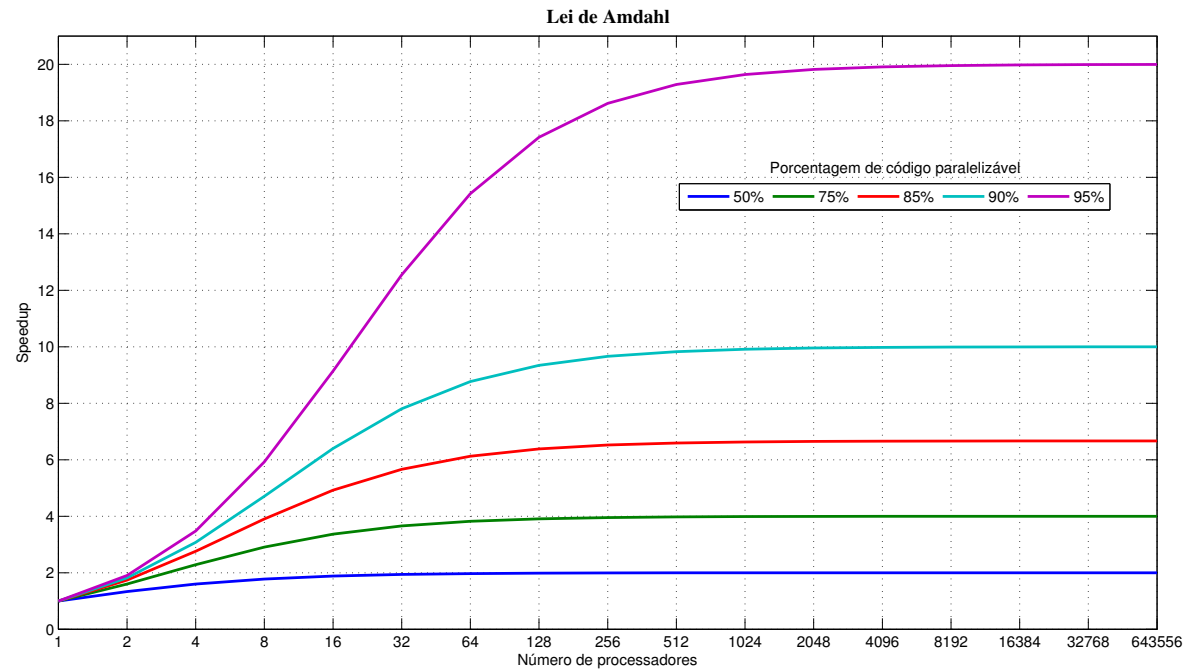

Figura 2.12: Gráfico da Lei de Amdahl calculando o speedup para vários números diferentes de processadores e porcentagens de código paralelizável. É possível perceber que a limitação teórica de speedup é definida pela porção paralelizável do código. 
CAPÍTULO

Materiais e Métodos

\subsection{Dispositivos utilizados}

Para a avaliação de desempenho foram utilizados dois smartphones além de um computador para fins comparativos de resultado. Ambos os celulares são da marca Samsung, sendo um deles o modelo Galaxy S II (GT-I9100) que possui chipset Exynos 4 Dual, fabricado pela própria Samsung e que embarca dois núcelos de processamento de arquitetura ARM Cortex-A9, com frequência de clock de 1.2GHz e 1GByte de memória RAM.

O segundo é um Galaxy Note II, o qual utiliza o chipset Exynos 4 Quad, com quatro núcleos de processamento com arquitetura ARM Cortex-A9, com frequência de clock de $1.8 \mathrm{GHz}$ e 2GBytes de memória RAM.

O computador utlizado no comparativo é equipado com processador AMD Phenom II X4 830, com frequência de clock de $2.8 \mathrm{GHz}$ e 4GBytes de memória RAM.

Os três equipamentos estão utilizando a distribuição Linux Ubuntu 12.04 LTS como sistema operacional. A diferença entre os dispositivos móveis e o computador é que os celulares estão com o sistema Android como base, o que pode reduzir os recursos disponíveis para o Linux, como memória e processador. Mas para fins da análise isso não terá impacto algum, visto que essas são as condições normais de operação dos smartphones. 
Tabela 3.1: Especificação dos dispositivos utilizados nos experimentos

\begin{tabular}{lcccll}
\hline \hline Dispositivo & Arquitetura & Processador & Núcleos & $\begin{array}{l}\text { Frequência } \\
(\mathrm{GHz})\end{array}$ & $\begin{array}{l}\text { Memória } \\
\text { (Gbytes) }\end{array}$ \\
\hline Galaxy S II & ARM & Cortex-A9 & 2 & 1.2 & 1 \\
\hline Galaxy Note II & ARM & Cortex-A9 & 4 & 1.8 & 2 \\
\hline HP Pavilion & x86_64 & Phenom II X4 830 & 4 & 2.8 & 4 \\
\hline
\end{tabular}

Os dispositivos móveis foram ligados ao computador por meio de cabos USB e foi emulada uma rede ethernet por esse cabo para diminuir a latência na transmissão dos dados. Portanto a interferência da rede sem fio é descartadas nesses experimentos.

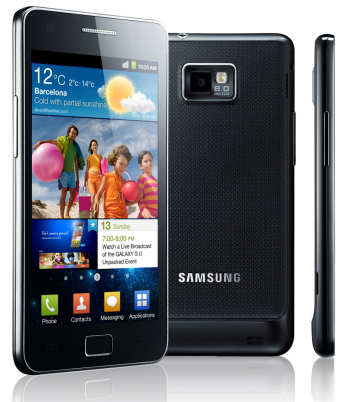

(a) Smartphone Samsung Galaxy S II. Possui processador ARM Cortex-A9 de dois núcleos com frequência de clock de $1.2 \mathrm{GHz}$

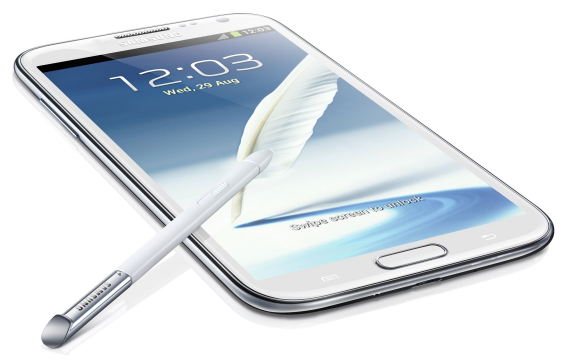

(b) Smartphone Samsung Galaxy Note II. Possui processador ARM CortexA9 de 4 núcleos com frequência de clock de $1.8 \mathrm{GHz}$

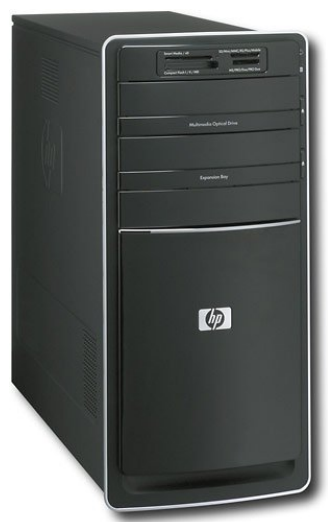

(c) Computador HP Pavilion. Possui processador AMD Phenom II X4 830 de 4 núcleos com frequência de clock de $2.8 \mathrm{GHz}$

Figura 3.1: Dispositivos utilizados na avaliação de desempenho do cluster híbrido

\subsection{Algoritmos para avaliação}

Para avaliar o desempenho desse cluster híbrido foram escritos dois códigos em linguagem C com computação concorrente. Esse processamento paralelo funciona tanto 
internamente ao processador para troca de informação entre os processos sendo executados em cada núcleo, como também em rede, entre os dispositivos e seus processadores com seus múltiplos núcleos. Sendo assim, os códigos desenvolvidos podem ser executados em um processador de $\mathrm{N}$ núcleos ou em um cluster de $\mathrm{X}$ dispositivos com $\mathrm{Y}$ processadores e Z núcleos de forma transparente.

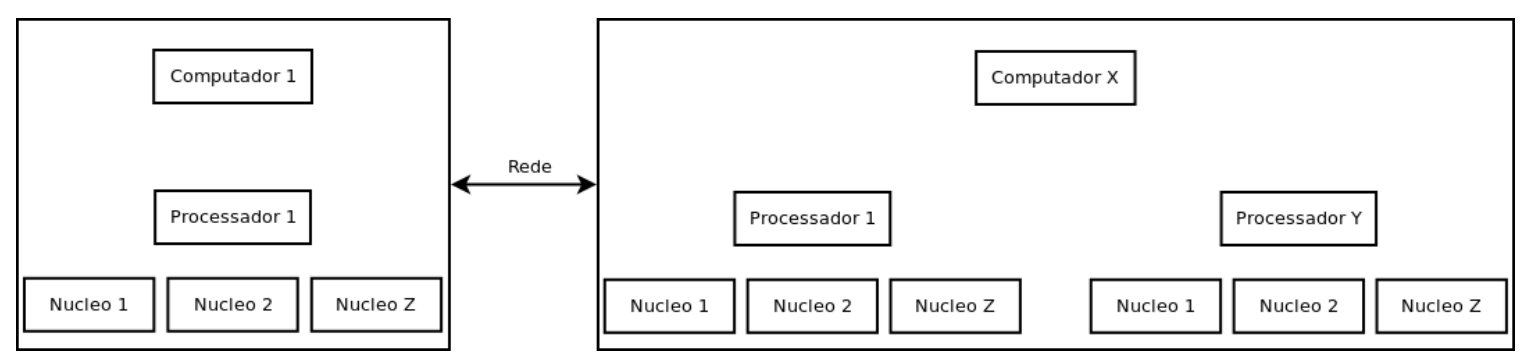

Figura 3.2: Representação de uma organização de X dispositivos com Y processadores e $\mathrm{Z}$ núcleos de processamento. Os dispositivos estão interligados em rede.

Para viabilizar a programação concorrente foi utilizada a biblioteca OpenMPI, a qual implementa o padrão MPI e é capaz de suportar cluster híbridos, ou seja, que possuem dispositivos de diferentes arquiteturas executando o mesmo programa, que é o caso do cluster de avaliação (OPENMPI, 2013). Do inglês Message Passing Interface, MPI é um padrão para troca de mensagens entre processos em programação paralela baseado no Fórum MPI, formado por 40 organizações participantes, incluindo pesquisadores, desenvolvedores de software, usuários e fornecedores. O objetivo do MPI é estabelecer uma padronização para troca de mensagens entre aplicações que seja portável, eficiente e flexível (OPENMPI, 2013). Ele não é por si só uma biblioteca, mas sim uma especificação de como codificar aplicações que sejam compatíveis com implementações desse padrão. Seu início deu-se entre 1992 e 1994, com o esforço de inúmeros grupos de colaboradores que na década de 1980 e começo de 1990 perceberam que era necessário estabelecer um padrão em troca de mensagens em computação paralela para melhorar desempenho, portabilidade, custo financeiro e funcionalidades. Apesar de já estar disponível a versão MPI-3.0 do padrão MPI, a versão utilizada nesse projeto é a MPI-2.0, pois é a versão disponível no Ubuntu Linux 12.04 para todos os dispositivos e já atende aos requisitos da avaliação. 


\subsubsection{Aplicativo para cálculo de DFT em cluster}

O primeiro código desenvolvido faz o cálculo da Transformada Discreta de Fourier (DFT) de um sinal de áudio. O algoritmo para cálculo de DFT utilizado foi da biblioteca FFTW (Fastest Fourier Transform in the West) que é otimizada para várias arquiteturas de processadores, incluindo a x86 de 32 e 64 bits e também a ARM, oferecendo um desempenho semelhante em qualquer arquitetura escolhida (FFTW, 2013). O FFTW é uma biblioteca livre para linguagem de programação C para o cálculo de da DFT em uma ou mais dimensões, de tamanho arbitrário, e com números reais ou complexos. Ela também contempla as transformadas seno e cosseno (DCT e DST). Pela sua facilidade de uso, alto desempenho e portabilidade para diferentes arquiteturas, foi escolhida para os testes realizados neste projeto (FFTW, 2013).

O código de avaliação consiste em ler um arquivo de áudio digital, no formato WAV, com um canal apenas e processar a sua Transformada Discreta de Fourier usando janelas retangulares. É possível determinar qual a distância em amostras entre uma janela e outra no sinal de entrada. A Figura 3.3 mostra um esboço de como o sinal é recortado em janelas amostrais e quais as referências para mostrar a distância entre janelas em amostras e também o tamanho das janelas. Com o sinal quebrado em janelas amostrais, o processamento é dividido entre os núcleos e nós do cluster. O nó mestre, ou servidor, é responsável por distribuir as janelas para cada processador, ou nó escravo, que está aguardando processamento. O nó mestre também processa dados enquanto faz uma varredura periódica para identificar qual processador está livre para receber mais dados.

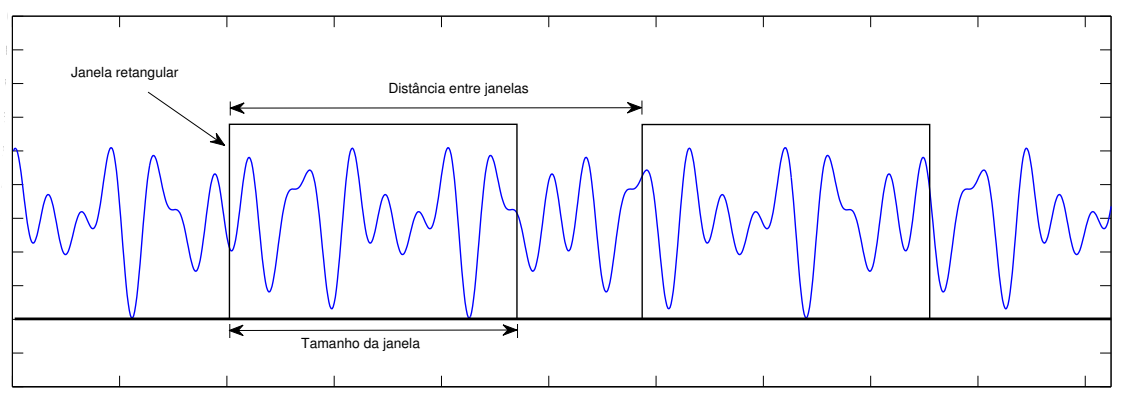

Figura 3.3: Esboço representando um sinal com duas janelas temporais retangulares e observações para a distância entre as janelas e o tamanho de cada janela. Quando essa janela temporal é feita no espaço discreto, esse valores de distância são medidos em amostras e não mais no tempo. 
Para a avaliação do desempenho é calculado o tempo total de processamento dos dados, desde o início da distribuição das janelas, até que o último nó do cluster termine os cálculos. Os sincronismos para iniciar o processamento e também para finalizá-lo são feitos pela função MPI_Barrier(), que faz com que o código só continue a execução quando todos os processos do cluster atingirem essa mesma parte do código. O diagrama de sequência da comunicação entre os nós do cluster pode ser observado na Figura 3.4.

Para que os nós escravos façam o processamento dos dados é necessário que cada nó envie para o nó servidor uma mensagem com o texto "ready", indicando que o processamento dos dados previamente selecionados já terminou e que está pronto para o processamento de um novo conjunto de dados. Para enviar mensagens bloqueantes a função MPI_Send() é utilizada pelo nó que está enviando e a função MPI_Recv() deve ser utilizada pelo nó que receberá a mensagem.

Assim que o nó mestre detecta que um nó escravo enviou uma mensagem desse tipo, ele verifica se há mais janelas disponíveis aguardando processamento e envia um intervalo de janelas para que esse nó inicie um novo lote de execução. Esse intervalo é pré-definido em tempo de compilação do código, mas pode ser facilmente modificado para ser definido em tempo de execução, possibilitando algoritmos adaptativos para melhor escolher o tamanho das janelas dependendo do poder de processamento do nó que faz a requisição.

Dessa forma o processamento é dividido entre todos os nós configurados no cluster de forma automática, não havendo necessidade de qualquer configuração extra.

Para o cálculo do tempo de execução há uma função do sistema operacional GNU/Linux chamada gettimeofday. Essa função retorna uma estrutura com o tempo atual do sistema em segundos e microssegundos. A resolução do relógio do sistema não é especificada. Armazenando o valor retornado por essa função no início de execução do código e depois feita a diferença com o valor retornado no final da execução é possível computar o tempo total de execução em microssegundos.

O objetivo da avaliação através desse código é computar o tempo total de processamento quando for executado um número arbitrário de processos em paralelo. Somando todos os dispositivos disponíveis há um total de 10 núcleos de processamento. Será criado no máximo 1 processo para cada núcleo. Portanto serão executados no máximo 10 


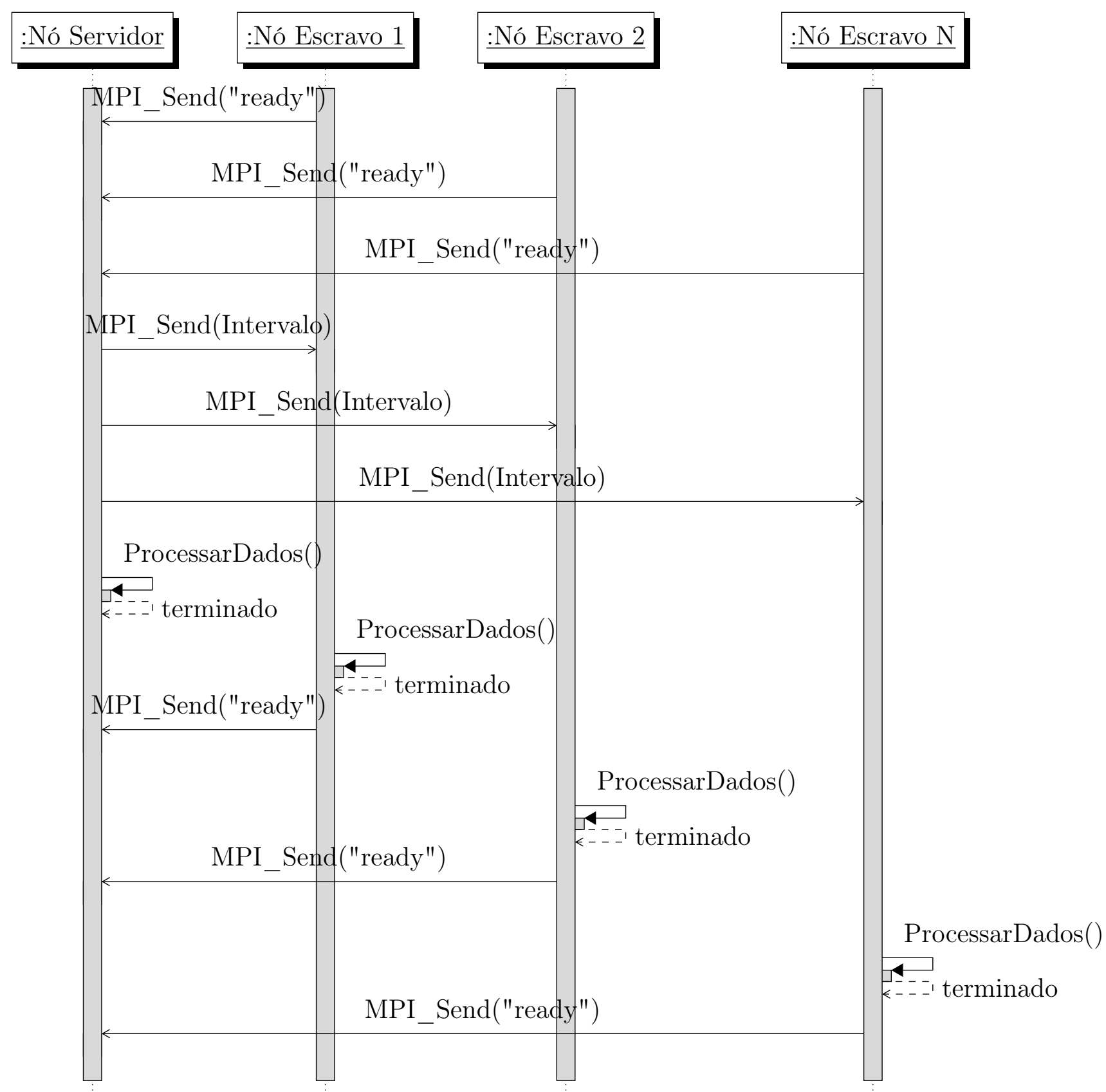

Figura 3.4: Diagrama de sequência das trocas de mensagens entre os nós do cluster. O nó mestre é responsável por distribuir o trabalho entre os outros nós do cluster. Com essa arquitetura é possível adicionar $\mathrm{N}$ nós para executar a tarefa em conjunto sem alteração no algoritmo.

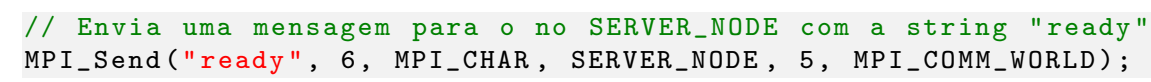

Figura 3.5: Trecho de código em linguagem C mostrando o envio da mensagem de fim de processamento de um nó escravo por interface MPI. 
processos concorrentes no cluster.

Os testes foram divididos em 4 experimentos. O experimento de número 1 testará o cluster com os dois dispositivos móveis conectados. O processo servidor será executado no dispositivo Galaxy Note II, de 4 núcleos. Assim que todos os seus núcleos estiverem ocupados, o segundo dispositivo, Galaxy S II, será utilizado para complementar o processamento. A Figura 3.6 mostra a ordem de uso dos processadores para cada configuração. Serão executadas 10 repetições para cada configuração.
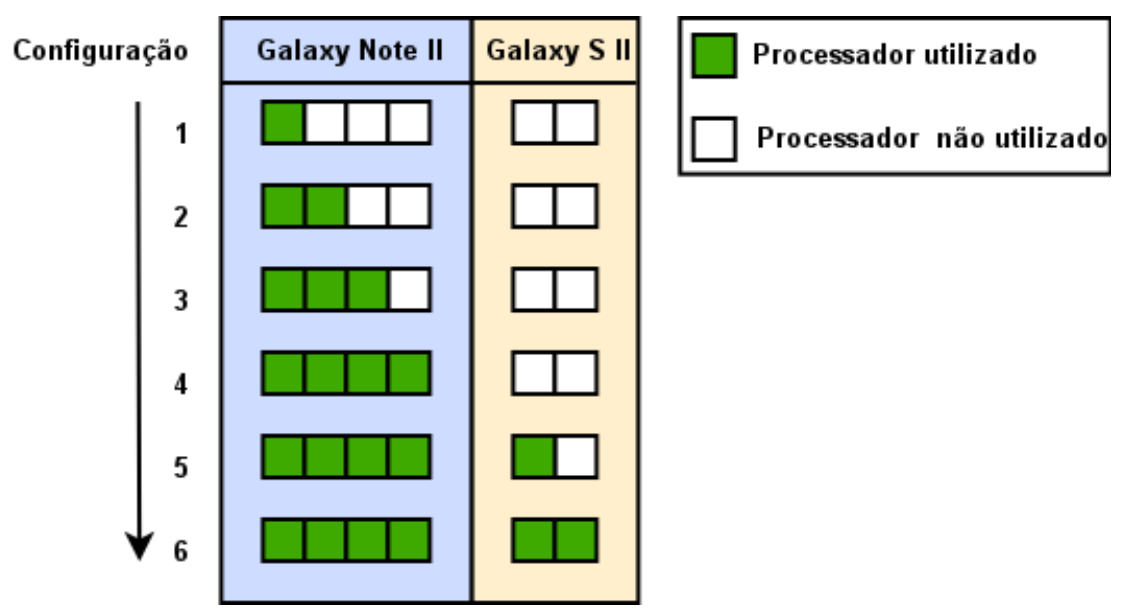

Figura 3.6: Sequência de uso dos processadores do experimento 1. O processo servidor é executado no dispositivo Galaxy Note II. O dispositivo Galaxy S II é o responsável por complementar o processamento do cluster. Para cada configuração (de 1 a 6) são repetidas 10 medições.

O experimento de número 2 também fará a avaliação utilizando apenas os dois dispositivos móveis conectados. Porém o processo servidor será executado no dispositivo Galaxy S II, de apenas 2 núcleos. O Galaxy Note II será utilizado para os últimos 4 processos concorrentes. A Figura 3.7 mostra como foram utilizados os processadores para cada configuração. Também serão executadas 10 repetições para cada configuração.

O experimento de número 3 utiliza apenas o computador como dispositivo para execução do algoritmo. A Figura 3.8. O objetivo é avaliar qual a capacidade de processamento de um computador em relação aos dispositivos móveis selecionados para o trabalho.

Para os experimentos 1, 2 e 3 foram utilizadas as mesmas configurações para o aplicativo de avaliação: janela retangular de 512 amostras e distância entre janelas de 128 amostras.

O arquivo utilizado foi criado para esse propósito e é chamado SoundTest-Linear.wav. Este arquivo contém um sinal de áudio que varre as frequências de $0 \mathrm{~Hz}$ a $22050 \mathrm{~Hz}$. O 


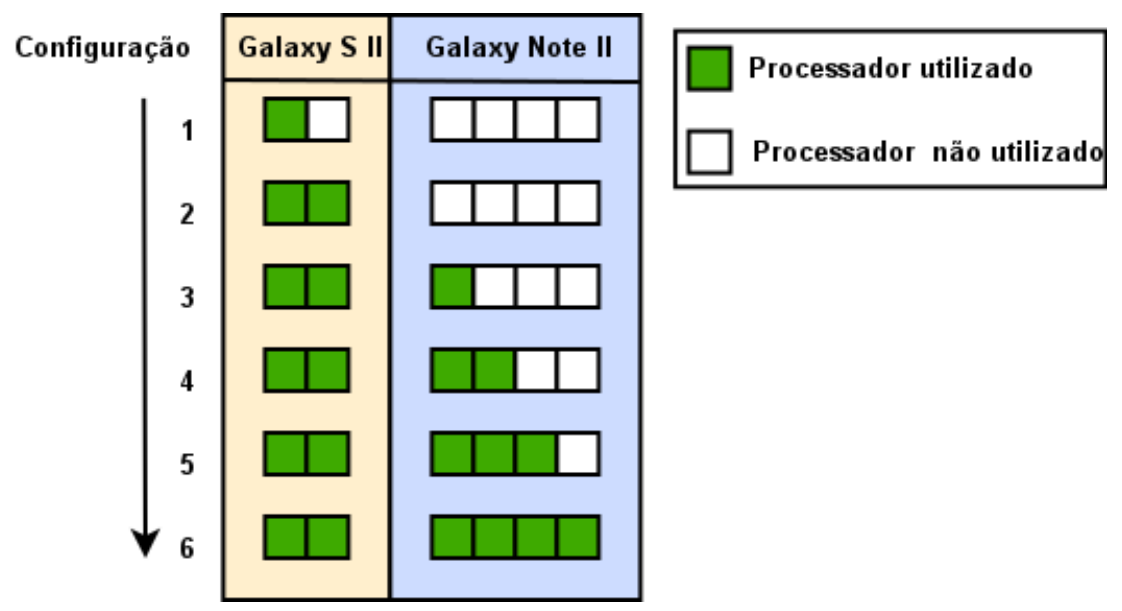

Figura 3.7: Sequência de uso dos processadores do experimento 2. O processo servidor é executado no dispositivo Galaxy S II. O dispositivo Galaxy Note II é o responsável por complementar o processamento do cluster. Para cada configuração (de 1 a 6 ) são repetidas 10 medições.

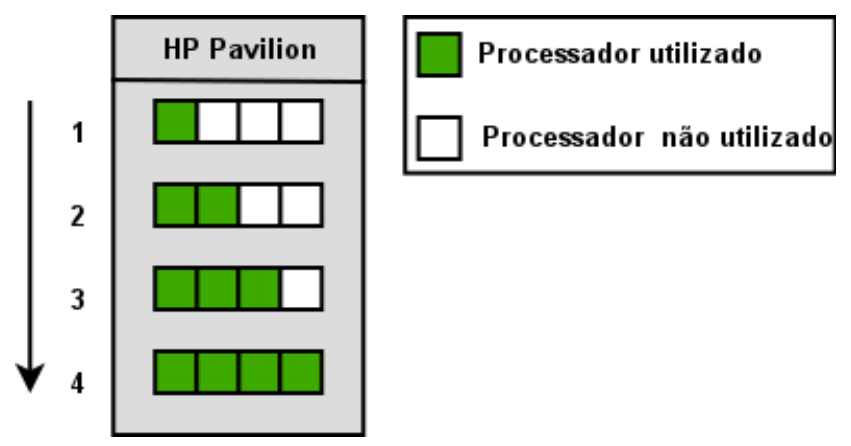

Figura 3.8: Sequência de uso dos processadores do experimento 3. O processo servidor é executado no dispositivo HP Pavilion e apenas ele faz parte do cluster. Para cada configuração (de 1 a 4) são repetidas 10 medições.

espectrograma desse sinal de áudio pode ser visto na Figura 3.9.

O experimento 4 fará uso de todos os 3 dispositivos conectados no mesmo cluster. O objetivo é avaliar qual a influência dos processadores dos dispositivos móveis em relação aos processadores dos computadores. Para esse experimento os parâmetros foram alterados para que fosse necessário um maior número de janelas para processar o arquivo de áudio, aumentando o tempo de execução e diminuindo o erro das medições. A distância entre as janelas foi definida para 5 amostras. Para esse experimento o computador é o servidor que distribui as tarefas para o cluster. A Figura 3.10 mostra a sequência de uso dos processadores nas diferentes configurações do experimento. 


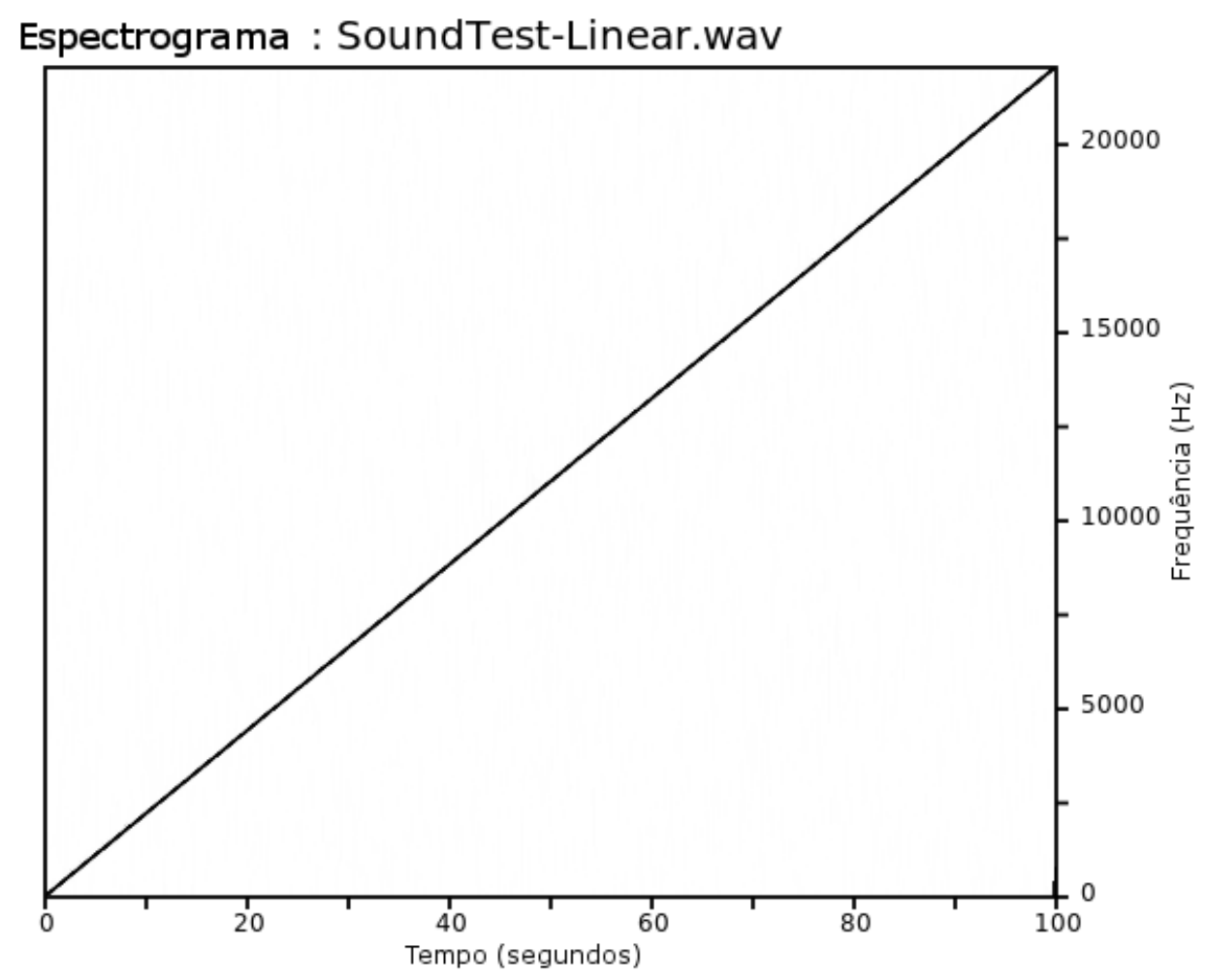

Figura 3.9: Espectrograma do sinal de som utilizado na avaliação.

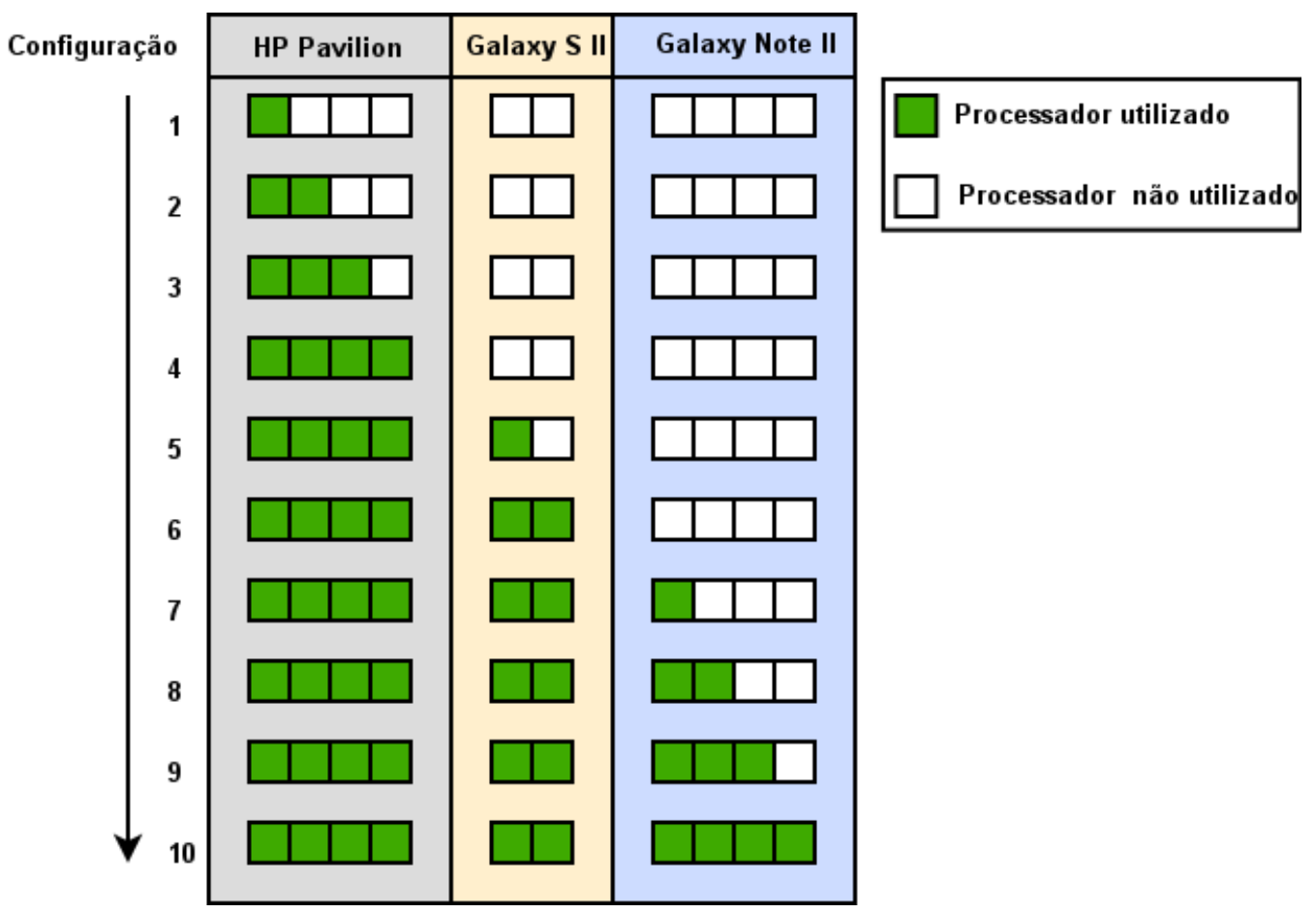

Figura 3.10: Sequência de uso dos processadores do experimento 4. O processo servidor é executado no dispositivo HP Pavilion e os dispositivos Galaxy Note II e Galaxy S II complementam o cluster. Para cada configuração (de 1 a 10) são repetidas 10 medições.

\subsubsection{Aplicativo para cálculo do número $\pi$ em cluster}

O segundo aplicativo desenvolvido para a avaliação do desempenho da arquitetura proposta calcula o número $\pi$ utilizando o método da integração. Para isso utilizou-se a 
definição de arco tangente. A função de arco tangente pode ser representada pela integral da equação 3.1 .

Sabe-se, também, que a função arco tangente de 1 é dada pela equação 3.2 .

Definindo z=1 na equação 3.1, obtem-se a equação 3.3 .

Igualando as equações 3.2 e 3.3, obtem-se a equação 3.4 .

Isolando $\pi$, obtem-se a equação 3.5 que é a equação utilizada pelo algorit mo dos próximos experimentos.

$$
\begin{gathered}
\operatorname{arctg}(z)=\int_{0}^{z} \frac{1}{1+x^{2}} d x \\
\operatorname{arctg}(1)=\pi / 4 \\
\operatorname{arctg}(1)=\int_{0}^{1} \frac{1}{1+x^{2}} d x \\
\int_{0}^{1} \frac{1}{1+x^{2}} d x=\pi / 4 \\
\pi=4 * \int_{0}^{1} \frac{1}{1+x^{2}} d x
\end{gathered}
$$

Para o cálculo dessa integral deve-se recorrer ao cálculo numérico de integrais definidas. Por definição uma integral definida pode ser expressa da seguinte forma:

$$
S=\int_{a}^{b} f(x) d x=\lim _{N \rightarrow \infty} \sum_{i=0}^{N} f\left(x_{i}\right) \Delta x
$$

Onde:

$$
\Delta x=\frac{b-a}{N}
$$

A integral da função $f(x)$ pode ser representada pela soma de pequenos retângulos de base $d x$ e altura $f(x)$, em que o produto deles é a área deste retângulo. Somando todas estas áreas infinitesimais obtem-se a área total abaixo da curva da função. A equação 3.7 
define o comprimento dos intervalos infinitesimais que dividirão o intervalo (b-a).

Para calcular a equação 3.5 pode-se expressar o somatório:

$$
\pi=4 * \int_{0}^{1} \frac{1}{1+x^{2}} d x=4 * \lim _{N \rightarrow \infty} \sum_{i=0}^{N} \frac{1}{1+x^{2}} \Delta x
$$

Onde:

$$
\Delta x=\frac{1-0}{N}
$$

Quanto maior for $N$ para a divisão do intervalo, mais preciso será o resultado. Mas isso também aumenta o custo computacional. Um exemplo de integração numérica por retângulos pode ser visto na Figura 3.11.

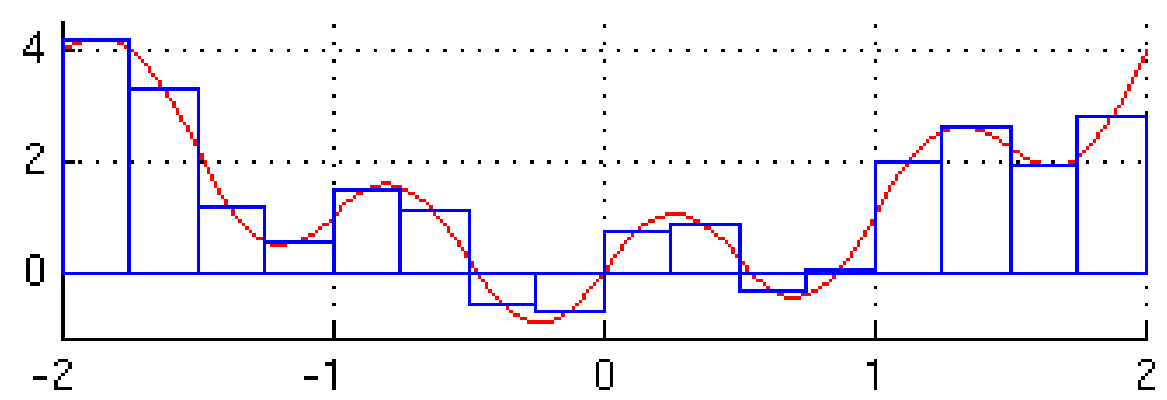

Figura 3.11: Exemplo de integração numérica pelo método dos retângulos. As áreas dos infinitos retângulos são somadas para resultar no total da área do gráfico. Quanto maior o número de retângulos, mais próximo do valor exato é o resultado.

O objetivo da avaliação não é a precisão do cálculo, mas quanto maior for a necessidade de grande processamento, melhor para a análise dos resultados. Por isso deve-se escolher o maior valor possível para $N$.

O trecho do código em linguagem $\mathrm{C}$ que faz o cálculo do número $\pi$ é dado por:

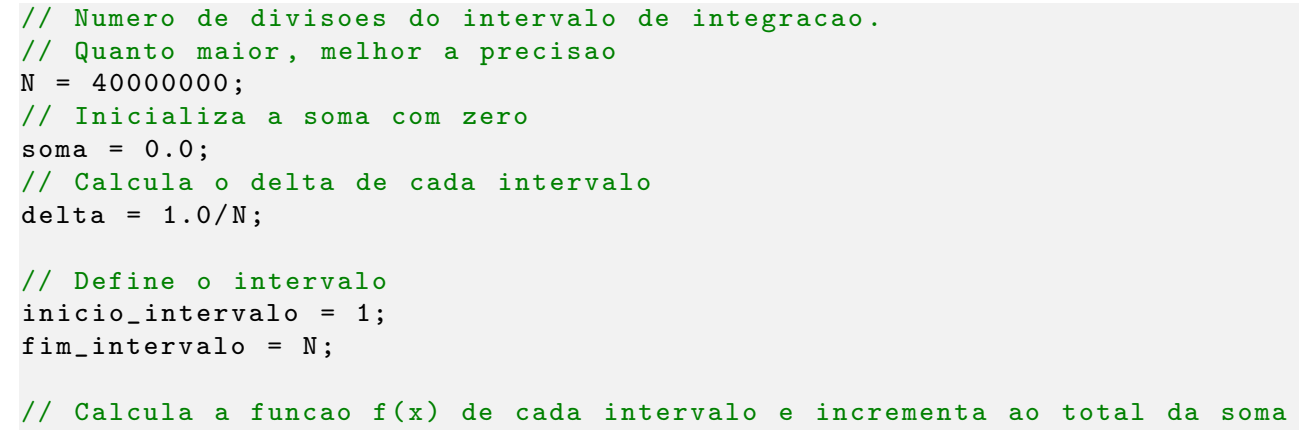




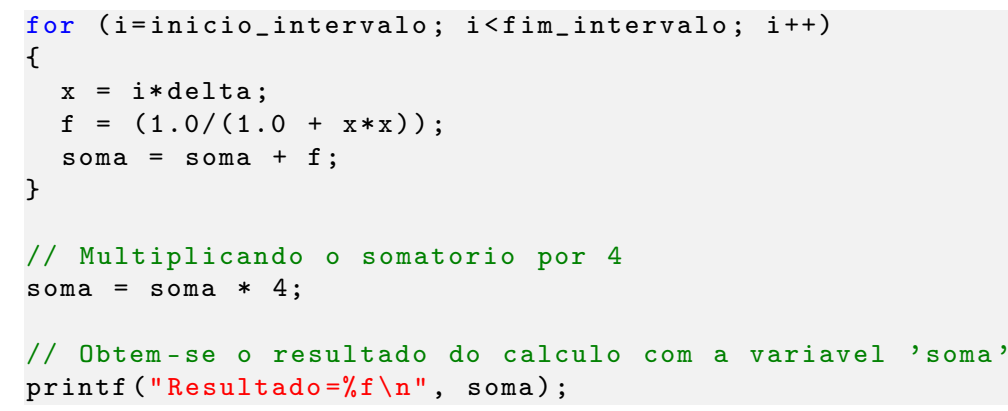

Uma vez que o algoritmo para o cálculo do número $\pi$ é iterativo, é possível dividir os intervalos em diferentes processos paralelos em um cluster de computadores e diminuir o tempo total de processamento. No aplicativo desenvolvido para esse trabalho foi definido $N=2.000 .000 .000$ (dois bilhões) que é um número suficientemente grande e é possível de ser representado em uma variável de 32 bits com sinal, que representaria um intervalo máximo de $[0,2147483647]$ para os exeprimentos 5, 6 e 7. Para o experimento de número 8 foi definido $N=4.000 .000 .000$ (quatro bilhões) que pode ser representado por uma variável de 32 bits sem sinal, que pode representar um intervalo de [0,4294967295].

A divisão dos intervalos é semelhante ao do algoritmo para o cálculo da DFT usando MPI. O nó servidor é responsável por dividir os intervalos para processamento entre os nós do cluster de forma transparente. Quando um nó termina o processamento de um determinado intervalo, ele requisita um novo intervalo para o servidor. Se ainda houver um intervalo que não foi computado, esse intervalo é atribuído e enviado para o nó requisitante. Se todos os intervalos já tiverem sido computados, então o servidor envia uma mensagem de fim de processamento para todos os nós e exibe o resultado computado para o usuário.

Para a avaliação do desempenho do cluster de dispositivos móveis mais o computador, foi computado o tempo total de processamento entre o início do cálculo até que todos os processos enviem seus resultados para o servidor. Esse tempo foi medido em milissegundos com a função gettimeofday() do GNU/Linux.

Foram realizados um total de 4 experimentos, nomeados de 5 a 8 para diferenciar dos experimentos anteriores do outro aplicativo de avaliação proposto. Nos 3 primeiros experimentos todos os experimentos foi atribuído $\mathrm{N}=2.000 .000 .000$ e para o quarto experimento foi atribuído $\mathrm{N}=4.000 .000 .000$, sendo $\mathrm{N}$ o número de iterações da integração numérica. Para cada experimento o aplicativo é executado primeiramente apenas com 1 
processo, depois com 2 processos paralelos e assim por diante, até que a última execução seja com o número de processos paralelo igual ao número de núcleos de processamento disponíveis no cluster. Foram realizados 10 execuções para cada configuração em cada experimento. Ou seja, foram repetidas 10 execuções com 1 processo no experimento 1 , outras 10 repetições com 2 processos no experimento 1 novamente, e assim por diante.

O experimento de número 5 testará o cluster com apenas os dois dispositivos móveis conectados. O processo servidor será executado no dispositivo Galaxy S 2, de 2 núcleos. Assim que todos os seus núcleos estiverem ocupados, o segundo dispositivo, Galaxy Note II, será utilizado para complementar o processamento. Serão executadas 10 repetições para cada número de processos em paralelo.

O experimento de número 6 também fará a avaliação utilizando os dois dispositivos móveis conectados. Porém o processo servidor será executado no dispositivo Galaxy S II, de apenas 2 núcleos. O Galaxy Note II será utilizado para os últimos 4 processos concorrentes. Também serão executadas 10 repetições para cada número de processos em paralelo.

O experimento de número 7 utiliza apenas o computador como dispositivo para execução do algoritmo. O objetivo é avaliar qual a capacidade de processamento de um computador em relação aos atuais dispositivos móveis.

O experimento 8 fará uso de todos os 3 dispositivos conectados no mesmo cluster. O objetivo é avaliar qual a influência dos processadores dos dispositivos móveis em relação aos processadores dos computadores. Para esse experimento os parâmetros foram alterados para que fosse necessário um maior número iterações para calcular o número $\pi$, melhorando a precisão do cálculo e também facilitando a diferenciação dos tempos de execução para cada número arbitrário de processos concorrentes. 

CAPÍTULO

Resultados e Discussão

\subsection{Experimentos com algoritmo de DFT}

Os experimentos de 1 a 4 são relacionados ao teste com o algoritmo da transformada de Fourier discreta.

O resultado do experimento 1 está descrito na Tabela 4.1 com as médias e suas respectivas variâncias para cada configuração mensurada. O tempo de execução serial desse algoritmo para esse experimento, com o Galaxy Note II como servidor, (Ts) foi de 63,20s em média. O tempo de cálculo com 4 processos paralelos $(T p(4))$, os quais são todos executados no mesmo dispositivo, foi de 24,20s em média. Esse resultado reprensenta um speedup de 2,61. O overhead para cada processo foi de 33.46s, mostrando uma eficiência de 65,39\% aproximadamente. Considerando o total de 6 processos paralelos quando acrescentado o dispositivo Galaxy S II, obtem-se um tempo total de execução de $T p(6)=17,72$, com um speedup de 3,57, um overhead de 43,14s e uma eficiência de 59,43\% aproximadamente.

O experimento 2 tem seu resultado com detalhes mostrados na Tabela 4.2. Neste caso, os dois primeiros processos são executados no dois núcleos do processador do Galaxy S II. Quando há 3 ou mais processos o Galaxy Note II de quatro núcleos complementa o 
processamento. O tempo de execução serial para esse dispositivo foi de $T s=97,90 s$. Utilizando os dois núcleos com um processo cada, obteve-se $T p(2)=75,03 \mathrm{~s}$. Isso representa um speedup de 1,30 aproximadamente. O tempo de overhead foi de 52,16s, mostrando uma eficiência de 65,24\% aproximadamente. Já quando um segundo dispositivo é adicionado, no caso do Galaxy Note II, tem-se um total de tempo de execução Tp(6) $=18,13 \mathrm{~s}$. Nesse caso o tempo de overhead foi de 10,88s apenas, mostrando uma eficiência de 90,00\%.

Comparando os experimentos 1 e 2, nos quais a diferença de configuração é apenas de qual dispositivo é o servidor, nota-se que se um dispositivo de maior capacidade de processamento é adicionado ao cluster, a eficiência aumenta significativamente.

No experimento 3 todos os processos foram executados no processador do computador, Phenom II X4 de quatro núcleos. Na Tabela 4.3 é possível verificar o tempo de execução de cada rodada com 1 a 4 processos concorrentes e suas respectivas médias e intervalo de confiança de 95\%. Nesse experimento, o tempo de execução serializada do algoritmo foi de $T s=10,08 s$ em média e o tempo de execução em paralelo para 4 processos foi de $T p=2,63 s$ em média. Isso demonstra um tempo de overhead de 0,46s e uma eficiência de $95,64 \%$.

As tabelas 4.4 e 4.5 mostram em detalhes o tempo de processamento de cada rodada do experimento 4 com 1 a 10 processos em paralelo. Os quatro primeiros processos são executados no processador Phenom II X4, os processos cinco e seis são executados no Cortex-A9 de dois núcleos e os processos sete, oito, nove e dez são executados no CortexA9 de quatro núcleos. O tempo de execução do processo serial é dado pela média de $T s=255,05 s$. Considerando o total de 10 processos simultâneos sendo executados em 3 dispositivos do cluster, o tempo de overhead é aproximadamente de 332,45s. A eficiência nesse experimento foi de $E p=43,41 \%$.

A eficiência nesse experimento ficou bastante baixa em relação aos outros experimentos. Isso acontece porque o tempo de execução para apenas um processo é dado por um processador bem mais veloz que os processadores dos dispositivos adicionados ao cluster. Pode-se notar essa diferença nos experimentos 1 e 2. No experimento 1, no qual o processo único é executado no processador de maior capacidade, a eficiência foi de 59,43\% e no experimento 2, no qual o processo único foi executado no processador de menor capacidade, 
Tabela 4.1: Dez medições de tempo de execução do experimento 1 com suas respectivas médias e intervalos de confiança de $95 \%$ para processamento com 1 a 6 processos concorrentes.

\begin{tabular}{c|rrrrrr}
\hline \hline \multicolumn{7}{c}{ Experimento 1 (Tempo em segundos) } \\
\hline \hline Execução & 1 & \multicolumn{7}{c}{ Número de processos paralelos } & \\
& & 2 & 3 & 4 & 5 & 6 \\
\hline \hline 1 & 63,50 & 36,62 & 28,09 & 23,89 & 20,90 & 17,58 \\
\hline 2 & 62,80 & 37,47 & 27,36 & 24,04 & 20,34 & 17,81 \\
\hline 3 & 62,82 & 37,21 & 27,43 & 23,89 & 20,22 & 17,83 \\
\hline 4 & 63,35 & 36,61 & 27,06 & 24,11 & 20,37 & 17,49 \\
\hline 5 & 64,74 & 36,72 & 27,00 & 25,23 & 20,44 & 17,84 \\
\hline 6 & 63,15 & 36,38 & 28,14 & 24,21 & 20,74 & 17,50 \\
\hline 7 & 62,47 & 36,96 & 27,78 & 24,38 & 19,77 & 17,89 \\
\hline 8 & 63,31 & 36,83 & 26,71 & 24,11 & 20,05 & 17,72 \\
\hline 9 & 63,11 & 36,54 & 27,11 & 24,05 & 20,79 & 17,92 \\
\hline 10 & 62,78 & 37,10 & 27,71 & 24,04 & 20,42 & 17,67 \\
\hline \hline Média & $63,20 \pm 0,39$ & $36,84 \pm 0,21$ & $27,44 \pm 0,30$ & $24,20 \pm 0,24$ & $20,40 \pm 0,21$ & $17,73 \pm 0,10$ \\
\hline \hline
\end{tabular}

Tabela 4.2: Dez medições de tempo de execução do experimento 2 com suas respectivas médias e intervalos de confiança de $95 \%$ para processamento com 1 a 6 processos concorrentes.

\begin{tabular}{|c|c|c|c|c|c|c|}
\hline \multicolumn{7}{|c|}{ Experimento 2 (Tempo em segundos) } \\
\hline \multirow[t]{2}{*}{ Execução } & \multicolumn{6}{|c|}{$\begin{array}{ll}\text { Número de processos paralelos } \\
\end{array}$} \\
\hline & 1 & 2 & 3 & 4 & 5 & 6 \\
\hline 1 & 97,69 & 76,28 & 38,89 & 26,11 & 20,97 & 17,57 \\
\hline 2 & 98,20 & 73,19 & 39,24 & 25,78 & 20,13 & 17,66 \\
\hline 3 & 98,53 & 71,22 & 39,42 & 26,73 & 19,97 & 18,63 \\
\hline 4 & 97,09 & 74,82 & 40,17 & 25,58 & 20,85 & 17,87 \\
\hline 5 & 99,30 & 77,36 & 38,31 & 26,70 & 20,89 & 18,85 \\
\hline 6 & 95,93 & 78,71 & 37,91 & 26,67 & 19,89 & 17,82 \\
\hline 7 & 96,71 & 78,37 & 39,51 & 27,03 & 20,66 & 18,38 \\
\hline 8 & 98,75 & 78,49 & 38,95 & 25,94 & 20,82 & 18,51 \\
\hline 9 & 98,11 & 67,59 & 39,08 & 26,50 & 20,76 & 17,45 \\
\hline 10 & 98,70 & 74,31 & 38,07 & 26,85 & 20,54 & 18,55 \\
\hline Média & $97,90 \pm 0,65$ & $75,03 \pm 2,24$ & $38,96 \pm 0,43$ & $26,39 \pm 0,31$ & $20,55 \pm 0,25$ & $18,13 \pm 0,31$ \\
\hline
\end{tabular}


a eficiência foi de 90,00\%, um valor significativamente maior que o primeiro.

\subsection{Experimentos com cálculo do número $\pi$}

Os experimentos de 5 a 8 estão relacionados com o algoritmo para cálculo do número $\pi$ pelo método da integração.

No experimento 5 , com os resultados detalhados na Tabela 4.6, o processador CortexA9 de dois núcleos é responsável pelos dois primeiros processos. Os próximos quatro processos são repassados para o Cortex-A9 de quatro núcleos presente no Galaxy Note II. O tempo de execução serial desse exeperimento é em média 87,49s. O tempo de execução para 2 processos é de $T p(2)=46,95 s$ de média. Esses valores correspondem a um tempo de overhead de $T_{o}=6,41 \mathrm{~s}$ e uma eficiência de $93,17 \%$. Considerando todos os 6 processos paralelos e os 2 dispositivos em cluster, o tempo de overhead foi de 10,31s e a eficiência é de aproximadamente $89,46 \%$.

No experimento 6 é trocada a ordem dos dispositivos, portanto, os 4 primeiros processos são executados no Galaxy Note II, enquanto que os processos 5 e 6 são executados no Galaxy S II. O resultado pode ser observado na Tabela 4.7. Nesse experimento o tempo de execução serial foi em média 58,70s. Utilizando os 4 processadores do dispositivo servidor, o tempo paralelo foi de $T p(4)=15,79 s$ na média. Um tempo de overhead de $4,46 \mathrm{~s}$ e eficiência de $E p(4)=92,94 \%$. Quando são executados 6 processos paralelos, o tempo de execução cai para $T p(6)=13,33 \mathrm{~s}$ em média. Dessa forma, o tempo de overhead sobe para 21,28 s e a eficiência cai para $E p(6)=73,39 \% s$.

Na Tabela 4.8 encontram-se os resultados do experimento 7. Todos os quatro processos são executados no processador Phenom II X4 de quatro núcleos. O tempo de execução serial foi de $T s=37,84 s$. O tempo total para a execução de 4 processos paralelos nos quatro núcleos disponíveis foi de 9,62s em média. O tempo de overhead foi de 0,64 s e a eficiência do algoritmo nesse experimento foi de $98,34 \%$.

O experimento de número 8 tem os resultados apresentados nas Tabelas 4.9 e 4.10. Os primeiros 4 processos são executados no computador, enquanto que os próximos 4 processos são executados no Galaxy Note II. Por último, os processos 9 e 10 são executados no Galaxy S II. Neste último experimento o tempo total de um único processo fazendo 
Tabela 4.3: Dez medições de tempo de execução do experimento 3 com suas respectivas médias e intervalos de confiança de $95 \%$ para processamento com 1 a 4 processos concorrentes.

\begin{tabular}{c|rrrr}
\hline \hline \multicolumn{5}{c}{ Experimento 3 (Tempo em segundos) } \\
\hline \hline Execução & Número de processos paralelos & \\
& 1 & 2 & 3 & 4 \\
\hline \hline 1 & 10,16 & 5,30 & 3,44 & 2,81 \\
\hline 2 & 10,12 & 5,15 & 3,48 & 2,58 \\
\hline 3 & 10,20 & 5,14 & 3,44 & 2,67 \\
\hline 4 & 10,27 & 5,13 & 3,42 & 2,62 \\
\hline 5 & 10,05 & 5,32 & 3,52 & 2,62 \\
\hline 6 & 10,04 & 5,16 & 3,44 & 2,62 \\
\hline 7 & 9,98 & 5,19 & 3,50 & 2,60 \\
\hline 8 & 10,00 & 5,14 & 3,43 & 2,60 \\
\hline 9 & 10,03 & 5,14 & 3,46 & 2,60 \\
\hline 10 & 9,91 & 5,13 & 3,46 & 2,62 \\
\hline \hline Média & $10,08 \pm 0,07$ & $5,18 \pm 0,05$ & $3,46 \pm 0,02$ & $2,63 \pm 0,04$ \\
\hline \hline
\end{tabular}

Tabela 4.4: Dez medições de tempo de execução do experimento 4 com suas respectivas médias e intervalos de confiança de $95 \%$ para processamento com 1 a 5 processos concorrentes.

\begin{tabular}{c|rrrrr}
\hline \hline \multicolumn{5}{c}{ Experimento 4 - Parte 1 (Tempo em segundos) } \\
\hline \hline Execução & \multicolumn{5}{c}{ Número de processos paralelos } \\
& 1 & 2 & 3 & 4 & \\
& 260,01 & 129,98 & 87,43 & 67,12 & 64,75 \\
\hline \hline 1 & 253,53 & 130,61 & 88,38 & 65,58 & 65,78 \\
\hline 2 & 257,49 & 129,45 & 87,16 & 66,49 & 64,63 \\
\hline 3 & 257,17 & 131,02 & 87,13 & 67,10 & 63,72 \\
\hline 4 & 252,88 & 130,72 & 86,53 & 66,10 & 64,90 \\
\hline 5 & 251,91 & 130,46 & 87,54 & 66,06 & 64,18 \\
\hline 6 & 254,26 & 133,49 & 88,02 & 65,78 & 64,63 \\
\hline 7 & 255,32 & 132,51 & 87,60 & 65,27 & 65,93 \\
\hline 8 & 252,90 & 133,81 & 87,09 & 65,89 & 64,50 \\
\hline 9 & 255,07 & 132,92 & 88,76 & 67,18 & 66,20 \\
\hline 10 & & & & & \\
\hline \hline Média & $255,05 \pm 1,56$ & $131,50 \pm 0,96$ & $87,56 \pm 0,41$ & $66,26 \pm 0,42$ & $64,92 \pm 0,50$ \\
\hline \hline
\end{tabular}


Tabela 4.5: Dez medições de tempo de execução do experimento 4 com suas respectivas médias e intervalos de confiança de $95 \%$ para processamento com 6 a 10 processos concorrentes.

\begin{tabular}{c|rrrrr}
\hline \hline \multicolumn{5}{c}{ Experimento 4 - Parte 2 (Tempo em segundos) } \\
\hline \hline Execução & \multicolumn{5}{c}{ Número de processos paralelos } \\
& 6 & 7 & 8 & 9 & 10 \\
\hline \hline 1 & 63,64 & 62,01 & 60,79 & 60,46 & 57,22 \\
\hline 2 & 63,35 & 62,62 & 59,77 & 60,05 & 57,86 \\
\hline 3 & 64,56 & 62,39 & 60,36 & 60,34 & 58,74 \\
\hline 4 & 64,25 & 63,25 & 60,58 & 59,62 & 57,51 \\
\hline 5 & 64,37 & 62,75 & 60,31 & 58,68 & 58,75 \\
\hline 6 & 64,29 & 62,38 & 61,39 & 59,87 & 59,80 \\
\hline 7 & 63,90 & 62,73 & 60,82 & 59,97 & 59,54 \\
\hline 8 & 63,93 & 62,41 & 61,31 & 59,70 & 58,95 \\
\hline 9 & 64,20 & 61,90 & 61,12 & 59,79 & 59,79 \\
\hline 10 & 64,28 & 62,10 & 59,96 & 59,92 & 59,33 \\
\hline \hline Média & $64,08 \pm 0,23$ & $62,45 \pm 0,25$ & $60,64 \pm 0,34$ & $59,84 \pm 0,30$ & $58,75 \pm 0,58$ \\
\hline \hline
\end{tabular}

Tabela 4.6: Dez medições de tempo de execução do experimento 5 com suas respectivas médias e intervalos de confiança de $95 \%$ para processamento com 1 a 6 processos concorrentes.

\begin{tabular}{|c|c|c|c|c|c|c|}
\hline \multicolumn{7}{|c|}{ Experimento 5 (Tempo em segundos) } \\
\hline \multirow[t]{2}{*}{ Execução } & \multicolumn{6}{|c|}{$\begin{array}{ll}\text { Número de processos paralelos }\end{array}$} \\
\hline & 1 & 2 & 3 & 4 & 5 & 6 \\
\hline 1 & 87,60 & 48,34 & 32,95 & 24,11 & 19,70 & 16,94 \\
\hline 2 & 87,20 & 47,09 & 34,20 & 23,87 & 19,29 & 16,19 \\
\hline 3 & 87,08 & 46,69 & 31,96 & 23,88 & 18,95 & 16,14 \\
\hline 4 & 87,41 & 46,81 & 31,69 & 23,63 & 18,84 & 16,24 \\
\hline 5 & 87,17 & 46,74 & 32,04 & 23,98 & 18,85 & 16,11 \\
\hline 6 & 88,11 & 46,52 & 31,95 & 23,82 & 19,35 & 16,24 \\
\hline 7 & 87,42 & 47,37 & 32,15 & 23,85 & 19,14 & 16,22 \\
\hline 8 & 87,66 & 46,88 & 31,84 & 23,74 & 19,26 & 16,28 \\
\hline 9 & 87,52 & 46,39 & 32,02 & 24,10 & 18,94 & 16,24 \\
\hline 10 & 87,72 & 46,67 & 31,80 & 24,37 & 19,22 & 16,39 \\
\hline Média & $87,49 \pm 0,19$ & $46,95 \pm 0,35$ & $32,26 \pm 0,47$ & $23,94 \pm 0,13$ & $19,15 \pm 0,17$ & $16,30 \pm 0,15$ \\
\hline
\end{tabular}


Tabela 4.7: Dez medições de tempo de execução do experimento 6 com suas respectivas médias e intervalos de confiança de $95 \%$ para processamento com 1 a 6 processos concorrentes.

\begin{tabular}{c|rrrrrr}
\hline \hline \multicolumn{7}{c}{ Experimento 6 (Tempo em segundos) } \\
\hline \hline Execução & \multicolumn{7}{c}{ Número de processos paralelos } \\
& 1 & 2 & 3 & 4 & 5 & \\
\hline \hline 1 & 58,73 & 30,97 & 20,92 & 16,23 & 14,95 & 13,86 \\
\hline 2 & 58,82 & 29,82 & 19,99 & 15,72 & 14,52 & 13,44 \\
\hline 3 & 58,60 & 29,81 & 19,95 & 16,35 & 14,68 & 13,30 \\
\hline 4 & 58,93 & 29,88 & 19,95 & 15,30 & 14,39 & 13,19 \\
\hline 5 & 58,93 & 29,85 & 19,96 & 15,47 & 14,39 & 13,06 \\
\hline 6 & 58,55 & 29,79 & 20,03 & 15,72 & 14,81 & 13,12 \\
\hline 7 & 58,75 & 29,77 & 19,93 & 15,90 & 14,45 & 13,20 \\
\hline 8 & 58,59 & 29,80 & 19,94 & 15,60 & 14,51 & 13,30 \\
\hline 9 & 58,53 & 30,52 & 19,94 & 15,37 & 14,34 & 13,45 \\
\hline 10 & 58,54 & 29,77 & 20,03 & 16,20 & 14,45 & 13,36 \\
\hline \hline Média & $58,70 \pm 0,10$ & $30,00 \pm 0,25$ & $20,06 \pm 0,19$ & $15,79 \pm 0,23$ & $14,55 \pm 0,12$ & $13,33 \pm 0,14$ \\
\hline \hline
\end{tabular}

Tabela 4.8: Dez medições de tempo de execução do experimento 7 com suas respectivas médias e intervalos de confiança de $95 \%$ para processamento com 1 a 4 processos concorrentes.

\begin{tabular}{c|rrrr}
\hline \hline \multicolumn{5}{c}{ Experimento 7 (Tempo em segundos) } \\
\hline \hline Execução & \multicolumn{1}{c}{ Número de processos paralelos } \\
& 1 & 2 & 3 & 4 \\
\hline \hline 1 & 37,79 & 19,13 & 12,71 & 9,55 \\
\hline 2 & 38,23 & 19,16 & 12,70 & 9,56 \\
\hline 3 & 37,75 & 19,16 & 12,85 & 9,64 \\
\hline 4 & 37,83 & 19,25 & 12,80 & 9,59 \\
\hline 5 & 37,79 & 19,16 & 12,85 & 9,59 \\
\hline 6 & 38,25 & 19,03 & 12,79 & 9,66 \\
\hline 7 & 37,39 & 18,95 & 12,78 & 9,79 \\
\hline 8 & 37,74 & 19,13 & 12,77 & 9,66 \\
\hline 9 & 37,39 & 19,03 & 12,74 & 9,55 \\
\hline 10 & 38,24 & 19,22 & 12,78 & 9,60 \\
\hline \hline Média & $37,84 \pm 0,20$ & $19,12 \pm 0,06$ & $12,77 \pm 0,03$ & $9,62 \pm 0,05$ \\
\hline \hline
\end{tabular}


o cálculo foi de $T s=81,01 \mathrm{~s}$ em média. O tempo para 10 processos paralelos sendo executados nos 3 dispositivos do cluster foi de $T p(10)=14,64 s$. O tempo de overhead desse experimento foi de $65,39 \mathrm{~s}$ em média e a eficiência foi de apenas $E p(10)=55,33 \%$.

Novamente o baixo índice de eficiência já era esperado, mas o experimento 8 foi mais eficiente que o experimento 4 porque o cálculo do número $\pi$ não depende do acesso ao disco, como no caso do cálculo da FFT de um dado sinal. 
Tabela 4.9: Dez medições de tempo de execução do experimento 8 com suas respectivas médias e intervalos de confiança de $95 \%$ para processamento com 1 a 5 processos concorrentes.

\begin{tabular}{c|rrrrr}
\hline \hline \multicolumn{5}{c}{ Experimento 8 - Parte 1 } & Tempo em segundos) \\
\hline \hline Execução & \multicolumn{5}{c}{ Número de processos paralelos } \\
& 1 & 2 & 3 & 4 & 5 \\
\hline \hline 1 & 80,43 & 41,44 & 27,61 & 20,76 & 18,94 \\
\hline 2 & 81,84 & 41,28 & 27,48 & 20,64 & 19,36 \\
\hline 3 & 80,36 & 41,12 & 27,45 & 20,67 & 19,16 \\
\hline 4 & 80,30 & 40,91 & 27,56 & 20,62 & 19,15 \\
\hline 5 & 81,17 & 41,27 & 27,46 & 20,70 & 19,50 \\
\hline 6 & 81,79 & 41,17 & 27,37 & 20,85 & 19,24 \\
\hline 7 & 81,77 & 41,18 & 27,49 & 20,70 & 19,46 \\
\hline 8 & 80,32 & 40,92 & 27,61 & 20,70 & 19,02 \\
\hline 9 & 81,81 & 41,35 & 27,56 & 20,79 & 18,94 \\
\hline 10 & 80,32 & 41,09 & 27,52 & 20,71 & 19,28 \\
\hline \hline Média & $81,01 \pm 0,45$ & $41,17 \pm 0,11$ & $27,51 \pm 0,05$ & $20,71 \pm 0,04$ & $19,21 \pm 0,13$ \\
\hline \hline
\end{tabular}

Tabela 4.10: Dez medições de tempo de execução do experimento 8 com suas respectivas médias e intervalos de confiança de $95 \%$ para processamento com 6 a 10 processos concorrentes.

\begin{tabular}{c|rrrrr}
\hline \hline \multicolumn{5}{c}{ Experimento 8 - Parte 2 } & (Tempo em segundos) \\
\hline \hline Execução & \multicolumn{5}{c}{ Número de processos paralelos } \\
& 6 & 7 & 8 & 9 & 10 \\
\hline \hline 1 & 18,75 & 17,59 & 15,65 & 15,80 & 13,79 \\
\hline 2 & 18,41 & 17,04 & 15,77 & 14,86 & 14,24 \\
\hline 3 & 18,42 & 17,06 & 16,41 & 15,87 & 15,01 \\
\hline 4 & 17,55 & 16,84 & 16,54 & 15,44 & 15,24 \\
\hline 5 & 17,83 & 16,83 & 15,81 & 15,29 & 14,72 \\
\hline 6 & 18,13 & 16,54 & 16,72 & 15,36 & 14,72 \\
\hline 7 & 18,42 & 17,54 & 15,51 & 14,86 & 14,75 \\
\hline 8 & 18,04 & 16,73 & 15,55 & 14,94 & 13,77 \\
\hline 9 & 17,64 & 16,41 & 15,56 & 15,11 & 14,94 \\
\hline 10 & 17,30 & 16,99 & 15,78 & 15,09 & 15,23 \\
\hline \hline Média & $18,05 \pm 0,29$ & $16,96 \pm 0,24$ & $15,93 \pm 0,28$ & $15,26 \pm 0,22$ & $14,64 \pm 0,33$ \\
\hline \hline
\end{tabular}





\section{Conclusão}

A arquitetura prosposta, formando um cluster híbrido de computadores e dispositivos móveis se mostrou factível. Com o mesmo código fonte e com o auxílio da interface MPI foi possível o processamento paralelo com arquiteturas diferentes e mesclando computadores com celulares e tablets.

Analisando os resultados obtidos nas avaliações, observa-se que os processadores ARM dos dispositivos móveis ainda são limitados em poder de processamento se comparados aos processadores dos computadores pessoais de arquitetura x86_64, porém mostram que tem influência significativa no processamento de dados paralelo.

As grandes fabricantes mundiais de processadores e dispositivos móveis estão interessadas no mercado de celulares e tablets. Com a concorrência acirrada, a tendência é que novos e melhores processadores sejam lançados no mercado, assim como ocorreu com os processadores para computadores na disputa entre Intel e AMD. Já há disponível no mercado processadores ARM de 64 bit, o chip A7 da Apple e que equipa o smartphone iPhone 5S.

A Intel, grande fabricante de processadores para computadores, principalmente, se interessou no grande mercado que é esse de plataformas móveis e colocou esforços no desenvolvimento de processadores para essa linha. Atom é uma plataforma com arquitetura 
x86 com baixo consumo de energia projetado para computação móvel. Outra fabricante de processadores gráficos, NVIDIA, também aderiu a esse novo mercado com o desenvolvimento dos chipsets Tegra com arquitetura ARM. A Apple, fabricante da linha de celulares iPhone e tablets iPad, nos últimos modelos começou a desenvolver seus próprios chipsets em arquitetura ARM para seus dispositivos para ter uma maior integração entre hardware e software. O primeiro chipset desenvolvido pela Apple foi o A4, equipando iPhone 4 e iPhone 4S, além do iPad de primeira geração. A Samsung expandiu seu desenvolvimento de chipsets com arquitetura ARM para atender esse mercado, principalmente equipando seus próprios dispositivos.

Em um futuro próximo espera-se que esses processadores poderão atingir níveis de processamento bastante satisfatórios para processamento de dados e algoritmos complexos, haja vista a concorrência entre os grande fabricantes de processadores.

O fato de o sistema Android ser capaz de executar um sistema GNU/Linux completo em paralelo mostrou que migrar um cluster de computadores para um cluster de celulares inteligentes e tablets é transparente e factível. O código deve apenas ser recompilado para funcionar em uma arquitetura de processador que é utilizada no dispositivo.

A arquitetura proposta pode trazer grandes ganhos em espaço físico, uma vez que os dispositivos móveis são bastante pequenos em tamanho; baixo consumo de energia, por serem plataformas móveis que operam com baterias; e poder de processamento satisfatórios se comparados aos computadores, devido ao grande avanço tecnológico dos processadores para smartphones impulsionado pela concorrência das grandes fabricantes no mercado.

Neste trabalho a avaliação de desempenho dos dispositivos móveis foi feita com códigos escritos em linguagem $\mathrm{C}$, que pode ser considerada de baixo nível se comparada com linguagens mais modernas como Perl, Python, Ruby, entre outras. Uma vez que a arquitetura proposta utiliza o sistema GNU/Linux, todos os recursos desse sistema operacional podem ser utilizados, inclusive linguagens de mais alto nível.

Um software interessante disponível na internet é o BOINC. É uma plataforma aberta para a chamada computação voluntária e também a computação em grid. Na computação voluntária as pessoas (voluntários) disponibilizam seus recursos computacionais para o processamento de dados de projetos. A diferença para a computação em grid é que 
os dados de processamento de voluntários não são confiáveis, exigindo processamento replicado, além de que na computação em grid o ambiente de processamento é mais controlado. O BOINC está disponível em diversas plataformas, como Windows, Mac, Linux e, recentemente, Android.

Um próximo passo para esse trabalho é utilizar a arquitetura proposta como base para outros trabalhos mais complexos, usando, por exemplo, a biblioteca oferecida pelo projeto IPython (PéREZ; GRANGER, 2007). O IPython oferece uma rica arquitetura para computação interativa, em que o programador pode testar o seu código de forma rápida pelo fato de o código poder ser alterado enquanto é executado. Ele também oferece suporte à programação paralela. Há vários projetos que estão sendo desenvolvidos utilizando essa ferramenta e eles poderiam ser migrados para a arquitetura proposta por este trabalho de forma transparente na grande maioria dos casos. 



\section{Referências Bibliográficas}

AlMASI, G. S.; GOTTLIEB, A. Highly Parallel Computing. Redwood City, CA, USA: Benjamin-Cummings Publishing Co., Inc., 1989. ISBN 0-8053-0177-1.

AMD. AMD History. 2013. Disponível em:

<http://www.amd.com/us/aboutamd/corporate-information/Pages/timeline.aspx>.

ANDERSON, B. Android Kernel versus the Linux Kernel. 2012. Disponível em: <http://www.all-things-android.com/content/android-kernel-versus-linux-kernel>.

ANDROID, L. on. What is Linux On Android. 2012. Disponível em: $<$ http://linuxonandroid.org/what-is-linuxonandroid/>.

BOOCH, G.; RUMBAUGH, J.; JACOBSON, I. UML : guia do usuário. 2. ed. Rio de Janeiro: Campus, 2006. ISBN 8535217843 (broch.).

CHAI, L.; GAO, Q.; PANDA, D. Understanding the impact of multi-core architecture in cluster computing: A case study with intel dual-core system. In: Cluster Computing and the Grid, 200\%. CCGRID 200\%. Seventh IEEE International Symposium on. [S.l.: s.n.], 2007. p. 471-478.

CHATTOPADHYAY, S. Embedded System Design. PHI Learning, 2013. ISBN 9788120347304. Disponível em: <http://books.google.com.br/books?id=HVdbKHt0mQC $>$.

COMPUTER System Architecture. Prentice-Hall Of India Pvt. Limited. ISBN 9788120335943. Disponível em: $<$ http://books.google.com.br/books?id=gnirrHCWUlsC $>$.

DAS, L. B. The X86 Microprocessors: Architecture And Programming (8086 To Pentium). Pearson Education, 2010. ISBN 9788131732465. Disponível em: $<$ http://books.google.com.br/books?id=zWrZY1OgTPsC $>$.

EXAME.COM. Venda de smartphones supera a de celulares pela primeira vez. 2013. Disponível em: <http://exame.abril.com.br/tecnologia/noticias/venda-de-smartphonessupera-a-de-celulares-pela-primeira-vez $>$.

FFTW. Introduction - Fastest Fourier Transform in the West. 2013. Disponível em: $<$ http://www.fftw.org/>.

FOSTER, I. et al. Cloud computing and grid computing 360-degree compared. In: Grid Computing Environments Workshop, 2008. GCE '08. [S.l.: s.n.], 2008. p. 1-10. 
GOOGLE. About Android. 2013. Disponível em: <http://www.android.com/about/>.

GROPP, W. MPI: the complete reference. The MPI-2 extensions. The MIT Press, 2003. (Scientific and Engineering Computation, v. 2). ISBN 9780262571234. Disponível em: $<$ http://books.google.com.br/books?id=uK3nr41r8zMC $>$.

HENNESSY, J. Computer organization and design : the hardware/software interface. San Francisco, Calif: Morgan Kaufmann Publishers, 1998. ISBN 1558604286.

HUMPHRIES, M. AMD updates 6-core Phenom II, TDP now just $95 \mathrm{~W}$. 2010. Disponível em: <http://www.geek.com/chips/amd-updates-6-core-phenom-ii-tdp-now-just-95w$1267196>$.

KADAM, S. S. Performance metrics for parallel systems. 2007. Disponível em: $<$ http://www.iacs.res.in/Performance ${ }_{M}$ etrics.pdf $>$.

KECKLER, S.; OLUKOTUN, O.; HOFSTEE, H. Multicore Processors and Systems. Springer London, Limited, 2009. (Integrated circuits and systems). ISBN 9781441902634. Disponível em: <http://books.google.com.br/books?id=aLaRfJq-59sC>.

KERNIGHAN, B.; RITCHIE, D. The C Programming Language. 2nd. ed. Englewood Cliffs,New Jersey,USA: Prentice Hall Inc., 1988.

KHRONOS. The open standard for parallel programming of heterogeneous systems. 2013. Disponível em: <http://www.khronos.org/opencl>.

KRAUS, J. An Introduction to CUDA-Aware MPI. 2013. Disponível em: $<$ https://developer.nvidia.com/content/introduction-cuda-aware-mpi>.

LILLY, P. A Brief History of CPUs: 31 Awesome Years of x86. 2009. Disponível em: <http://www.geek.com/chips/amd-updates-6-core-phenom-ii-tdp-now-just-95w$1267196>$.

LIN, W. et al. Implementations of grid-based distributed parallel computing. In: Computer and Computational Sciences, 2006. IMSCCS '06. First International Multi-Symposiums on. [S.l.: s.n.], 2006. v. 1, p. 312-317.

NVIDIA. CUDA FAQ. 2013. Disponível em: <https://developer.nvidia.com/cuda-faq>.

OLUKOTUN, K. et al. Chip Multiprocessor Architecture: Techiniques to Improve Throughput and Latency. Morgan \& Claypool Publishers, 2007. (G - Reference,Information and Interdisciplinary Subjects Series). ISBN 9781598291223. Disponível em:

$<$ http://books.google.com.br/books?id=spZZDwuAgUYC $>$.

OPENMPI. Frequently Asked Questions - OpenMPI. 2013. Disponível em: $<$ http://www.open-mpi.org/faq/>.

PEREIRA, L.; SILVA, M. da. Android para Desenvolvedores. [S.l.]: BRASPORT, 2009. ISBN 9788574524054.

PéREZ, F.; GRANGER, B. E. IPython: a System for Interactive Sscientific Computing. Comput. Sci. Eng., v. 9, n. 3, p. 21-29, maio 2007. Disponível em: <http://ipython.org>. 
ROSENBERG, O. The open standard for parallel programming of heterogeneous systems. 2011. Disponível em: $<$ http://www.khronos.org/assets/uploads/developers/library/overview/opencloverview.pdf $>$.

SAMSUNG. Samsung Exynos 5 Octa Product Overview. 2013. Disponível em: <http://www.samsung.com/global/business/semiconductor/minisite/Exynos/products5octa.html>. SU, C.-L. et al. Overview and comparison of opencl and cuda technology for gpgpu. In: Circuits and Systems (APCCAS), 2012 IEEE Asia Pacific Conference on. [S.l.: s.n.], 2012. p. 448-451.

SYSTEM, G. O. Linux and the GNU System. 2013. Disponível em: $<$ www.gnu.org/gnu/linux-and-gnu.html>.

TANENBAUM, A. S. Sistemas operacionais modernos. 3. ed. SÃ£o Paulo: Pearson Prentice Hall, 2009. ISBN 978-85-7605-237-1.

UBUNTU. Meet Ubuntu. 2013. Disponível em: <http://www.ubuntu.com/desktop>.

WASSON, S. Intel's Core 2 Quad Q9300 processor. 2008. Disponível em: $<$ http://techreport.com/review/14573/intel-core-2-quad-q9300-processor >. 

Anexos 

ANEXO

\section{Códigos fonte dos aplicativos de testes}

\section{A.1 Arquivo 'fft_mpi.c'}

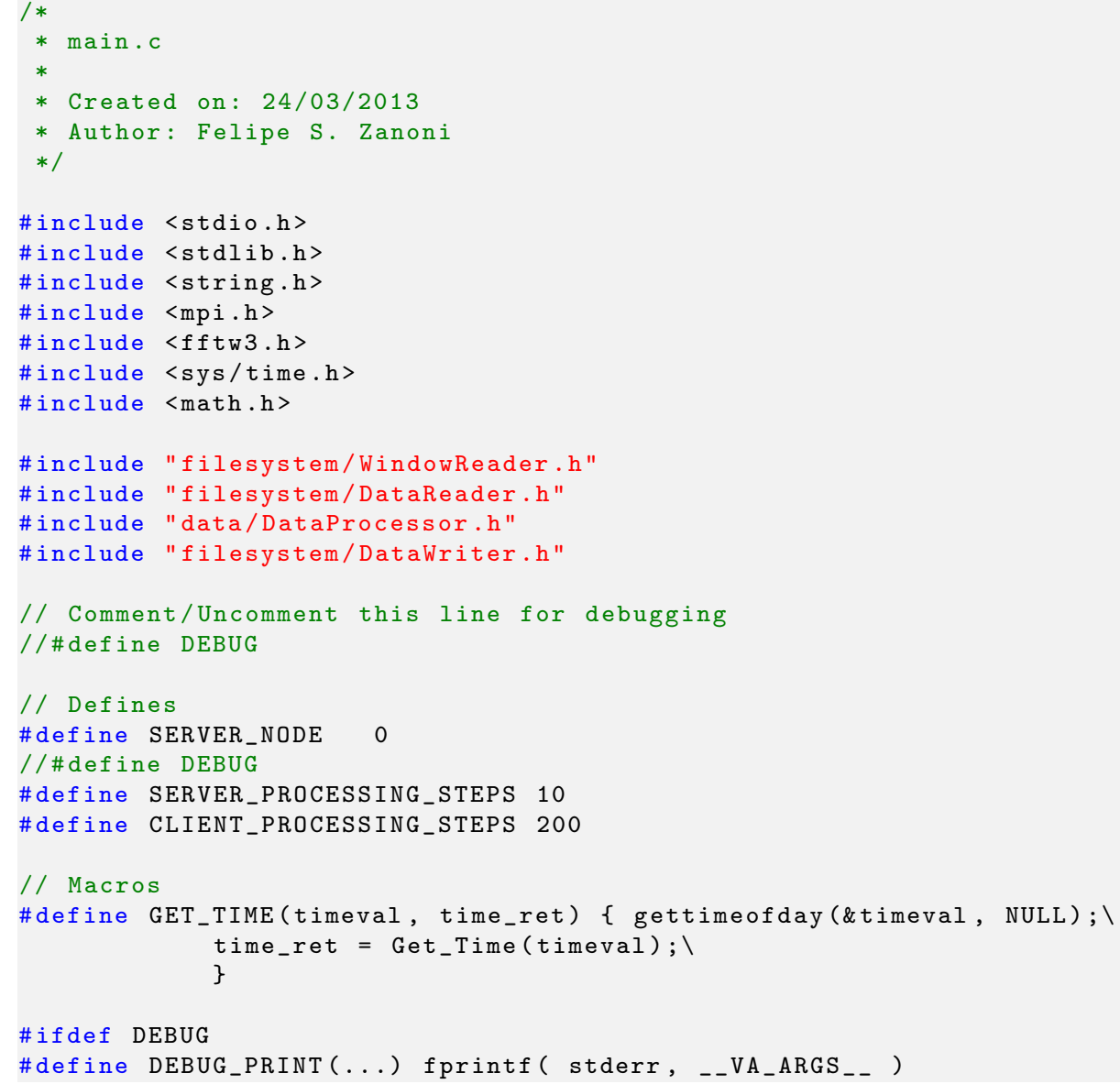




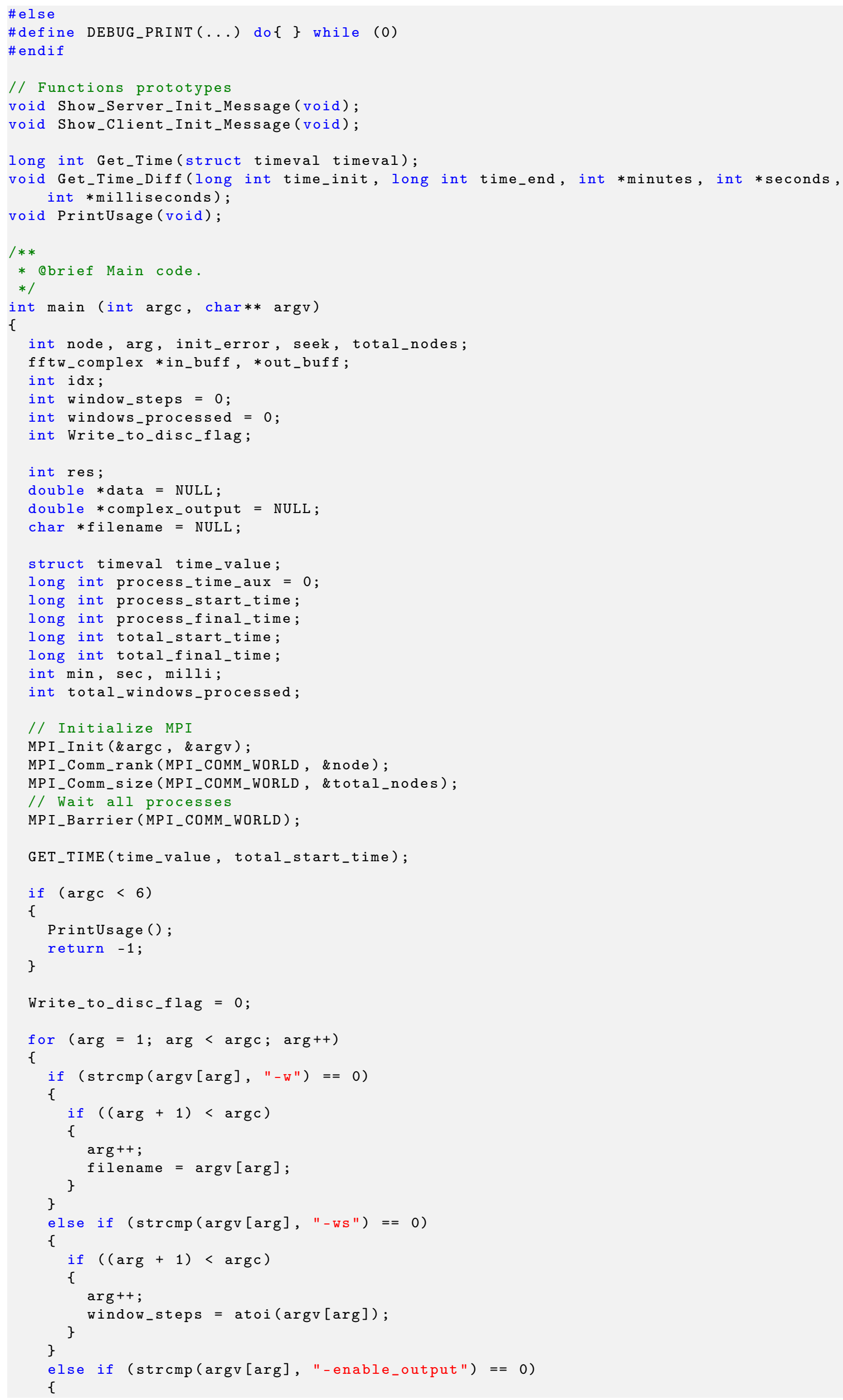




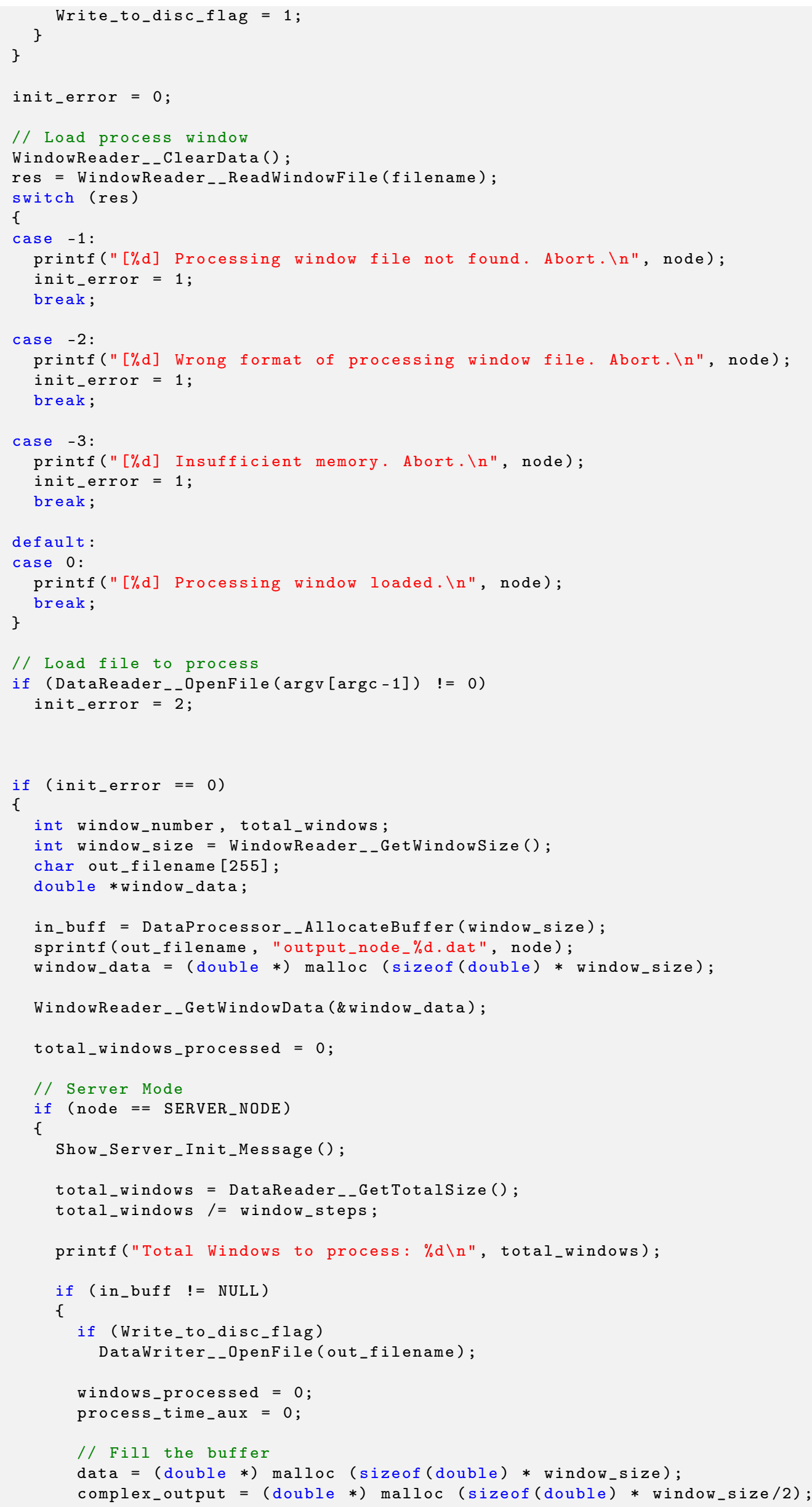




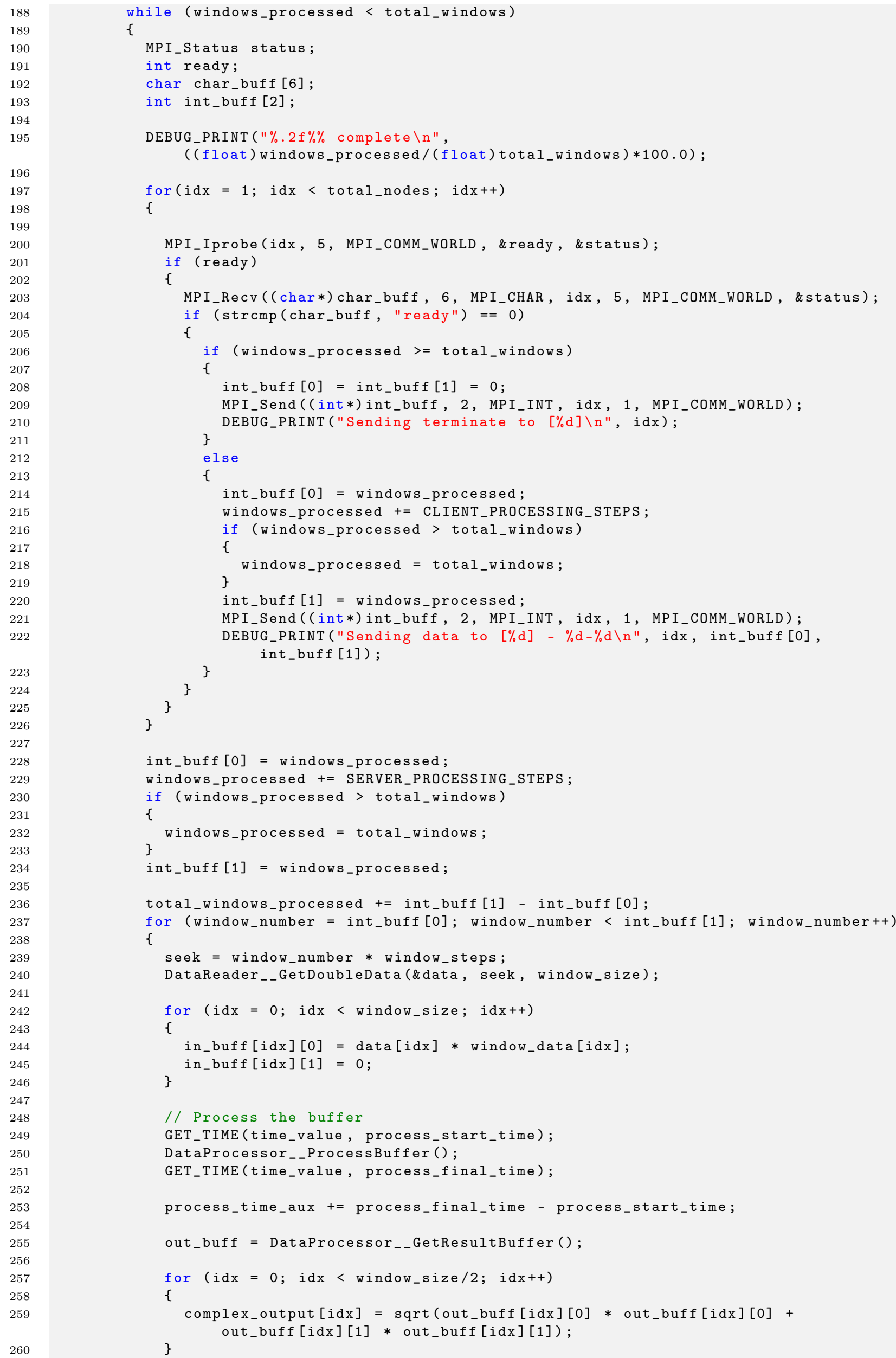


// Write to disc

if (Write_to_disc_flag) \}

DataWriter__AppendData (complex_output, window_size/2, window_number);

\}

\}

DEBUG_PRINT ( $\%$ d $/ \% d \backslash n "$, windows_processed, total_windows); printf ("100.00 complete! \n");

for $(i d x=1 ; i d x<$ total_nodes; idx ++$)$

\{

int int_buff [2];

int_buff[0] = int_buff [1] = 0 ;

DEBUG_PRINT ("Send terminate to \% node from total \%d $\backslash \mathrm{n} "$, idx, total_nodes);

\} MPI_Send ( (int *) int_buff, 2, MPI_INT, idx, 1, MPI_COMM_WORLD);

\section{\#ifdef DEBUG}

// Print total time on screen

Get_Time_Diff(0, process_time_aux, \&min, \&sec, \&milli);

printf ("Node \%d Only Processing Time: \t\%dm\%02ds\%03d $\backslash n "$, node, min, sec, $\operatorname{milli})$;

Get_Time_Diff(total_start_time, total_final_time, \&min, \&sec, \&milli); printf("Node \%d Total Processing Time: \t\%dm\%02ds\%03d $\backslash n "$, node, min, sec,

\# endif $\operatorname{milli})$;

\}

else

\{

// Client Node

Show_Client_Init_Message ();

if (in_buff $!=$ NULL)

\{

int int_buff [2];

int Running;

MPI_Status status;

if (Write_to_disc_flag)

DataWriter__penFile (out_filename);

// Fill the buffer

data $=($ double $*)$ malloc (sizeof (double) * window_size);

complex_output $=($ double $*)$ malloc (sizeof (double) * window_size/2);

int_buff[0] = int_buff[1] = 0 ;

Running = 1 ;

process_time_aux $=0$;

while (Running)

\{

int new_msg;

MPI_Iprobe (SERVER_NODE, 1, MPI_COMM_WORLD , \&new_msg, \&status); if (new_msg $==0$ )

\{

// Request new message

DEBUG_PRINT("\%d - Sending READY message $\backslash n "$, node);

\}

MPI_Send ("ready" , 6, MPI_CHAR, SERVER_NODE, 5, MPI_COMM_WORLD) ;

DEBUG_PRINT("\%d - receiving data $\backslash \mathrm{n} "$, node);

MPI_Recv ( (int $*)$ int_buff, 2, MPI_INT, SERVER_NODE, 1, MPI_COMM_WORLD, \&status);

if ( $($ int_buff [0] $==0)$ \&\& (int_buff [1] == 0))

\{

// End processing

Running $=0$;

else

\{ 


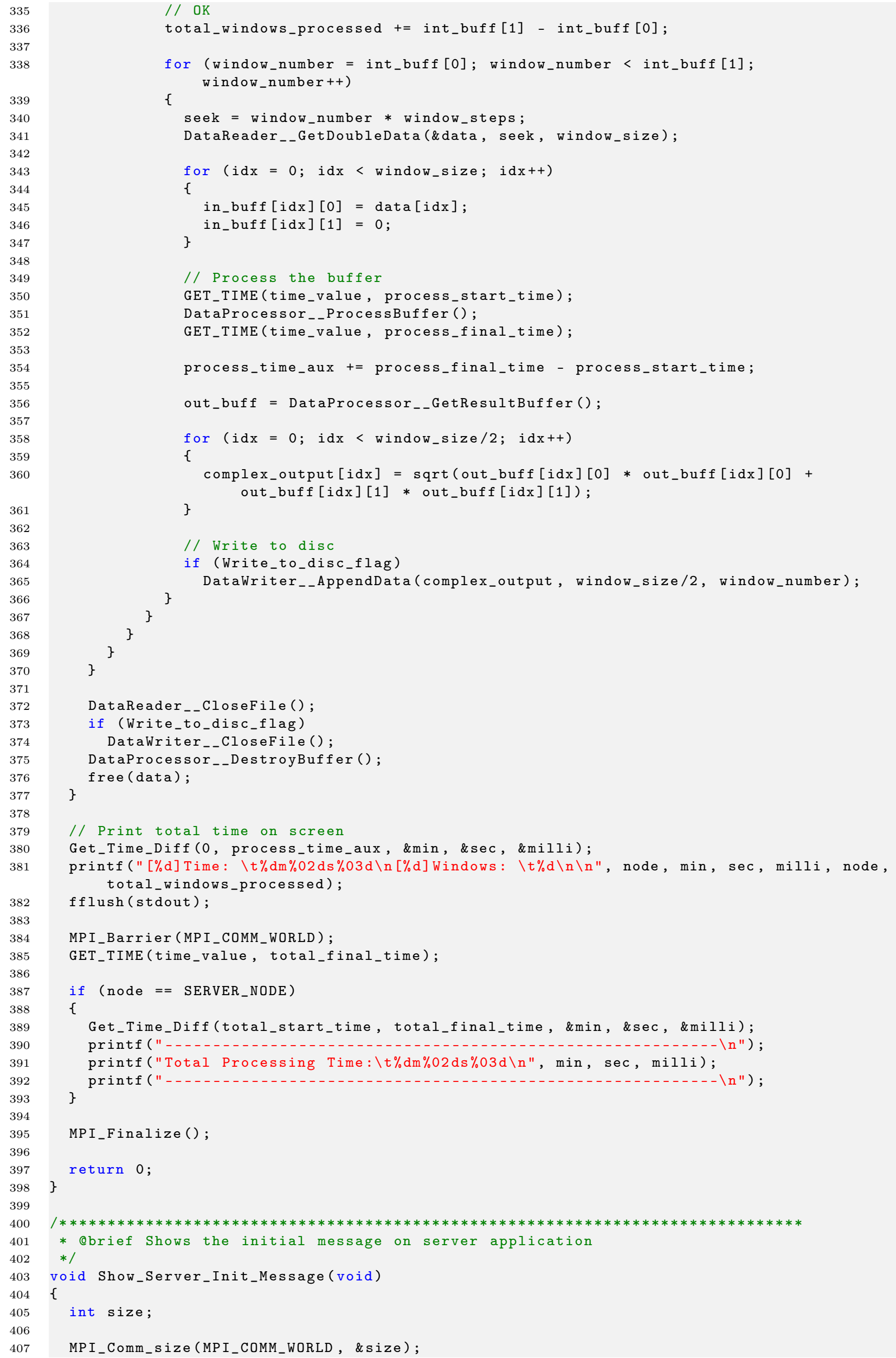


408

409

410

411

412

413

414

415

416

417

418

419
420

421

422

423

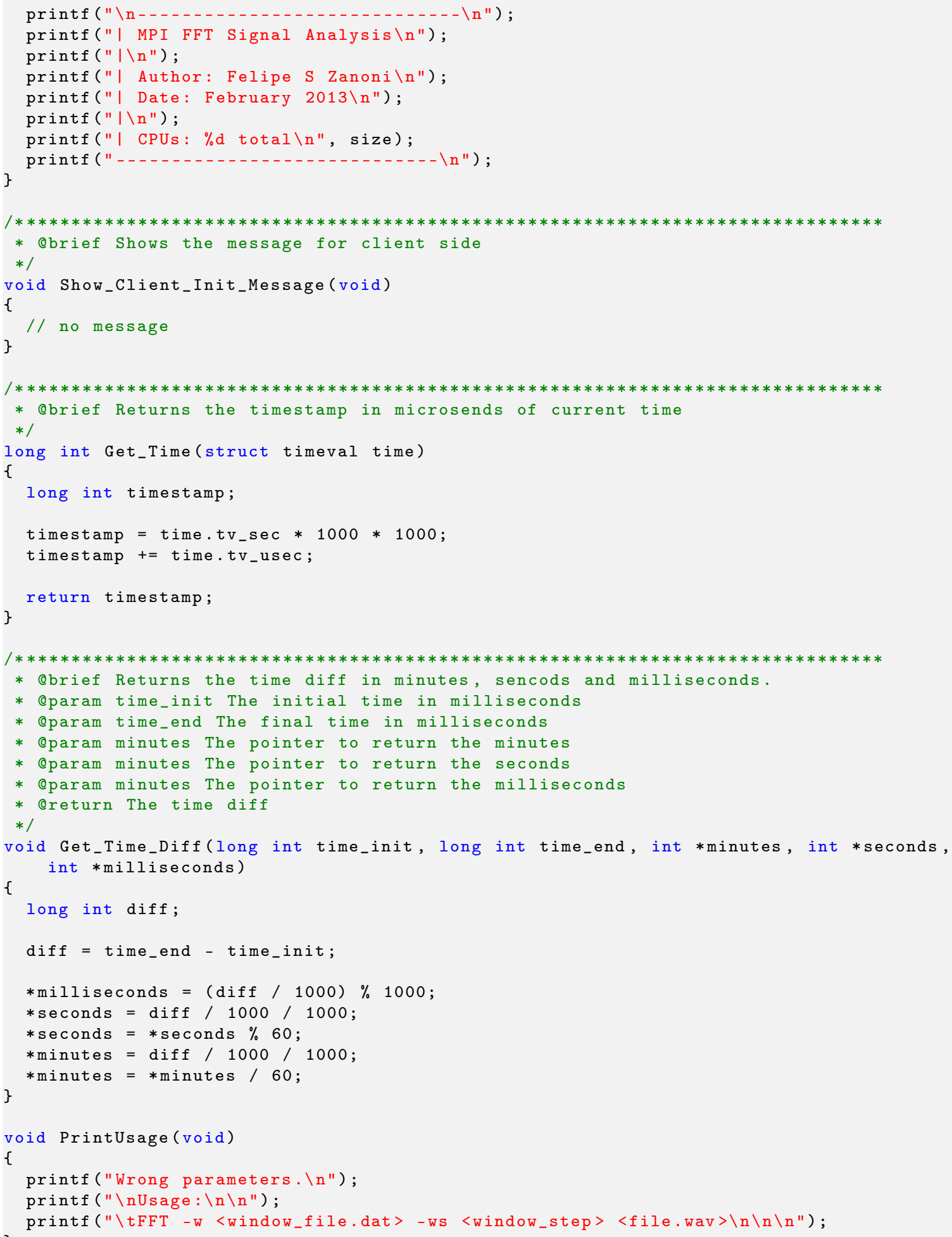

\section{A.2 Arquivo 'data/DataProcessor.h'}

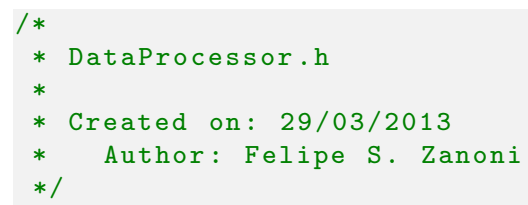




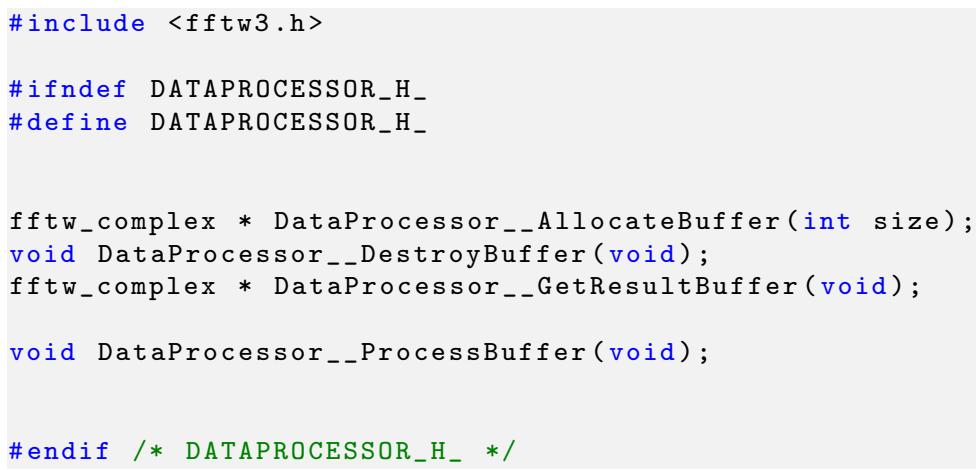

\section{A.3 Arquivo 'data/DataProcessor.c'}

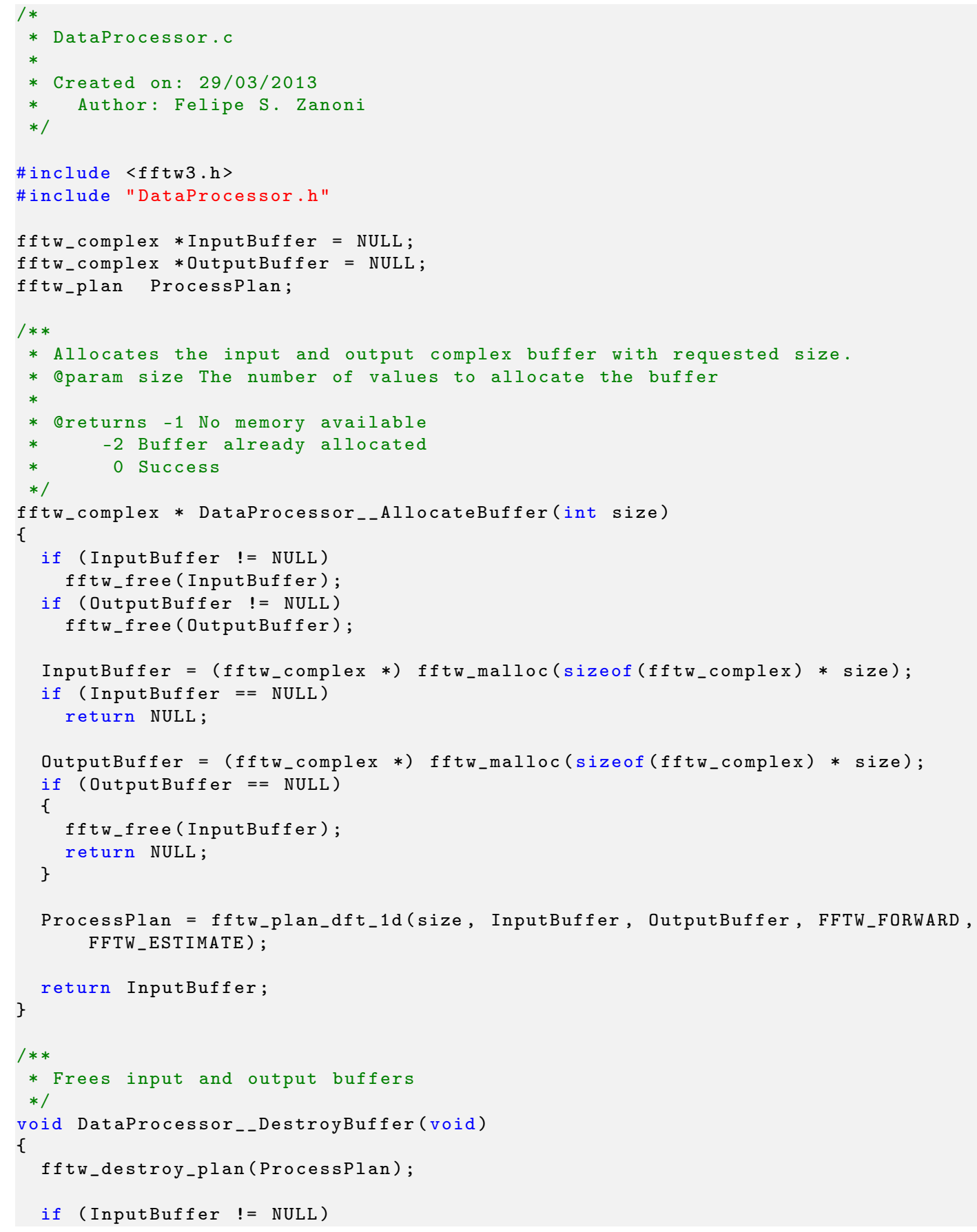




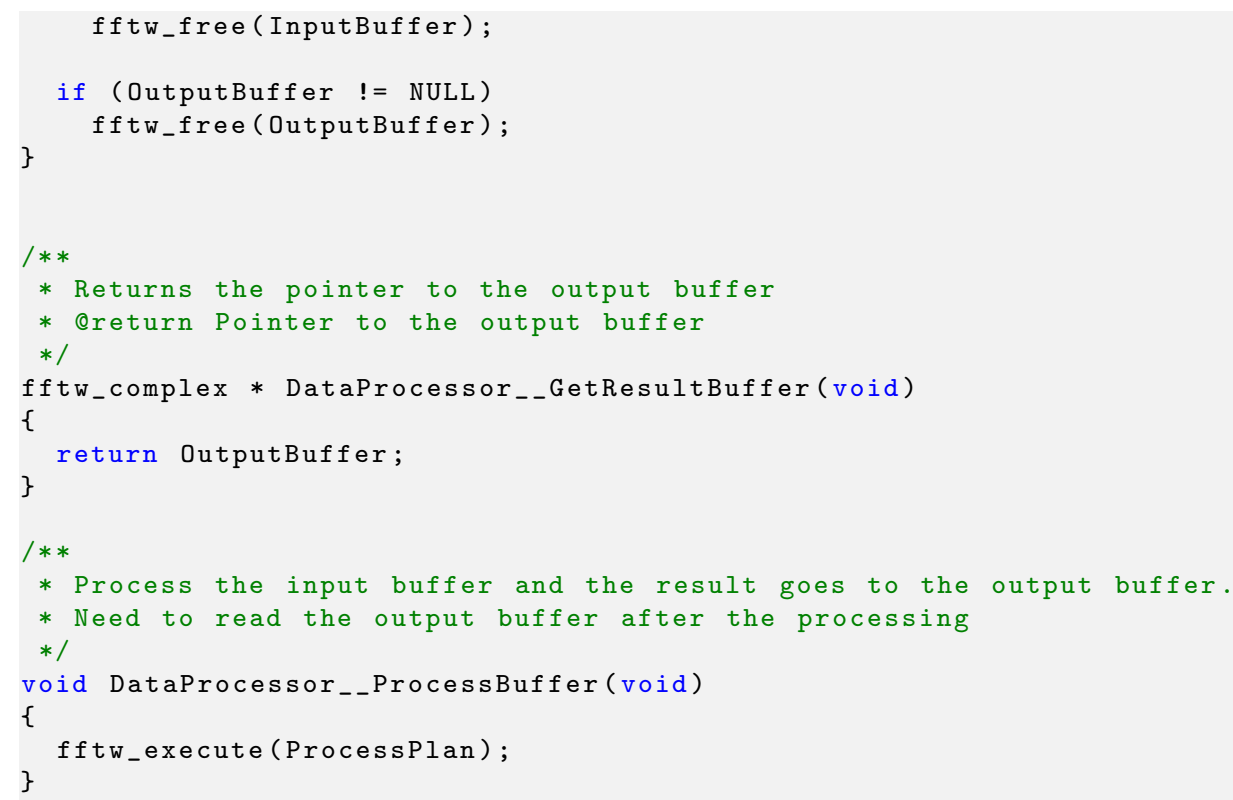

\section{A.4 Arquivo 'filesystem/DataReader.h'}

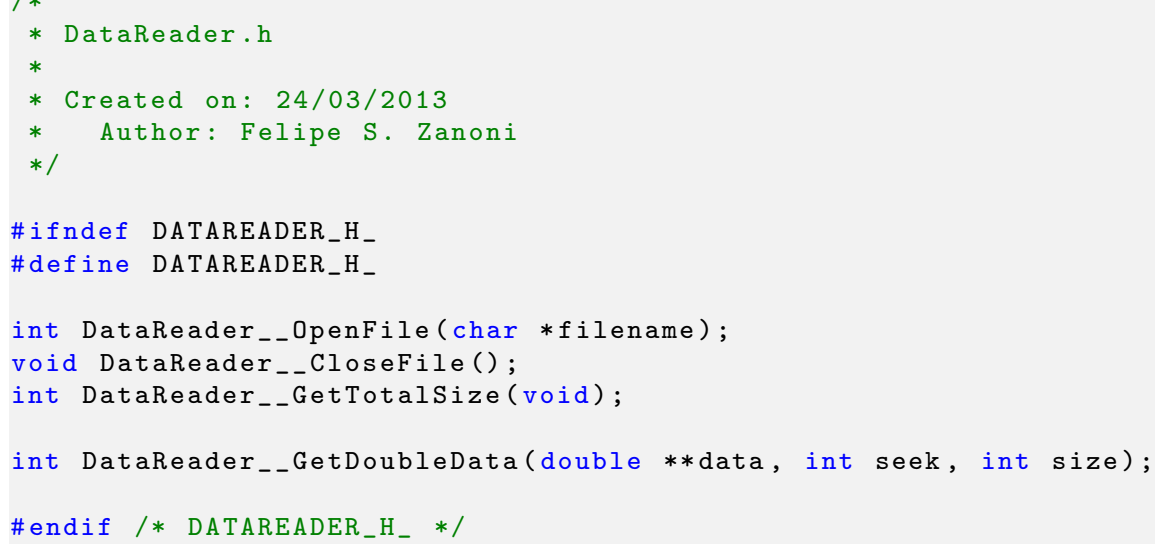

\section{A.5 Arquivo 'filesystem/DataReader.c'}

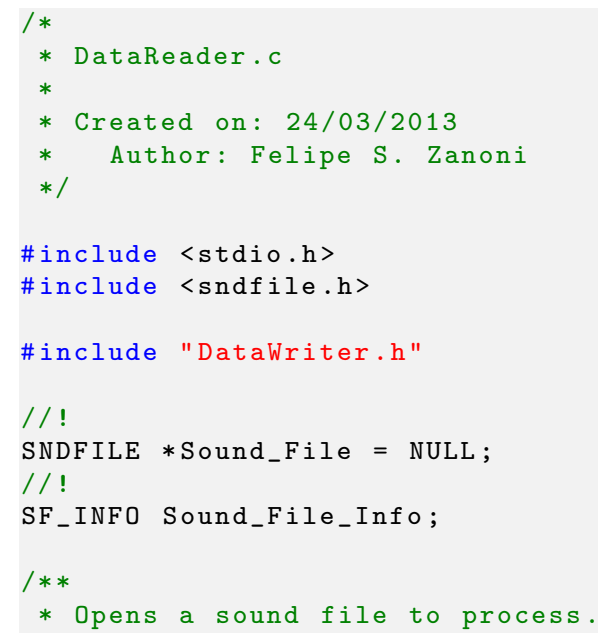




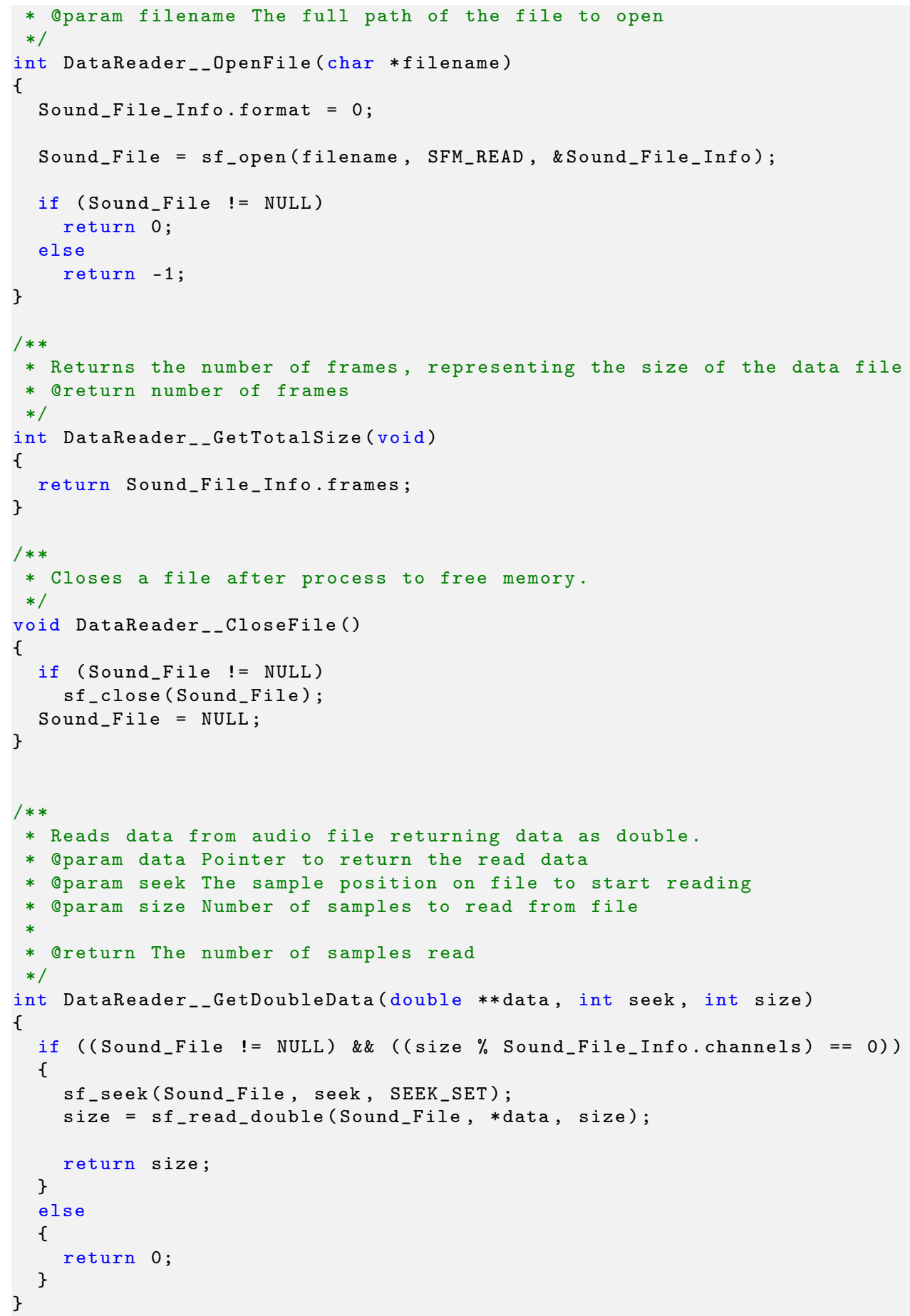

\section{A.6 Arquivo 'filesystem/DataWriter.h'}

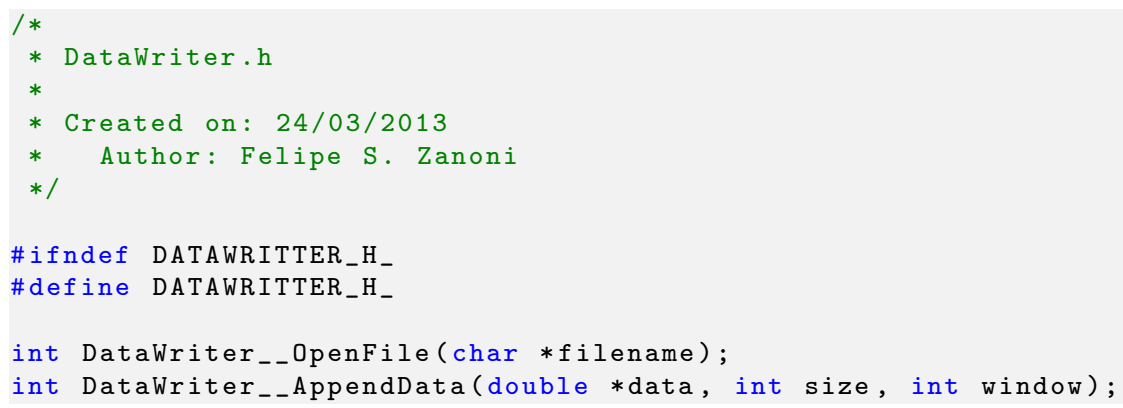




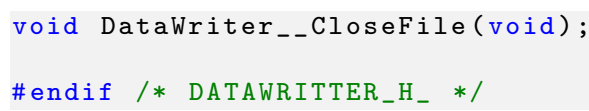

\section{A.7 Arquivo 'filesystem/DataWriter.c'}

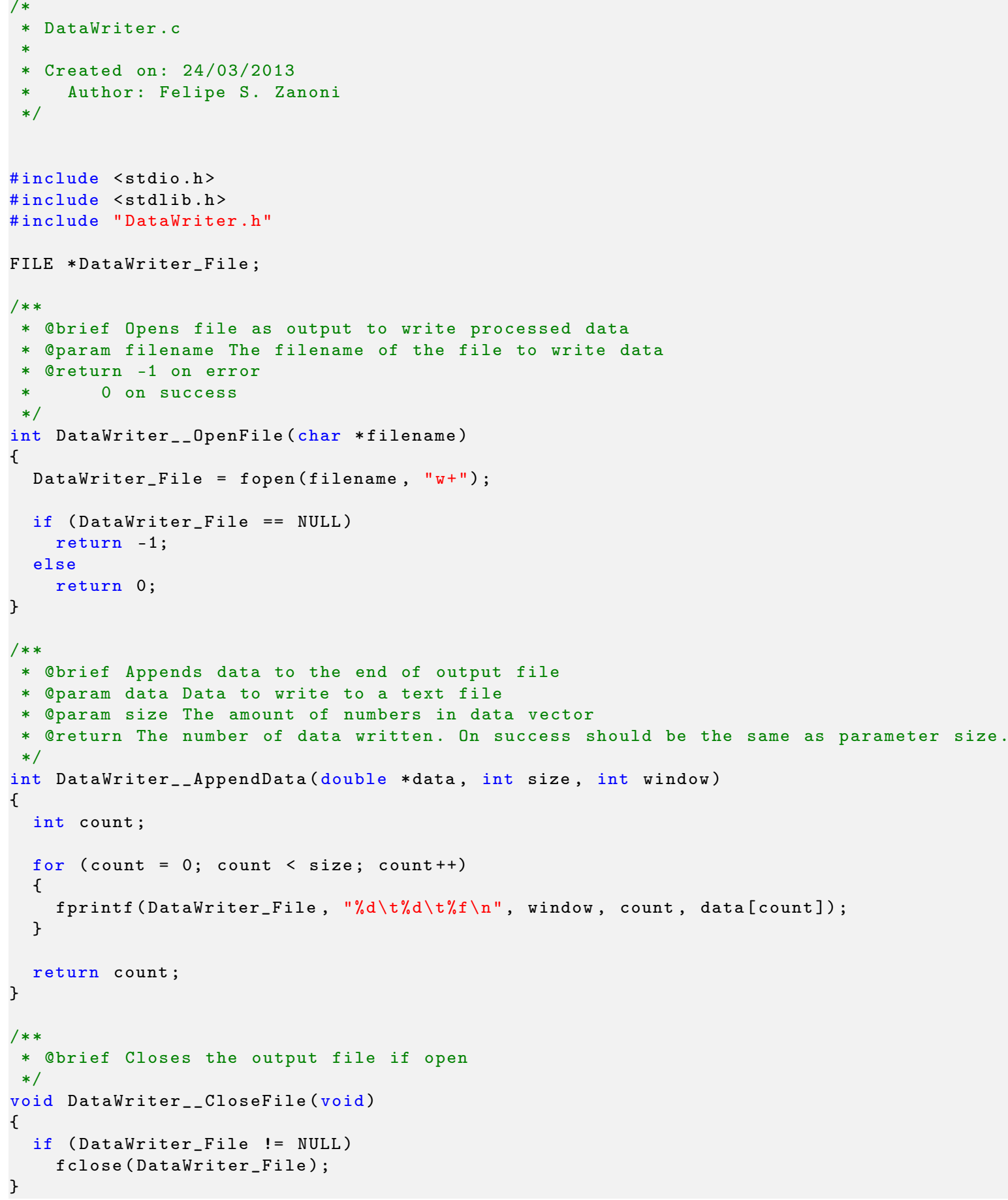

\section{A.8 Arquivo 'filesystem/WindowReader.h'}




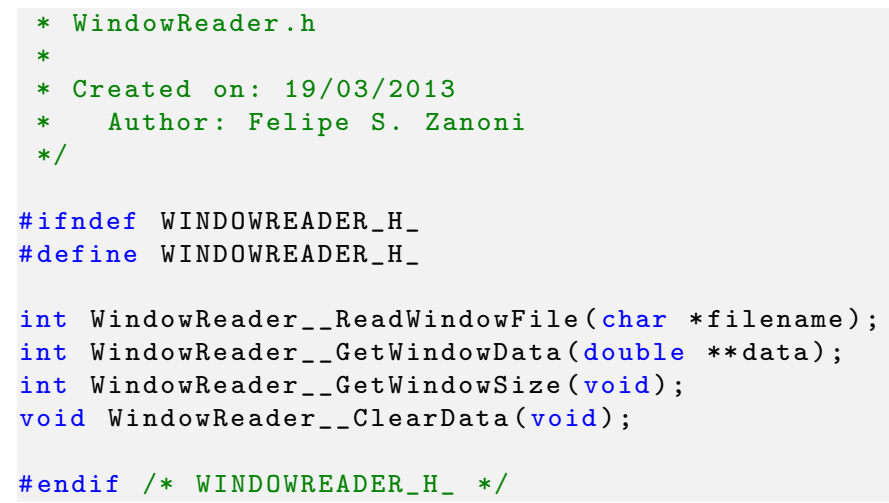

\section{A.9 Arquivo 'filesystem/WindowReader.c'}

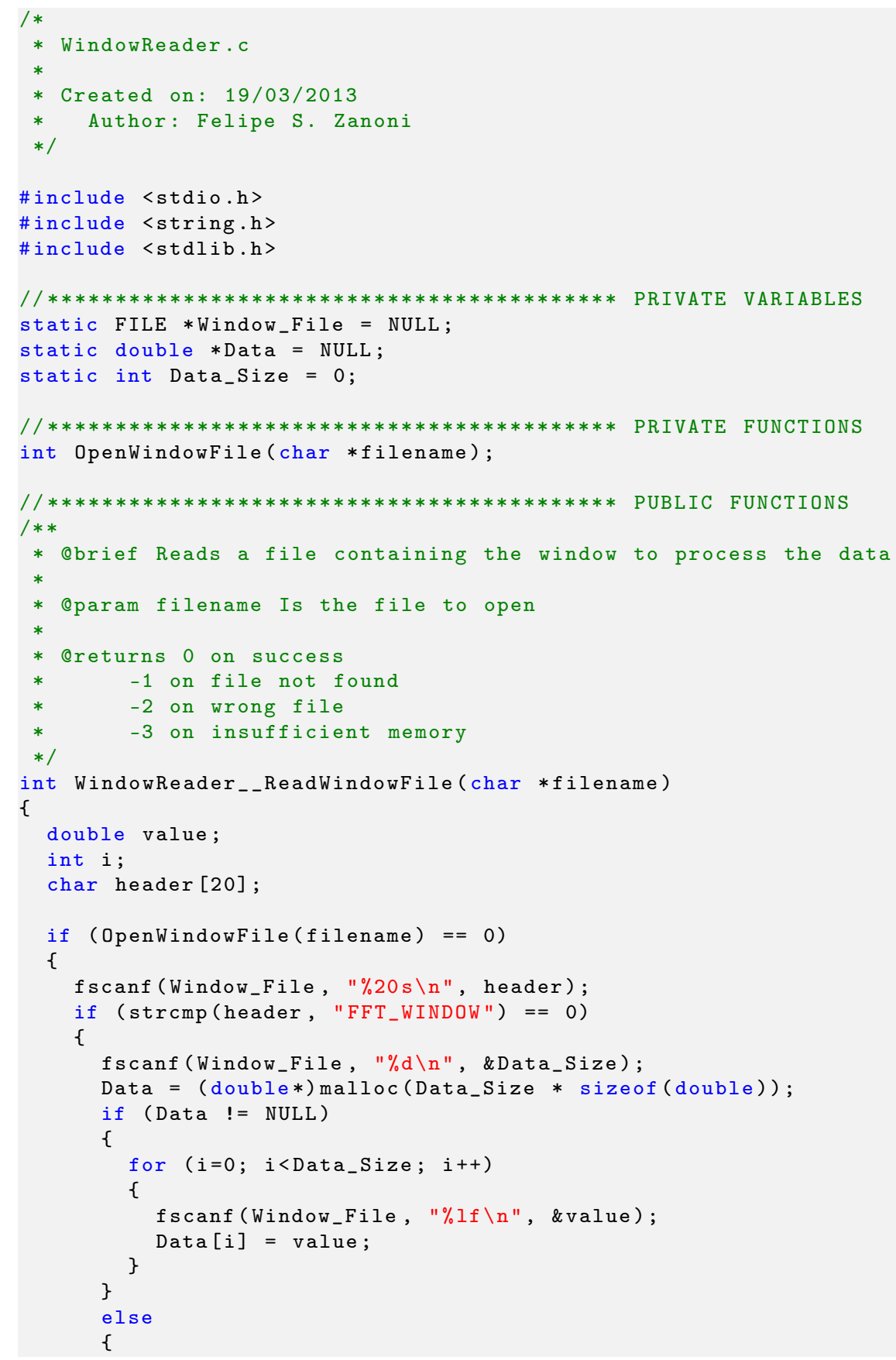




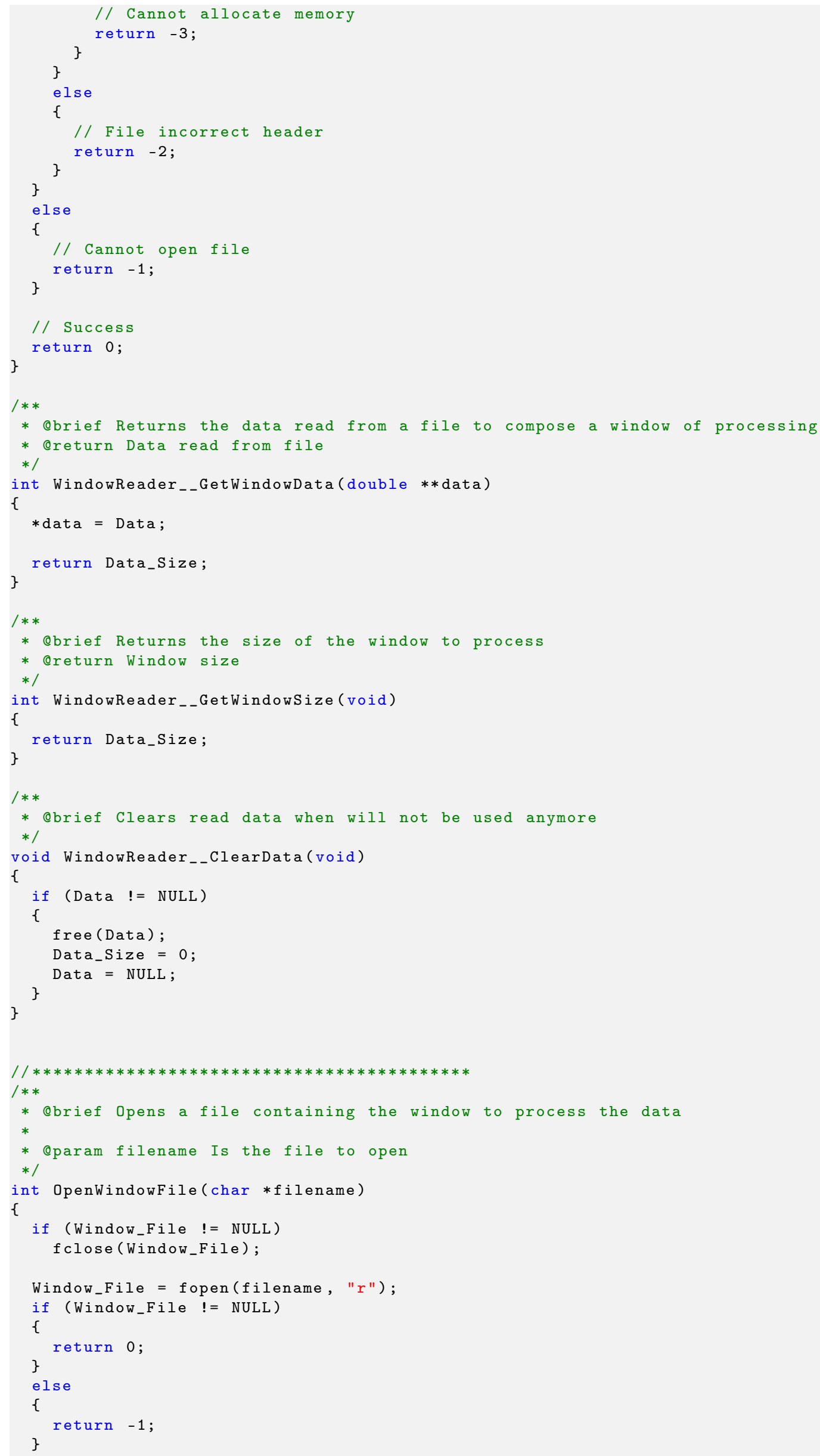




\section{A.10 Arquivo 'pi_mpi.c'}

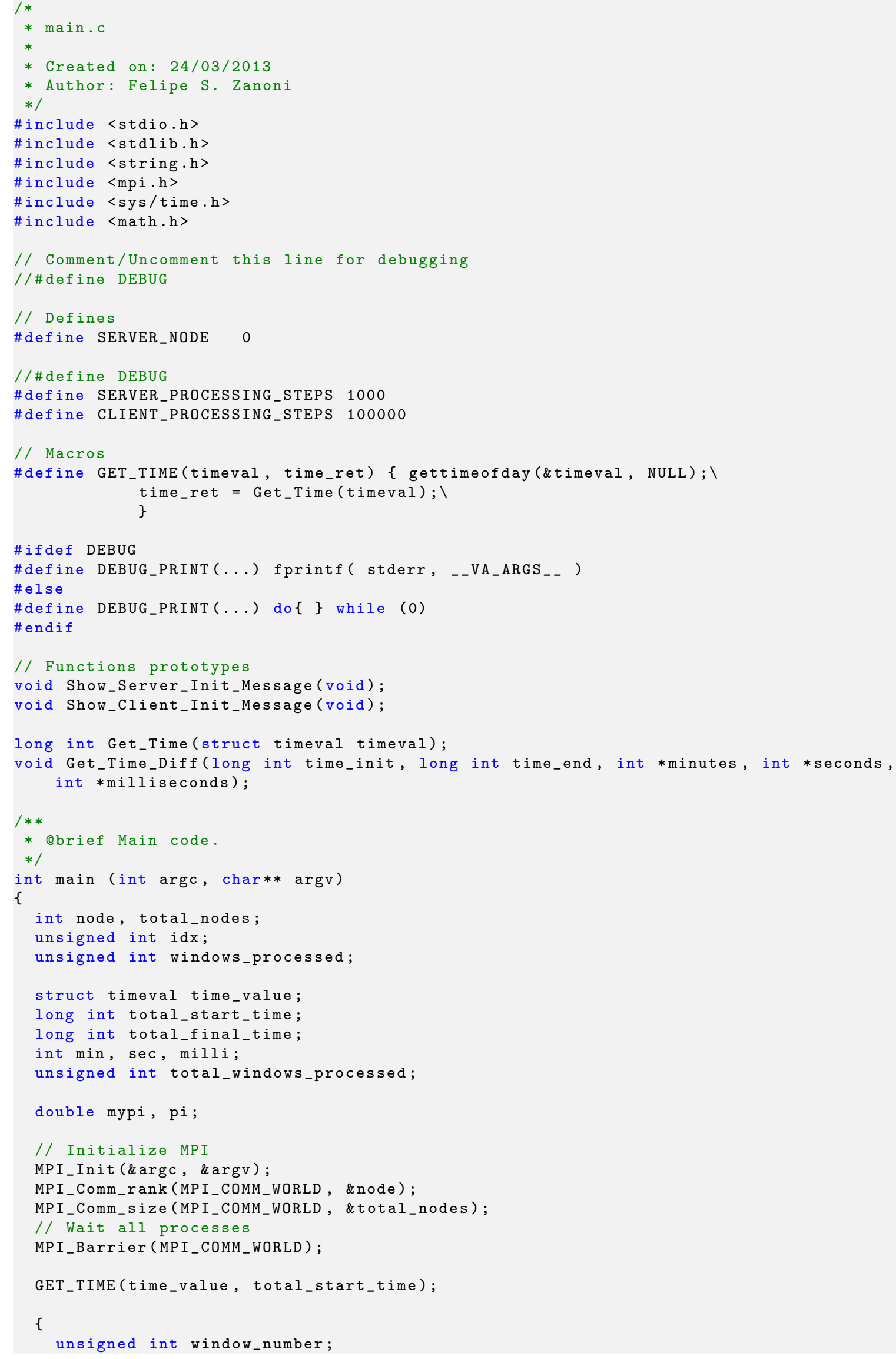


unsigned int total_windows $=4294000000 ; / / 4294967295$;

double h, sum;

total_windows_processed $=0$;

$\mathrm{h}=1.0 /($ double) total_windows;

// Server Mode

if (node $==$ SERVER_NODE)

\{

Show_Server_Init_Message();

printf("Total samples to process: \%u\n", total_windows);

\{

windows_processed $=0$;

mypi $=0.0$;

sum $=0.0$;

while (windows processed < total_windows)

\{

MPI_Status status ;

int ready;

char char_buff [6];

unsigned int int_buff[2];

for $(i d x=1 ; i d x<$ total_nodes $; i d x++)$

\{

MPI_Iprobe (idx, 5, MPI_COMM_WORLD, \&ready, \&status);

if (ready)

MPI_Recv ( ( char $*)$ char_buff, 6, MPI_CHAR, idx, 5, MPI_COMM_WORLD, \&status); if (strcmp (char_buff, "ready") == 0 )

if (windows_processed >= total_windows)

int_buff [0] = int_buff [1] = 0 ;

MPI_Send ( (unsigned int $*$ ) int_buff , 2, MPI_UNSIGNED, idx, 1 MPI_COMM_WORLD);

else

int_buff[0] = windows_processed;

windows processed $+=$ CLIENT_PROCESSING_STEPS

if (windows_processed > total_windows)

\{

windows_processed $=$ total_windows

nt buff [1] = windows_processed

MPI_Send ( (unsigned int $*$ ) int_buff, 2, MPI_UNSIGNED, idx, 1 , MPI_COMM_WORLD)

\}

int_buff[0] = windows_processed;

windows_processed $+=$ SERVER_PROCESSING_STEPS ;

if (windows_processed > total_windows)

windows_processed = total_windows

int_buff[1] = windows_processed;

total_windows_processed $+=$ int_buff [1] - int_buff [0]:

// Process data

for (window_number = int_buff[0]; window_number< int_buff[1]; window_number++)

double $\mathrm{x}=\mathrm{h} *(($ double $)$ window_number -0.5$)$;

sum $+=(4.0 /(1.0+x * x))$;

\} 


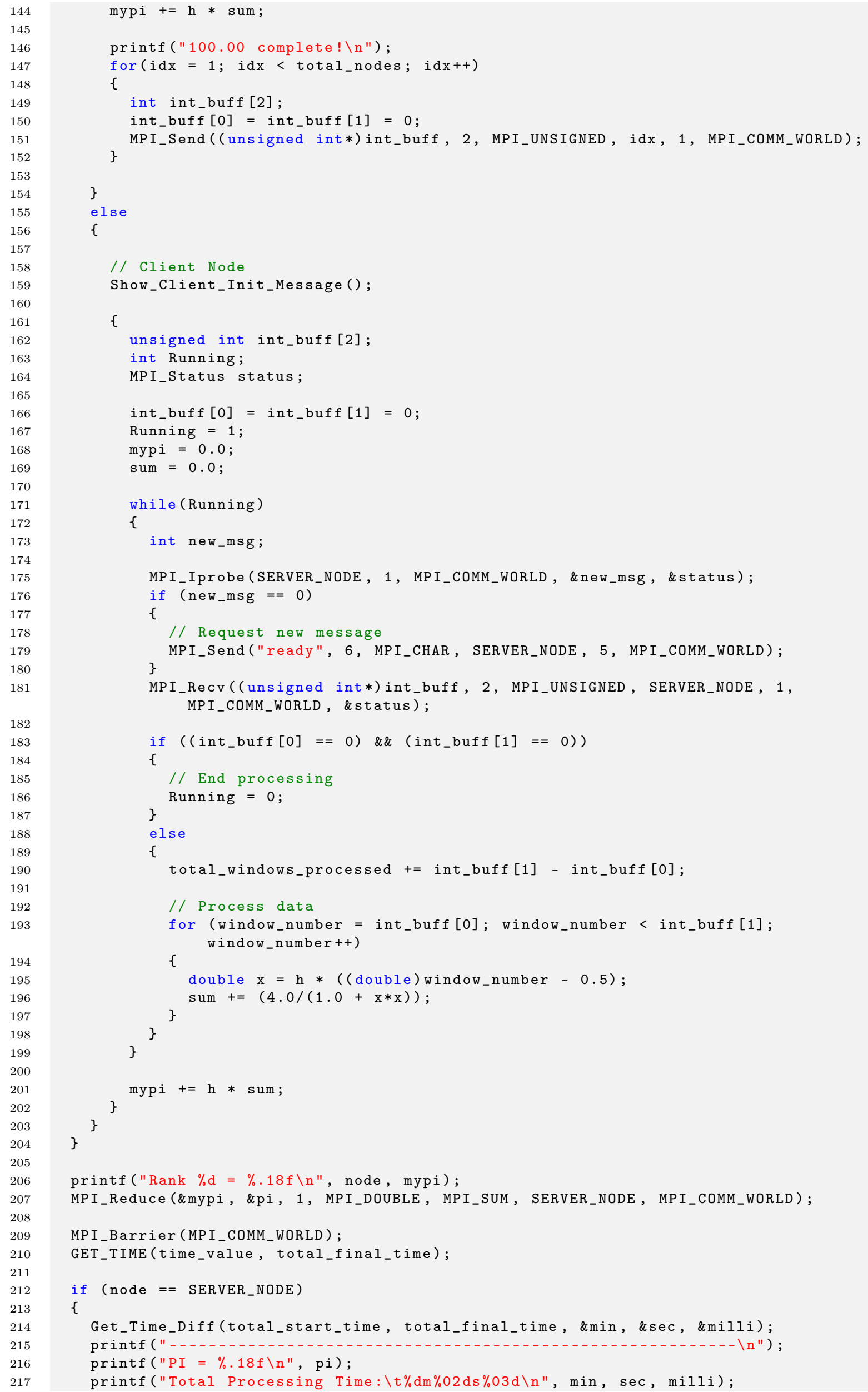




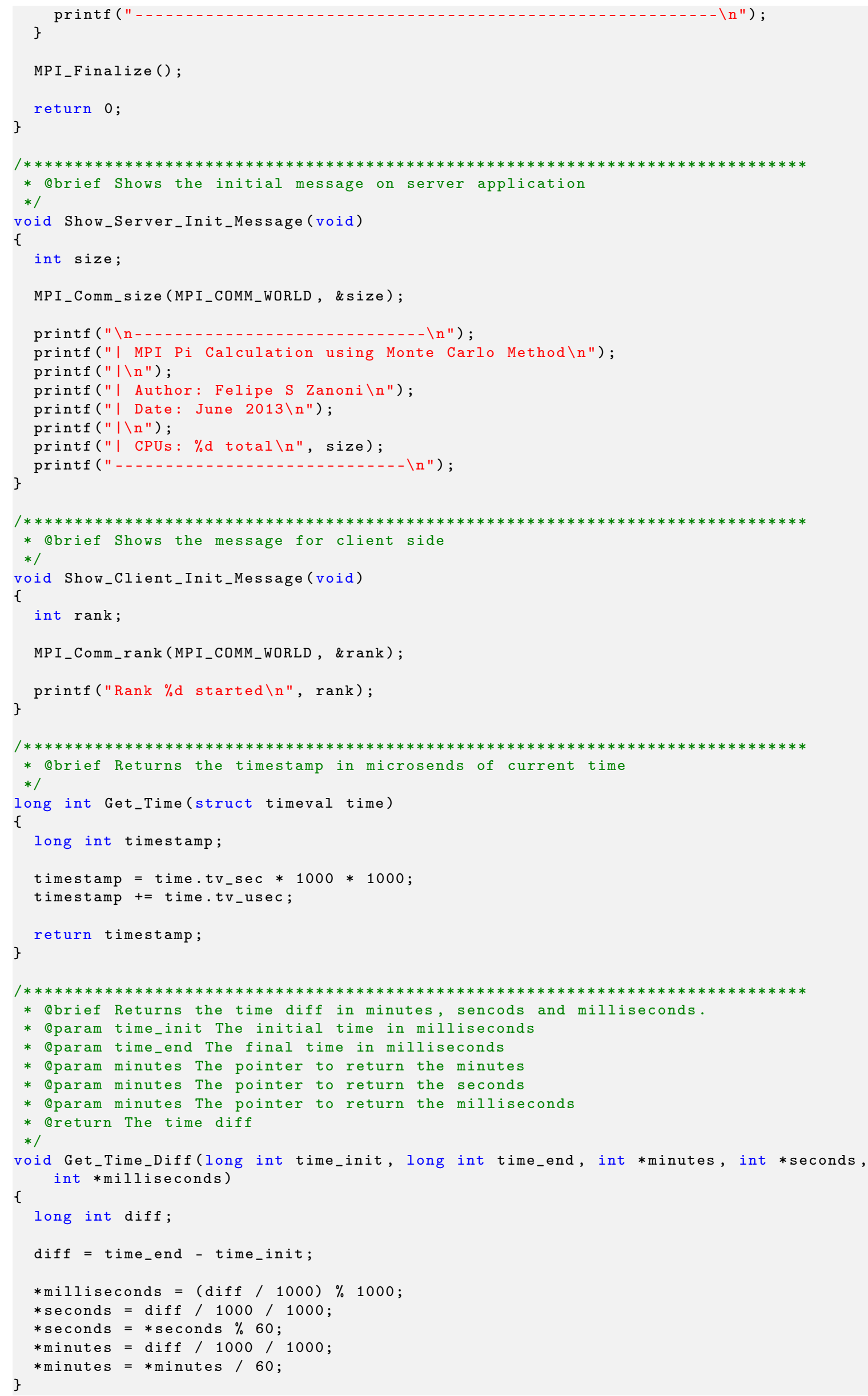





\section{ANEXO}

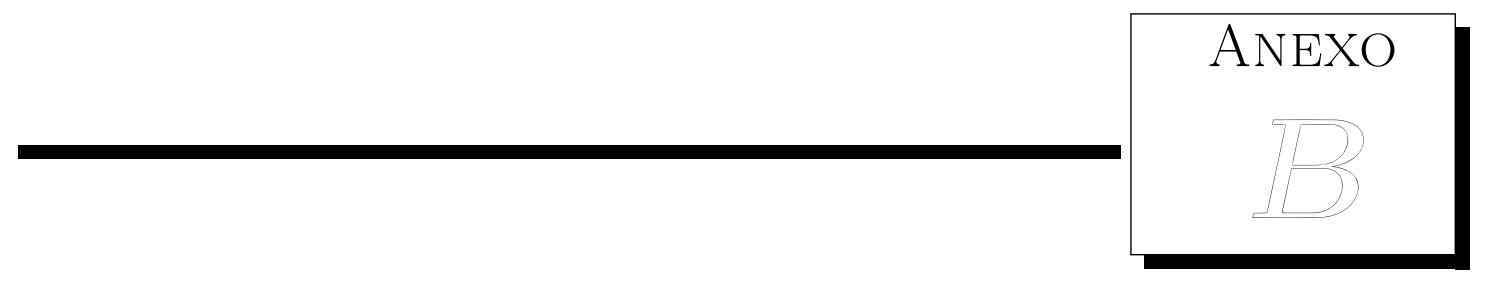

\section{Manual de Compilação e Uso dos Aplicativos}

Nesta parte do documento será descrito como compilar e executar ambos aplicativos de testes.

Para compilar códigos com a biblioteca MPI é necessário fazer uso do compilador mpicc. Ele fará a inclusão de todas as bibliotecas necessárias para compilar o código com MPI.

Os dois aplicativos tem dependência da biblioteca matemática math. Para o aplicativo de cáculo da DFT, será necessária a inclusão outras duas bibliotecas: libsndfile para trabalhar com arquivos do tipo wav; fftw3 para trabalhar com Transformadas Discretas de Fourier.

Para compilar o código do aplicativo de cálculo de DFT usa-se a seguinte linha de comando:

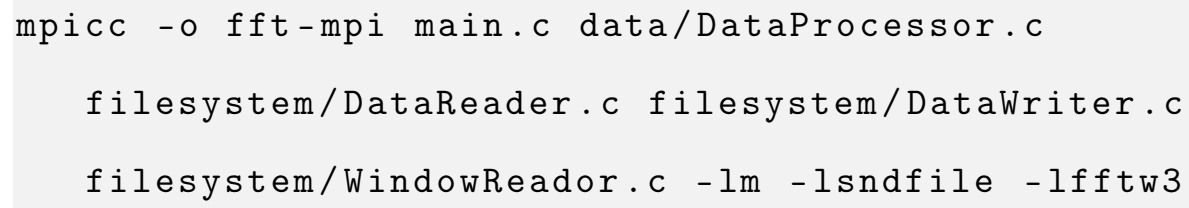

Após a compilação será criado o aplicativo fft-mpi.

Para compilar o código do aplicativo de cálculo do número $\pi$ deve-se entrar com o seguinte comando: 
mpicc -o pi-mpi main.c-lm

Após a compilação será criado o aplicativo pi-mpi

Para fazer a execução de códigos com a biblioteca MPI algumas configurações são necessárias. É recomendado que se siga a configuração da implementação MPI desejada. Nesse trabalho foi utilizada o Open-MPI. Para configurar o cluster com essa implementação é necessário criar um arquivo com os dispositivos que fazem parte da rede de processamento. O arquivo deve conter o nome ou endereço IP do dispositivo, seguido do número de núcleos de processamento disponíveis nesse dispositivo, separado por dois pontos, como dado no exemplo seguinte:

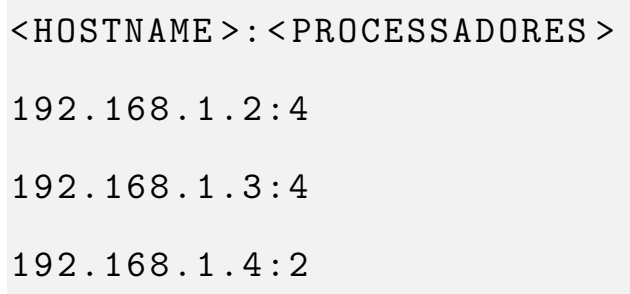

O comando para executar o código no cluster deve ser da seguinte forma:

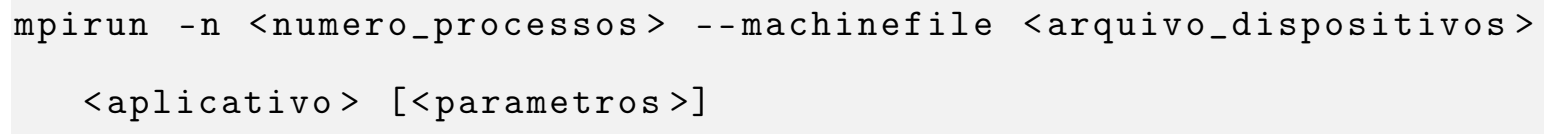

Sendo as configurações definidas na tabela abaixo:

\begin{aligned} & \hline \hline$<$ numero_processos $> \begin{array}{l}\text { Número de processos que serão executados em paralelo } \\ \text { no cluster }\end{array} \\ &<$ arquivo_dispositivos $>$ Arquivo de configuração com os dispositivos do cluster \\ &$<$ aplicativo $>$ Aplicativo que será executado em MPI \\ &$<$ parametros $>$ Parâmetros do aplicativo executado \\ & \hline\end{aligned}

Um exemplo de linha de comando para execução do software fft_mpi é dada por:

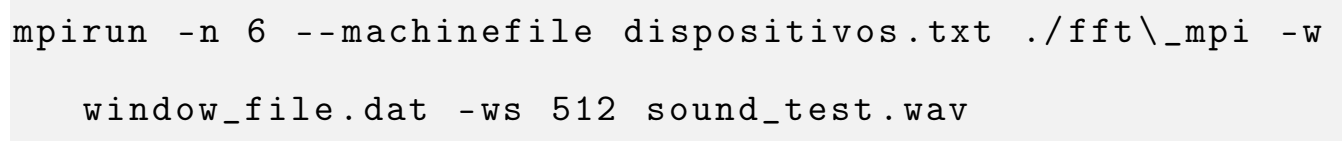

Para executar o aplicativo pi_mpi pode ser executada a linha de comando seguinte: mpirun -n 6 --machinefile dispositivos.txt ./pil_mpi

Os resultados dos tempos de processamento serão exibidos na tela onde os aplicativos foram executados. 